KfK 5253

März 1994

\title{
Stellar Neutron Capture Cross Sections of the Ba Isotopes
}

F. Voss, K. Wisshak, K. Guber, F. Käppeler, G. Reffo Institut für Kernphysik 

Kernforschungszentrum Karlsruhe

Institut für Kernphysik

KfK 5253

\section{STELLAR NEUTRON CAPTURE CROSS SECTIONS OF THE Ba ISOTOPES}

F. VOSS, K. WISSHAK, K. GUBER, F. KÄPPELER, G. REFFO*

*ENEA, Laboratorio Dati Nucleari, Viale Ercolani 8, I-40138 Bologna, Italy

Kernforschungszentrum Karlsruhe GmbH, Karlsruhe 
Als Manuskript gedruckt

Für diesen Bericht behalten wir uns alle Rechte vor

Kernforschungszentrum Karlsruhe $\mathrm{GmbH}$ Postfach 3640, 76021 Karlsruhe

ISSN 0303-4003 


\begin{abstract}
The neutron capture cross sections of ${ }^{134} \mathrm{Ba},{ }^{135} \mathrm{Ba},{ }^{136} \mathrm{Ba}$, and ${ }^{137} \mathrm{Ba}$ were measured in the energy range from 5 to $225 \mathrm{keV}$ at the Karlsruhe $3.75 \mathrm{MV}$ Van de Graaff accelerator. Neutrons were produced via the ${ }^{7} \mathrm{Li}(\mathrm{p}, \mathrm{n})^{7} \mathrm{Be}$ reaction by bombarding metallic Li targets with a pulsed proton beam. Capture events were registered with the Karlsruhe $4 \pi$ Barium Fluoride Detector. Several runs have been performed under different experimental conditions to study the systematic uncertainties, which resulted mainly from the large ratios of total to capture cross sections of up to 400 . The cross section ratios were determined with an overall uncertainty of $\sim 3 \%$, an improvement by factors of five to eight compared to existing data. Severe discrepancies were found with respect to previous results. Maxwellian averaged neutron capture cross sections were calculated for thermal energies between $\mathrm{kT}=10 \mathrm{keV}$ and $100 \mathrm{keV}$. These stellar cross sections were used in an s-process analysis. For the s-only isotopes ${ }^{134} \mathrm{Ba}$ and ${ }^{136} \mathrm{Ba}$ the $\mathrm{N}_{s}<\sigma>$ ratio was determined to $0.875 \pm 0.025$. Hence, a significant branching of the s-process path at ${ }^{134} \mathrm{Cs}$ can be claimed for the first time, in contrast to predictions from the classical approach. This branching yields information on the s-process temperature, indicating values around $\mathrm{T}_{8}=2$. The new cross sections are also important for the interpretation of barium isotopic anomalies, which were recently discovered in $\mathrm{SiC}$ grains of carbonaceous chondrite meteorites. Together with the results from previous experiments on tellurium and samarium, a general improvement of the $\mathrm{N}_{s}<\sigma>$ systematics in the mass range $\mathrm{A}=120$ to 150 is achieved. This allows for a more reliable separation of $\mathrm{s}-$ and $\mathrm{r}$-process yields, resulting in an improved assignment of the respective contributions to elemental barium that is required for comparison with stellar observations.
\end{abstract}




\section{ZUSAMMENFASSUNG}

\section{DIE STELLAREN $(n, \gamma)$ QUERSCHNITTE DER Ba ISOTOPE}

Die Neutroneneinfangquerschnitte von ${ }^{134} \mathrm{Ba},{ }^{135} \mathrm{Ba},{ }^{136} \mathrm{Ba}$, and ${ }^{137} \mathrm{Ba}$ wurden im Energiebereich von 3 bis $225 \mathrm{keV}$ am Karlsruher Van de Graaff Beschleuniger relativ zu Gold als Standard bestimmt. Neutronen wurden über die ${ }^{7} \mathrm{Li}(\mathrm{p}, \mathrm{n})^{7} \mathrm{Be}-$ Reaktion durch Beschuß metallischer Li-Targets mit einem gepulsten Protonenstrahl erzeugt. Einfangereignisse wurden mit dem Karlsruher $4 \pi$ Barium Fluorid Detektor nachgewiesen. Die Messung wurde unter verschiedenen experimentellen Bedingungen durchgeführt, um die systematischen Unsicherheiten, die sich vor allem aus dem ungünstigen Verhältnis von Streuung und Einfang ergeben, quantitativ zu untersuchen. Die Unsicherheiten im Verhältnis der Wirkungsquerschnitte konnten auf $\sim 3 \%$ verringert werden. Dies entspricht einer Verbesserung um Faktoren fünf bis acht im Vergleich zu früheren Ergebnissen. Die stellaren Einfangquerschnitte, die für thermische Energien von $\mathrm{kT}=10 \mathrm{keV}$ bis $100 \mathrm{keV}$ berechnet wurden, bildeten die Grundlage für detaillierte s-Prozeß-Analysen. Für die reinen s-Kerne ${ }^{134} \mathrm{Ba}$ und ${ }^{136} \mathrm{Ba}$ ergab sich ein $\mathrm{N}_{s}<\sigma>-$ Verhältnis von $0.875 \pm 0.025$. Damit läßt sich erstmals eine Verzweigung des s-Prozeß-Pfads beim ${ }^{134}$ Cs nachweisen, die im Rahmen der klassischen Näherung nicht zu erwarten war, und die auf s-Prozeß-Temperaturen um $\mathrm{T}_{8}=2$ hinweist. Die neuen Querschnitte sind auch für die Interpretation der Isotopenanomalien wichtig, die unlängst im Barium von $\mathrm{SiC}$ Einschlüssen in kohligen Chondriten entdeckt wurden. Zusammen mit früheren Experimenten an Tellur- und Samariumisotopen ergibt sich eine generelle Verbesserung der $N_{s}<\sigma>-$ Systematik im Massenbereich $A=$ 120 bis 150. Damit lassen sich die relativen s- und $\mathrm{r}-$ Prozeß-Ausbeuten genauer festlegen. Dadurch erreicht man auch eine zuverlässigere Trennung dieser Anteile im elementaren Barium, die für den Vergleich mit astronomischen Beobachtungen benötigt wird. 


\section{Contents}

1 INTRODUCTION 1

2 EXPERIMENT 3

2.1 Experimental Method . . . . . . . . . . . . . . . . . . 3

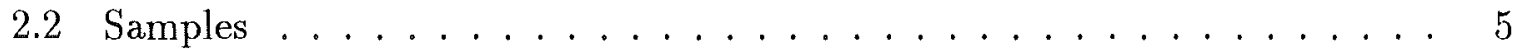

2.3 Measurements . . . . . . . . . . . . . . . . . 7

3 DATA ANALYSIS $\quad 8$

3.1 Total Cross Sections . . . . . . . . . . . . . . . . . 8

3.2 Capture Cross Sections . . . . . . . . . . . . . . . . . . . . 9

4 RESULTS FOR THE NEUTRON CAPTURE CROSS SECTIONS 31

5 DISCUSSION OF UNCERTAINTIES 40

6 MAXWELLIAN AVERAGED CROSS SECTIONS 43

7 ASTROPHYSICAL IMPLICATIONS

7.1 Normalization of the $\mathrm{N}_{s}<\sigma>$-Curve . . . . . . . . . . . . . . . 47

7.2 The $\mathrm{s}-$ Process Branching at ${ }^{134} \mathrm{Cs} \ldots \ldots \ldots \ldots . \ldots . \ldots . \ldots 9$

7.3 Decomposition into s- and $\mathrm{r}$-Process Contributions . . . . . . . . . 51

8 ACKNOWLEDGMENTS

9 REFERENCES 


\section{INTRODUCTION}

The main experimental program performed with the Karlsruhe $4 \pi$ Barium Fluoride Detector [1] is the accurate determination of neutron capture cross sections for neutron capture nucleosynthesis in s-process scenarios[2]. In this context, detailed analyses of branchings in the s-process path are of particular interest, since these branchings can be analyzed to derive information on the physical conditions during helium shell burning in Red Giant stars. A first experiment on tellurium isotopes[3] confirmed the old prediction by Clayton et al [4] that the product of neutron capture cross section $\langle\sigma\rangle$ and s-process abundance $\mathrm{N}_{s}$ is constant for neighboring isotopes with an uncertainty of only $1 \%$. The validity of this local approximation strongly supports the idea to interpret (mostly small) deviations from this behavior as the result of branchings in the neutron capture path of the s-process. In a previous experiment on samarium isotopes [5], a significant branching was observed and the analysis with the classical approach yielded a mean neutron density of $(3.8 \pm 0.6) \cdot 10^{8} \mathrm{~cm}^{-3}$, which is the most stringent value obtained so far.

The present investigation deals with the s-process in the mass region around barium. The neutron capture path from xenon to barium (Fig.1) shows that the two isotopes ${ }^{134} \mathrm{Ba}$ and ${ }^{136} \mathrm{Ba}$ are shielded from the r-process by their stable xenon isobars. The unstable isotopes ${ }^{133} \mathrm{Xe},{ }^{134} \mathrm{Cs}$, and ${ }^{135} \mathrm{Cs}$ are possible branching points due to the competition between neutron captures and $\beta$-decays. The most significant of these branchings occurs at ${ }^{134} \mathrm{Cs}$. Under laboratory conditions the $4^{+}$groundstate of this isotope decays by allowed $\beta$-decay to $4^{+}$states in the even even nucleus ${ }^{134} \mathrm{Ba}$ at excitation energies of $>1.4 \mathrm{MeV}$. This reduces the decay energy and yields a comparably long half life of $2.1 \mathrm{yr}$. However, at $\mathrm{s}$-process temperatures, part of the ${ }^{134} \mathrm{Cs}$ nuclei are excited to the $3^{+}$level at $60 \mathrm{keV}$, allowing for $\beta$-decays to the $2^{+}$level in ${ }^{134} \mathrm{Ba}$ at $0.6 \mathrm{MeV}$. The corresponding gain in decay energy leads to a considerable reduction of the half life, and, hence, to a temperaturedependent stellar decay rate of ${ }^{134} \mathrm{Cs}$. Accordingly, analysis of the related branchings at $A=133-135$ may yield information on the s-process temperature[6]. For this analysis, accurate neutron capture cross sections of the s-only barium isotopes are most important, since they allow to define the strength of these branchings.

A second problem, which requires accurate cross sections, is related to the large isotopic. anomalies in barium, which were recently discovered in SiC grains, a very resistant fraction of carbonaceous chondrite meteorites [7][8][9]. If these anomalies are interpreted as being due to an admixture of pure s-process barium to the ordinary solar system abundances, the expected yields, $\mathrm{N}_{s}$, have to be known reliably. Since the s-process yields are always inversely proportional to the stellar cross sections, these are again the crucial nuclear physics information. These anomalies were studied before via model calculations for the s-process in carbon stars by Gallino et al [10]. The observed isotopic pattern could only be reproduced if the previously available cross sections[11] were significantly modified, the 


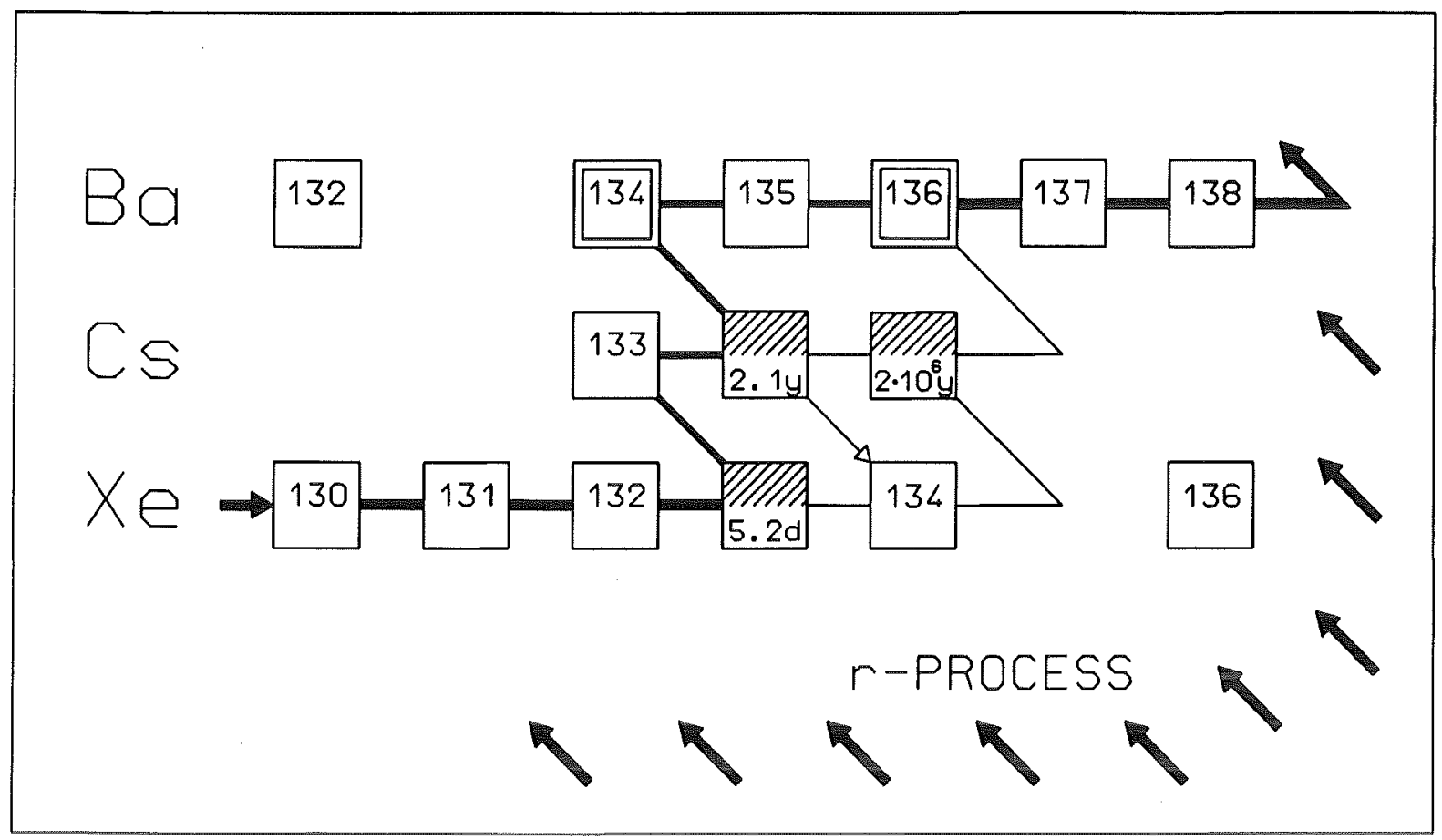

Figure 1: The s-process path in the region of the barium isotopes.

respective factors ranging from 1.0 to 2.2 for the different isotopes. The validity of this interpretation depends on whether these large differences can be verified by an improved experiment.

Another important aspect is related to astronomical studies of the surface composition of Red Giant stars, since barium can be considered as an s-process indicator. About $90 \%$ of the barium in nature is of s-process origin, while only $\sim 10 \%$ are contributed by the $\mathrm{r}$-process. This s-assignment allows to study the enrichment of the stellar envelope with freshly produced s-process matter from the helium burnig shell. Since europium is an almost pure $\mathrm{r}$-process counterpart, variation of the $\mathrm{Ba} / \mathrm{Eu}$ ratio with metallicity represents a critical test for galactic evolution models[12][13].

Last but not least, ${ }^{136} \mathrm{Ba}$ represents one of the normalization points of the $\mathrm{N}_{s}<\sigma>-$ curve, together with ${ }^{124} \mathrm{Te}$ and ${ }^{150} \mathrm{Sm}$. The accurate cross sections of these three isotopes allow for a significant improvement of the mean neutron exposure in the main s-process component, which is most sensitively defined in the mass range $A=120-150$. Together with the improved cross sections of the other $\mathrm{Te}, \mathrm{Ba}$, and $\mathrm{Sm}$ isotopes, the $\mathrm{r}$-process residuals can be updated as well. As pointed out by Meyer et al [14], the mass range around the first $\mathrm{r}$-process abundance peak is critical for $\mathrm{r}$-process calculations. Therefore, better data are important in this region to reduce the respective uncertainties in the results of Ref.[2], which are presently used for comparison with $\mathbf{r}$-process calculations.

The experimental status of the barium cross sections is unsatisfactory. There is only one experiment for all isotopes, but a number of publications with partly contradicting results. While the first series of publications [15][16][17] claimed uncertainties of $15-17 \%$ for the isotopes 134 to 137 and $20 \%$ for ${ }^{138} \mathrm{Ba}$, these results were confused by revisions[18][19], 
where the ${ }^{135} \mathrm{Ba}$ cross section was changed by $55 \%$. These discrepancies entered also into the evaluations of Bao and Käppeler[20] and of Beer, Voss, \& Winters[11], respectively. In the keV range only one other dataset was reported for ${ }^{135} \mathrm{Ba}[21]$, which confirmed the evaluation of Bao and Käppeler. From the data of Musgrove et al [18], an experimental value for the branching factor,

$$
(1-f) \approx \frac{\left(N_{s}<\sigma>\right)_{134} \mathrm{Ba}}{\left(N_{s}<\sigma>\right)_{136} \mathrm{Ba}}=0.99 \pm 0.21
$$

can be derived, which restricts a possible branching to $f \leq 20 \%$. From analyses with the classical approach, a branching of only $\sim 1 \%$ is expected[6].

In view of this situation, the neutron capture cross sections of ${ }^{134} \mathrm{Ba},{ }^{135} \mathrm{Ba},{ }^{136} \mathrm{Ba}$, and ${ }^{137} \mathrm{Ba}$ were measured with the Karlsruhe $4 \pi \mathrm{BaF}_{2}$ detector. Simultaneously, the very small cross section of neutron magic ${ }^{138} \mathrm{Ba}$ has been redetermined by Beer et al [22] using the pulse height weighting technique. The experiments reported here were difficult for

several reasons. First, the investigated cross sections are small, only 50 to $70 \mathrm{mb}$ for ${ }^{136} \mathrm{Ba}$ and ${ }^{137} \mathrm{Ba}$ at $30 \mathrm{keV}$. Secondly, chemically stable $\mathrm{BaCO}_{3}$ samples had to be used instead of the reactive elemental barium. Due to the light constituents in the compound, the scattering/capture ratio became as large as 300 to 400 at $30 \mathrm{keV}$, resulting in a significant background due to sample scattered neutrons. This background presents a severe problem, since scattered neutrons are captured in the barium isotopes of the scintillator, giving rise to the same sum energy signals in the detector as true capture events. This weakens the possibility to separate this background by selecting an appropriate sum energy window for determination of the cross section shape $(\S 3)$. Furthermore, nuclear level densities - and, consequently, the multiplicities of the capture cascades are comparably low for these nearly neutron magic isotopes. Thus, the possibility of the $4 \pi \mathrm{BaF}_{2}$ detector to separate true captures from natural background via the event multiplicity is reduced, too.

The low multiplicities result in very hard capture gamma-ray spectra. Hence, experiments using the pulse height weighting technique become extremely difficult, since the complete setup including detector, surroundings and the sample have to be modeled properly for obtaining the correct weighting function. This was not the case in the previous barium experiments and may explain the severe discrepancies found in the existing data.

The experiment and data analysis are described in $\S \S 2,3$. In $\S 4$, the differential cross sections are presented together with the respective isomeric ratios, which could be determined for the first time in an experiment based on the detection of the prompt gamma-ray cascade. The uncertainties are discussed in $\S 5$. The determination of stellar cross sections and the implications for astrophysics are given in $\S \S 6,7$.

\section{EXPERIMENT}

\subsection{Experimental Method}

The neutron capture cross sections of the barum isotopes 134 to 137 were measured in the energy range from 3 to $225 \mathrm{keV}$ using gold as a standard. Since the experimental 
method has been published in detail[1] [3][5][23], only a more general description is given here, complemented with the specific features of the present measurement. Neutrons were produced via the ${ }^{7} \mathrm{Li}(\mathrm{p}, \mathrm{n})^{7} \mathrm{Be}$ reaction by bombarding metallic Li targets with the pulsed proton beam of the Karlsruhe 3.75MV Van de Graaff accelerator. The neutron energy is determined by time of flight (TOF), the samples being located at a flight path of 78 $\mathrm{cm}$. The important parameters of the accelerator are: pulse width $<1 \mathrm{~ns}$, repetition rate $250 \mathrm{kHz}$, and average beam current $1.5-2.5 \mu \mathrm{A}$. In different runs, the proton energies were adjusted 10,30 , and $100 \mathrm{keV}$ above the threshold of the ${ }^{7} \mathrm{Li}(\mathrm{p}, \mathrm{n})^{7} \mathrm{Be}$ reaction at $1.881 \mathrm{MeV}$. In this way, continuous neutron spectra in the energy range of interest for $\mathrm{s}-$ process studies were obtained, ranging from 3 to $80 \mathrm{keV}, 3$ to $100 \mathrm{keV}$, and 3 to $200 \mathrm{keV}$, respectively. The use of different spectra allowed to optimize the signal to background ratio in different neutron energy regions $(\S 3)$.

The Karlsruhe $4 \pi$ Barium Fluoride Detector was used for the registration of capture gamma-ray cascades. This detector (a comprehensive description is given in Ref.[1]) consists of 42 hexagonal and pentagonal crystals forming a spherical shell of $\mathrm{BaF}_{2}$ with $10 \mathrm{~cm}$ inner radius and $15 \mathrm{~cm}$ thickness. It is characterized by a resolution in gamma-ray energy of $7 \%$ at $2.5 \mathrm{MeV}$, a time resolution of $500 \mathrm{ps,} \mathrm{and} \mathrm{a} \mathrm{peak} \mathrm{efficiency} \mathrm{of} 90 \%$ at 1 $\mathrm{MeV}$. Capture events are registered with $>95 \%$ probability.

In one run of the present experiment, an ADC system was used for data acquisition [24]. This system is based on CAMAC modules of type FERA (Le Croy). It allows to store the gamma-ray energy and TOF information of each individual detector module that has fired in a particular event. The purpose of the ADC system is fourfold.

- Capture cascades and capture gamma-ray spectra can be measured directly. This information is necessary to determine the overall detector efficiency for capture events and had previously been taken from theoretical calculations[23].

- The capture process itself can be investigated in more detail, e.g. by determining angular or multiplicity distributions of capture gamma-rays.

- The recorded event rate can be significantly reduced by rejecting events in sum energy and TOF regions that are not required for the evaluation of the cross section $(\S 3)$.

- The resolution in gamma-ray sum energy can be improved by off-line corrections of nonlinearity inthe gain of individual detector modules.

The combination of a $4 \pi \mathrm{BaF}_{2}$ detector with a Van de Graaff accelerator offers several advantages: The entire capture cascade is detected with good energy resolution. Thus, ambiguities in the detection efficiency due to different cascade multiplicities are avoided, and neutron capture events can be separated from gamma-ray background and from background due to capture of sample-scattered neutrons by selecting events with the proper sum energy. The high granularity of the detector allows for a further separation of capture events and background by means of the recorded event multiplicity. The short primary flight path and the inner radius of the detector guarantee that a part of the TOF spectrum is completely undisturbed by background from sample-scattered neutrons (§3). This range with optimum signal to background ratio can be used to normalize the 
cross section. The high detection efficiency allows the use of small samples avoiding large multiple scattering corrections. Finally, the ${ }^{7} \mathrm{Li}(\mathrm{p}, \mathrm{n})^{7} \mathrm{Be}$ reaction yields neutrons exactly and exclusively in the range of interest for s-process studies.

\subsection{Samples}

Isotopically enriched samples have been prepared from $\mathrm{BaCO}_{3}$ powder, which has a lower scattering yield compared to the nitrate. Therefore, two batches of sample material had to be converted from nitrate to carbonate. The relevant parameters of the six samples are compiled in Table 1. In addition to the four barium samples, a gold sample, a graphite sample, and an empty position in the sample ladder were used in all runs. The respective sample masses of the barium isotopes were selected according to the expected cross sections in order to obtain similar capture yields in all cases. The yield of the gold sample was larger by a factor of two. Compared to the previous experiment by Musgrove et al [16], the sample masses could be reduced by factors of 3 to 10 . Accordingly, the sample-related uncertainties for neutron multiple scattering and self-shielding corrections became significantly smaller.

Table 1: SAMPLE CHARACTERISTICS

\begin{tabular}{lcccccc}
\hline Sample $^{1}$ & $\begin{array}{c}\text { Thickness } \\
(\mathrm{mm})\end{array}$ & $\begin{array}{c}\text { Weight }^{2} \\
(\mathrm{~g})\end{array}$ & $\begin{array}{c}\left.\text { Canning }^{3} \text { at } / \text { barn }\right)^{5} \\
(\mathrm{mg})\end{array}$ & $\begin{array}{c}\text { Impurity } \\
(\%)^{6}\end{array}$ & $\begin{array}{c}\text { Neutron Binding } \\
\text { Energy }(\mathrm{MeV})\end{array}$ \\
\hline Au & 0.25 & 1.5048 & 1.8709 & 75.7 & & 6.513 \\
Graphite & 4.9 & 42.1544 & 3.1960 & 81.3 & & \\
${ }^{134} \mathrm{Ba}$ & 1.8 & 1.7959 & 2.2053 & 75.7 & $<0.1$ & 6.974 \\
${ }^{135} \mathrm{Ba}$ & 1.2 & 1.1168 & 1.3755 & 75.3 & $<0.1$ & 9.107 \\
${ }^{136} \mathrm{Ba}$ & 5.1 & 5.2964 & 6.5564 & 81.4 & $<0.1$ & 6.898 \\
${ }^{137} \mathrm{Ba}$ & 6.1 & 6.3918 & 7.9555 & 81.8 & $<0.1$ & 8.611 \\
Empty & & & & 75.6 & & \\
\hline
\end{tabular}

${ }^{1}$ all samples $22 \mathrm{~mm}$ in diameter

${ }^{2}$ for barium samples: weight of $\mathrm{BaCO}_{3}$

${ }^{3} 0.02 \mathrm{~mm}$ aluminum foil

${ }^{4}$ elements apart from carbon and oxygen

${ }^{5}$ for barium samples: sum of all $\mathrm{Ba}$ isotopes

$6 \%$ of weight

For accurate cross section measurements the exact characterization of the samples can be a serious problem[25]. In the present experiment, however, the corresponding uncertainty is practically negligible since barium carbonate is chemically very stable and also not hygroscopic. This stability was verified by heating the pressed sample pellets to $300 \mathrm{C}$ without finding any change in weight. After the measurements, the weight of all samples could be perfectly reproduced as well.

Eventually, the samples were not only checked for contamination with water but also 
Table 2: ISOTOPIC COMPOSITIONS (\%)

\begin{tabular}{ccccccccc}
\hline Sample & \multicolumn{7}{c}{ Isotope } & \\
& ${ }^{130} \mathrm{Ba}$ & ${ }^{132} \mathrm{Ba}$ & ${ }^{134} \mathrm{Ba}$ & ${ }^{135} \mathrm{Ba}$ & ${ }^{136} \mathrm{Ba}$ & ${ }^{137} \mathrm{Ba}$ & ${ }^{138} \mathrm{Ba}$ & \\
\hline${ }^{134} \mathrm{Ba}$ & 0.019 & 0.015 & 81.998 & 4.250 & 2.073 & 2.051 & 9.594 & KfK \\
& $<0.1$ & $<0.1$ & 82.1 & 4.21 & 2.04 & 2.04 & 9.6 & ORNL \\
${ }^{135} \mathrm{Ba}$ & 0.001 & 0.003 & 0.198 & 93.870 & 2.990 & 0.676 & 2.262 & KfK \\
& $<0.09$ & $<0.09$ & 0.16 & 94.00 & 2.87 & 0.64 & 2.33 & GUS \\
${ }^{136} \mathrm{Ba}$ & 0.002 & 0.003 & 0.078 & 0.972 & 92.677 & 1.812 & 4.456 & KfK \\
& $<0.03$ & $<0.03$ & 0.09 & 0.88 & 92.65 & 1.82 & 4.56 & ORNL \\
${ }^{137} \mathrm{Ba}$ & 0.000 & 0.001 & 0.023 & 0.074 & 0.312 & 82.250 & 17.340 & KfK \\
& $<0.05$ & $<0.05$ & $<0.05$ & 0.05 & 0.26 & 82.20 & 17.49 & GUS \\
$\mathrm{Ba}_{\text {nat }}$ & 0.108 & 0.102 & 2.432 & 6.621 & 7.873 & 11.231 & 71.633 & KfK \\
\hline
\end{tabular}

for possible deviations from the assumed stoichiometry. In a first analysis, part of the sample material was dissolved in diluted hydrochloric acid to a concentration of about $30 \mathrm{mg} / \mathrm{ml}$. The barium content of this solution was determined via $\mathrm{K}$-edge densitometry [26][27] as described in Ref.[5]. The standard solution for the calibration was prepared from natural barium carbonate, that was before heated to $300 \mathrm{C}$. The measured barium concentrations agreed within the experimental uncertainty of $0.2 \%$ with that calculated for pure $\mathrm{BaCO}_{3}$. A second batch of one of the samples was analysed for its water content as described in Ref.[5], but only an upper limit for a possible contamination of $0.05 \%$ in weight was found.

The third step in characterizing the samples concerned the isotopic composition, which was redetermined at KfK together with natural barium as an independent check. The results are compared in Table 2 with the compositions certified by the suppliers. The agreement between the various data sets is quite satisfactory.

Though it was not necessary to encapsulate the samples in vacuum sealed cannings, they were covered with an $0.02 \mathrm{~mm}$ thick aluminum foil to avoid any losses of sample material. Accordingly, a bare aluminum canning was mounted in the "empty" position of the sample changer (Table 1).

The diameter of all samples was $22 \mathrm{~mm}$. As can be seen from Table 1, some samples are comparably thick, resulting in neutron transmission values below 0.9 (Table 3 ). Since reliable total cross sections of the barium isotopes were not available in literature, the spectra measured with the neutron monitor at $260 \mathrm{~cm}$ flight path could not be corrected for this effect. Instead, the TOF spectra taken with this detector were used for a rough determination of the total cross sections. Though the accuracy of this method is inferior to that obtained in a dedicated experiment, the derived total cross sections are sufficient for a reliable calculation of the multiple scattering corrections ( 33 ). Normalization of the spectra to equal neutron flux was performed by means of the second monitor detector located close to the neutron target. 
Table 3: TRANSMISSIONS OF THE SAMPLES ${ }^{1}$

\begin{tabular}{lccccc}
\hline Sample & \multicolumn{5}{c}{ Neutron Energy (keV) } \\
& 10 & 20 & 40 & 80 & 160 \\
\hline${ }^{197} \mathrm{Au}$ & 0.972 & 0.976 & 0.979 & 0.982 & 0.984 \\
${ }^{134} \mathrm{Ba}$ & 0.956 & 0.958 & 0.960 & 0.962 & 0.964 \\
${ }^{135} \mathrm{Ba}$ & 0.970 & 0.972 & 0.974 & 0.976 & 0.977 \\
${ }^{136} \mathrm{Ba}$ & 0.891 & 0.893 & 0.894 & 0.897 & 0.900 \\
${ }^{137} \mathrm{Ba}$ & 0.873 & 0.876 & 0.878 & 0.881 & 0.885 \\
\hline
\end{tabular}

${ }^{1}$ Monte Carlo calculation with SESH code[28].

Table 4: PARAMETERS OF THE INDIVIDUAL MEASUREMENTS

\begin{tabular}{cccccccc}
\hline Run & $\begin{array}{c}\text { Flight } \\
\text { Path }\end{array}$ & $\begin{array}{c}\text { TOF } \\
\text { Scale }\end{array}$ & $\begin{array}{c}\text { Number } \\
\text { of } \\
\text { Cycles }\end{array}$ & $\begin{array}{c}\text { Maximum } \\
\text { Neutron } \\
\text { Energy } \\
(\mathrm{keV})\end{array}$ & $\begin{array}{c}\text { Measuring } \\
\text { Time }\end{array}$ & $\begin{array}{c}\text { Average } \\
\text { Beam } \\
\text { Current } \\
(\mu \mathrm{A})\end{array}$ & $\begin{array}{c}\text { Threshold } \\
\text { in Sum } \\
\text { Energy } \\
(\mathrm{MeV})\end{array}$ \\
\hline 1 & 786.7 & 0.7223 & 430 & 200 & 21 & 2.0 & 2.2 \\
2 & 786.7 & $\mathbf{0 . 7 2 2 2}$ & 399 & 80 & 17 & 2.4 & 2.3 \\
3 & 786.7 & $\mathbf{0 . 7 1 5 7}$ & 583 & 100 & 32 & 1.8 & 2.3 \\
\hline
\end{tabular}

\subsection{Measurements}

The samples were moved cyclically into the measuring position by a computer controlled sample changer. The data acquisition time per sample was about $10 \mathrm{~min}$, a complete cycle lasting about $1.2 \mathrm{~h}$. From each event, a 64 bit word was recorded on magnetic tape containing the sum energy and TOF information together with 42 bits indicating those detector modules that contributed. Three runs were performed using neutron spectra with different maximum energies. The essential parameters are compiled in Table 4 . To compensate for the reduced signal to background ratio caused by the larger background from scattered neutrons, the measuring time was increased by a factor 2 compared to the previous measurements[3][5]. The data in Run 3 were recorded with the ADC system. In Runs 1 and 2, 200 high density magnetic tapes containing roughly 35 Gbyte of information were recorded. In Run 3, where the information per event is much larger, the total amount of data could be kept at $\sim 20$ Gbyte, since half of the background events were cut off by the preprocessing unit. The spectra of the two neutron monitor detectors were stored on magnetic disk as well. 


\section{DATA ANALYSIS}

\subsection{Total Cross Sections}

The total cross sections of the barium isotopes were determined in the neutron energy range from 10 to $200 \mathrm{keV}$ from the TOF spectra measured with the ${ }^{6} \mathrm{Li}$ glass detector at a flight path of $260 \mathrm{~cm}$. The total cross sections and the related uncertainties were derived from these data as described in Ref.[5], and are listed in Table 5. The carbon and oxygen cross sections required in this procedure were taken from a recent evaluation (Joint Evaluated File, JEF)[29]. The total cross sections obtained for the carbon sample agree within $\pm 0.5 \%$ with the JEF data. This represents a significant improvement compared to the results reported in Ref.[5], where systematic differences of $3 \%$ were found, and may be explained by the fact that in the previous experiment the sample diameter of $15 \mathrm{~mm}$ was just sufficient to shade the lithium glass scintillator. Thus, even a small misalignment of this detector could have caused the observed deviations, while such an effect was excluded in the present experiment.

The total gold cross sections are also improved compared to the last experiment[5], confirming again that these cross sections are significantly larger on average than the data given by McLane et al [30]. This finding is supported by a recent measurement in Kiev[31]. The comparison of the experimental results with the ENDF/B-5 evaluation adopted in Ref.[30] is shown in Fig.2.

Table 5: THE MEASURED TOTAL CROSS SECTIONS ${ }^{1}$

\begin{tabular}{ccccccc}
\hline $\begin{array}{c}\text { Neutron Energy } \\
(\mathrm{keV})\end{array}$ & \multicolumn{6}{c}{ Total Cross Section (barn) } \\
\hline $10-15$ & 8.9 & 12.0 & 6.6 & 5.1 & 4.80 & 17.5 \\
$15-20$ & 6.4 & 11.4 & 5.0 & 3.4 & 4.63 & 14.9 \\
$20-30$ & 8.3 & 10.0 & 4.8 & 4.7 & 4.65 & 15.6 \\
$30-40$ & 5.1 & 8.7 & 4.6 & 4.6 & 4.61 & 15.0 \\
$40-60$ & 6.4 & 7.9 & 5.2 & 4.0 & 4.58 & 13.2 \\
$60-80$ & 6.4 & 6.4 & 5.4 & 4.8 & 4.51 & 11.1 \\
$80-100$ & 6.7 & 5.8 & 4.6 & 4.6 & 4.41 & 11.5 \\
$100-150$ & 5.8 & 7.3 & 4.8 & 4.5 & 4.34 & 11.7 \\
$150-200$ & 6.2 & 5.6 & 5.0 & 4.8 & 4.20 & 9.3 \\
\hline Uncertainty & $7.4 \%$ & $9.1 \%$ & $3.6 \%$ & $3.4 \%$ & $0.5 \%$ & $4.4 \%$
\end{tabular}

${ }^{1}$ determined from the count rate of the ${ }^{6} \mathrm{Li}$ glass neutron monitor at $260 \mathrm{~cm}$ flight path 


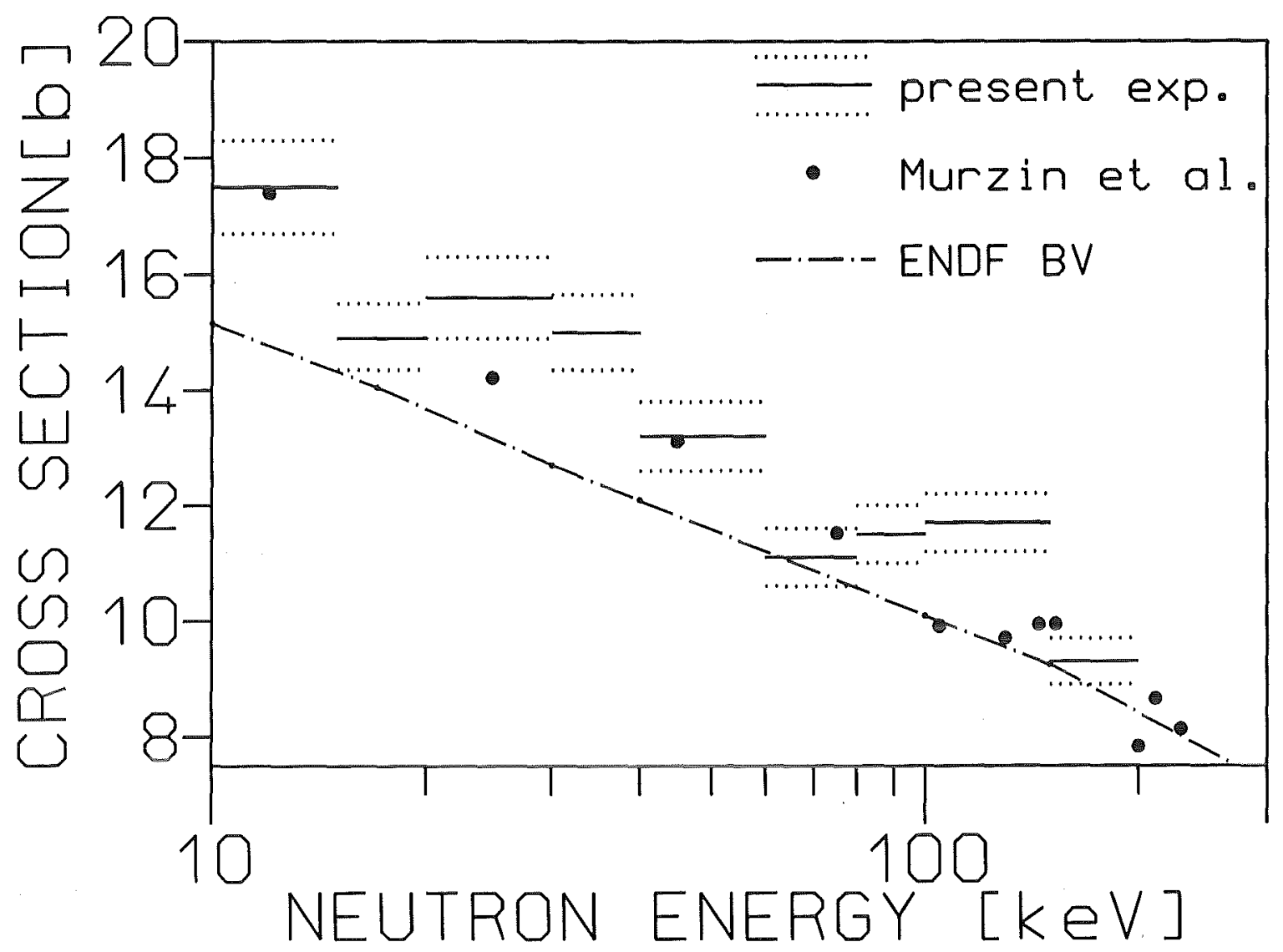

Figure 2: The total cross section of gold in comparison to the results of a recent experiment and evaluation

\subsection{Capture Cross Sections}

The data analysis was carried out analoguously to the procedure described previously [3][5][23]. All events stored on magnetic tape were sorted into two-dimensional sum energy versus TOF spectra according to event multiplicities (Evaluation 1). In Evaluation 2 , this procedure was repeated by rejecting those events, where only neighboring detector modules contributed to the sum energy signal. In this way, background from the natural radioactivity of the $\mathrm{BaF}_{2}$ crystals and from scattered neutrons can be reduced. For all samples, the resulting spectra were normalized to equal neutron flux using the neutron count rate of the second lithium glass monitor, which was located close to the neutron target. The corresponding normalization factors are all below $0.3 \%$ for Runs 1 and 3 , and below $1.0 \%$ for Run 2 (due to the faster deterioration of the thin Li targets used for neutron production in this run). The calculation of the two-dimensional spectra from the data recorded with the ADC system is slightly more complicated and was also performed as described in Ref.[5].

In the next step, the spectra measured without sample were subtracted to remove sample-independent backgrounds. A remaining constant background was determined at very long flight times, where no time-correlated events are expected. In the present 
Table 6: MATRIX FOR THE ISOTOPIC CORRECTION (\%) ${ }^{1}$

\begin{tabular}{cccccc}
\hline $\begin{array}{c}\text { Corrected } \\
\text { Spectrum }\end{array}$ & \multicolumn{5}{c}{ Measured spectrum } \\
& ${ }^{134} \mathrm{Ba}$ & ${ }^{135} \mathrm{Ba}$ & ${ }^{136} \mathrm{Ba}$ & ${ }^{137} \mathrm{Ba}$ & $\begin{array}{c}\text { Corrected Sample } \\
\text { Thickness }\left(10^{-3} \text { at/barn }\right)\end{array}$ \\
\hline${ }^{134} \mathrm{Ba}$ & 100 & -7.2423 & -0.7065 & -0.6773 & 1.4724 \\
${ }^{135} \mathrm{Ba}$ & -0.1480 & 100 & -0.6786 & -0.1302 & 1.0479 \\
${ }^{136} \mathrm{Ba}$ & -0.2713 & -4.8827 & 100 & -1.8166 & 4.9065 \\
${ }^{137} \mathrm{Ba}$ & -0.0981 & -0.4243 & -0.4026 & 100 & 5.2568 \\
\hline
\end{tabular}

${ }^{1}$ using the approximation that the abundances of ${ }^{130} \mathrm{Ba}={ }^{132} \mathrm{Ba}=0$, and that $\sigma\left({ }^{138} \mathrm{Ba}\right)=0$

measurement, the subtraction this time-independent component was more difficult than in previous experiments. The large scattering yields, especially from the ${ }^{136} \mathrm{Ba}$ and ${ }^{137} \mathrm{Ba}$ samples and from the thick graphite sample gave rise to an overlap with events from the previous pulse. Therefore, the count rate in the TOF region around $3.9 \mu \mathrm{s}$, where this background used to be determined, was not completely flat. Instead, the interval between the prompt gamma-ray peak and the onset of the capture events was used for normalization, which exhibits an additional delay of 200 ns. Even there, the count rates were not completely time-independent for the thickest samples. The respective systematic uncertainties are discussed in $\S 5$. The two-dimensional spectra of Run 3 containing all events with multiplicity $>2$ are shown in Fig. 3 and Fig.4. Note, that events at low sum energy and large TOF are suppressed by the preprocessing unit coupled to the ADC system.

At this point, the spectra contain only events that are correlated with the sample. The next correction to be made is for isotopic impurities (see Ref.[5] for details). The respective coefficients are compiled in Table 6. The corrections for the impurities of ${ }^{130} \mathrm{Ba}$, ${ }^{132} \mathrm{Ba}$, and ${ }^{138} \mathrm{Ba}$ were neglected. For the light isotopes 130 and 132 this is justified because they contribute always $<0.02 \%$ (Table 2). The corrections for the ${ }^{138} \mathrm{Ba}$ impurities were relatively small because of the small cross section of that isotope. Therefore, the resulting uncertainties can be tolerated even for the $17 \%$ impurity in the ${ }^{137} \mathrm{Ba}$ sample $(\S 5)$. The largest correction for isotopic impurities was found for the ${ }^{134} \mathrm{Ba}$ sample, but also in this case it did not exceed $6 \%$ of the measured effect (Fig.5).

After the correction for isotopic impurities, the background due to capture of sample scattered neutrons was removed from the spectra by means of the data measured with the carbon sample. The scattered neutrons are captured mainly in the barium isotopes of the scintillator. This is shown in Fig.6, where the sum energy of the events recorded with the graphite sample is plotted. In spite of its large abundance of $72 \%$, captures in ${ }^{138} \mathrm{Ba}$ are barely visible because of its very small capture cross section. 


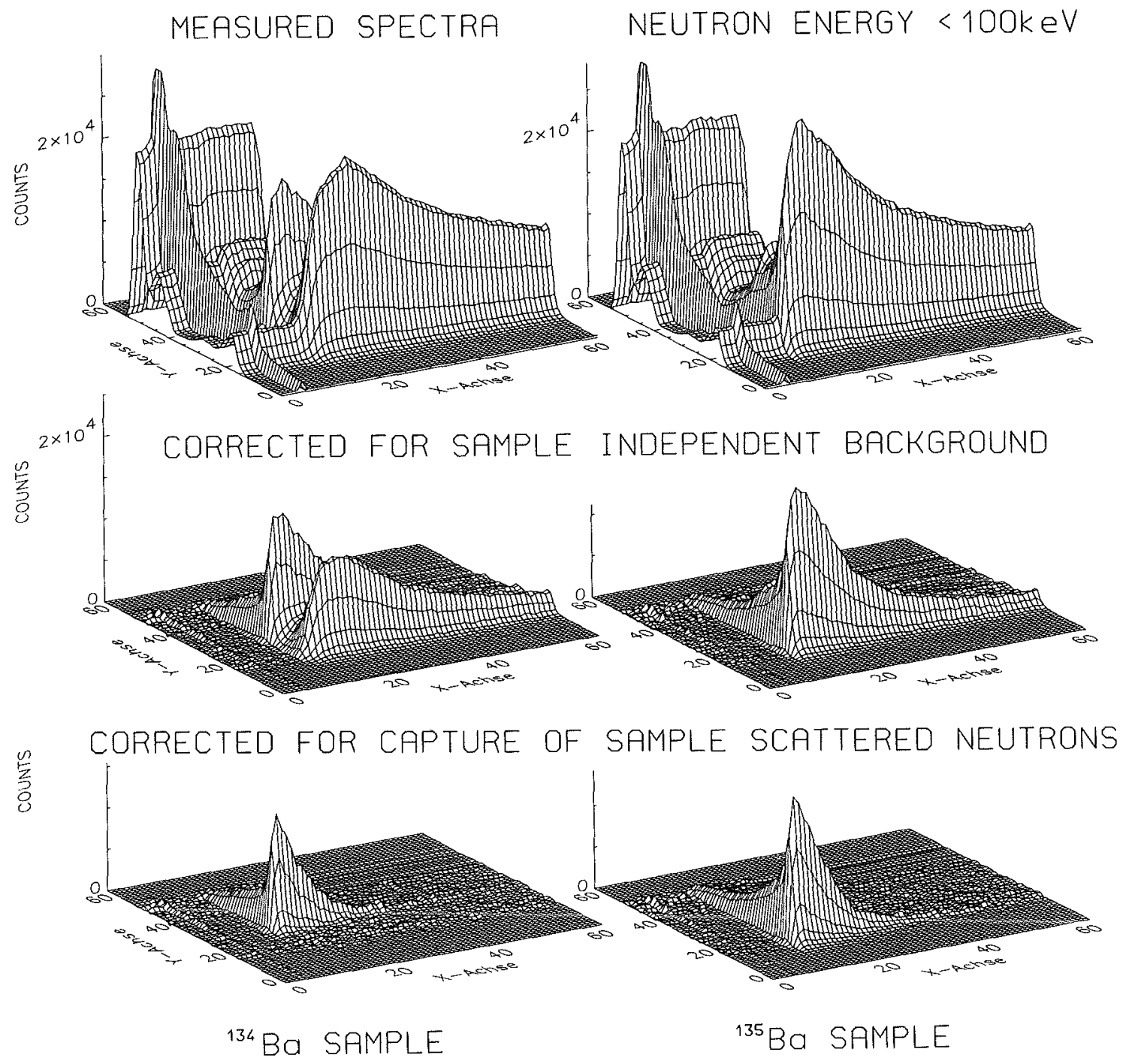

Figure 3: The different steps of background subtraction in the two dimensional sum energy $\times$ TOF spectra. The data are shown for ${ }^{134} \mathrm{Ba}$ and ${ }^{135} \mathrm{Ba}$ measured in run 3 with $100 \mathrm{keV}$ maximum neutron energy. (The original resolution of $128 \times 2048$ channels was compressed in the plots into $64 \times 64$ channels. The events at low sum energy and large TOF are suppressed by the preprocessing of the ADC system) 

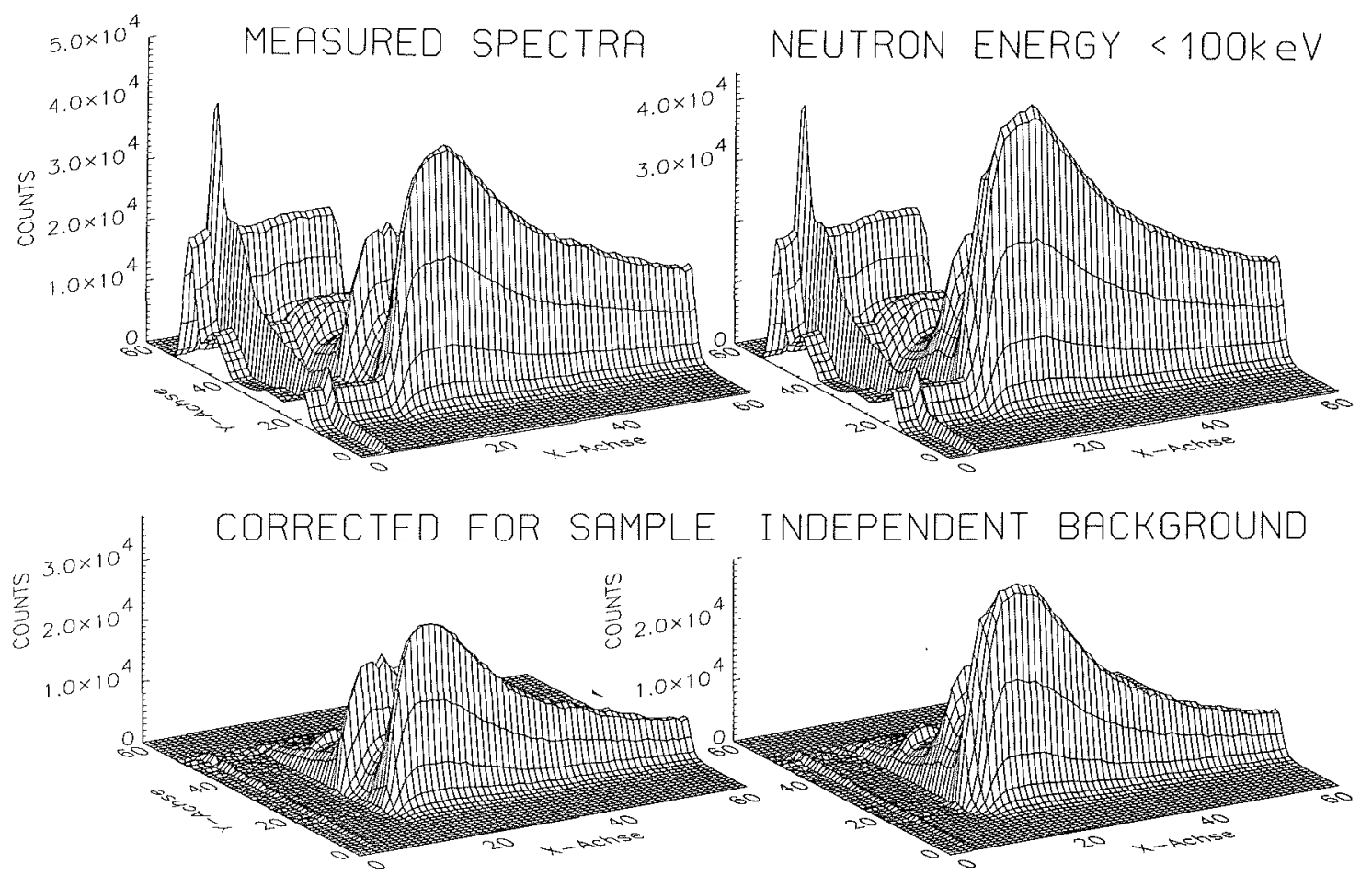

点 CORRECTED FOR CAPTURE OF SAMPLE SCATTERED NEUTRONS
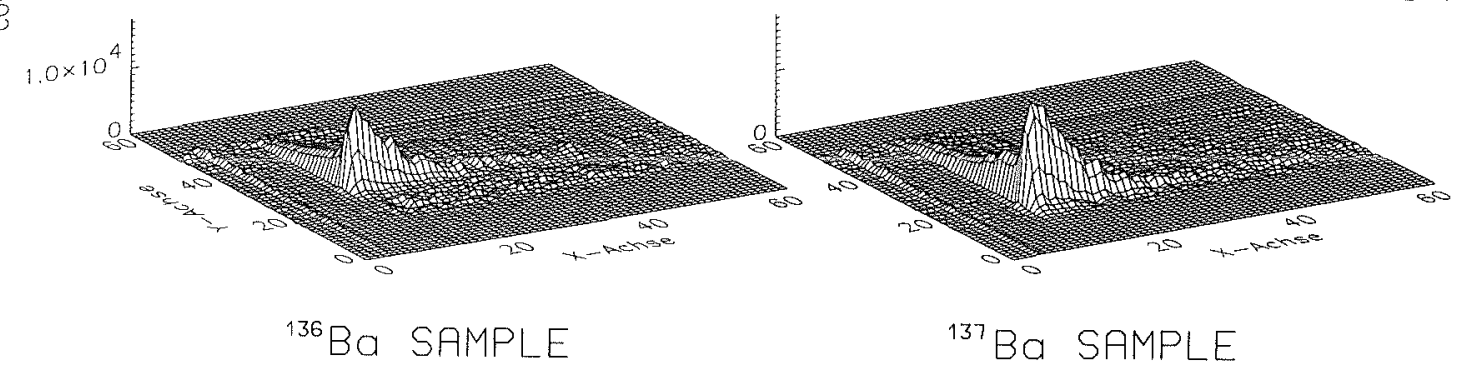

Figure 4: The same as Fig.3 but for the ${ }^{136} \mathrm{Ba}$ and ${ }^{137} \mathrm{Ba}$ sample. 


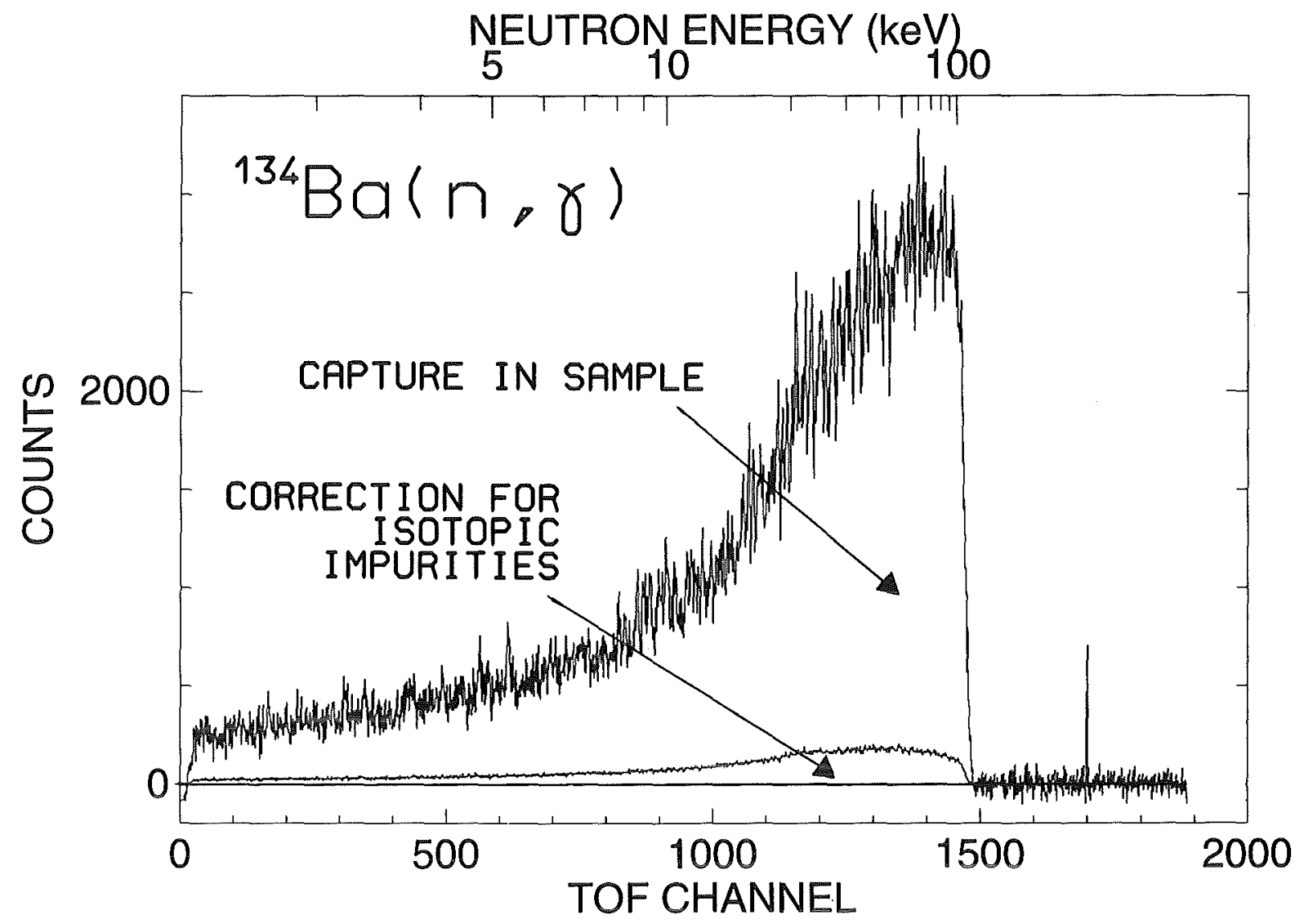

Figure 5: TOF spectrum measured with the ${ }^{134} \mathrm{Ba}$ sample. The background due to isotopic impurities is shown separately.

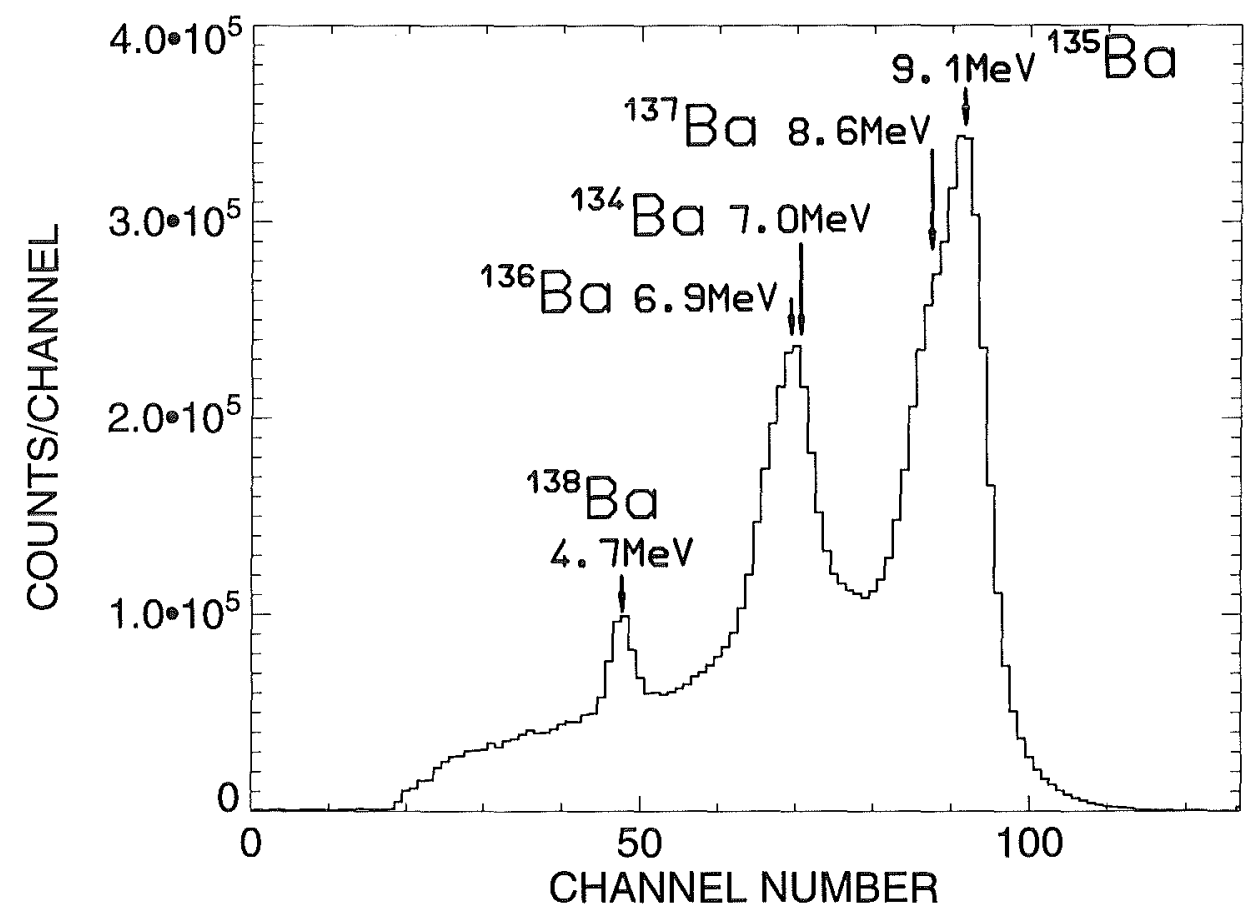

Figure 6: Sum energy spectrum measured with the graphite sample, showing capture events in the different barium isotopes of the scintillator 
In the present experiment, true captures in the samples are difficult to distinguish from background events due to capture of scattered neutrons in the scintillator, the only difference in the sum energy spectra being due to the different isotopic enrichments. The background subtraction is performed as in the previous experiments [3][5][23], using the sum energy window around $9 \mathrm{MeV}$ (channels 79 to 100 in Fig.6) for the even isotopes; for the odd isotopes, the peak due to captures in ${ }^{134} \mathrm{Ba}$ and ${ }^{136} \mathrm{Ba}$ around $7 \mathrm{MeV}$ (Fig.6) was integrated. The possibility to calculate this normalization versus TOF is very important for the accuracy of the cross sections measured with the $4 \pi \mathrm{BaF}_{2}$ detector. After this last correction, the spectra contain now only true capture events (lower part of Figs.3 and 4), and can eventually be used to determine the cross sections.

The separation of true capture events from background due to scattered neutrons is complicated by the carbon and oxygen content of the sample material. The TOF spectra of the ${ }^{134} \mathrm{Ba},{ }^{135} \mathrm{Ba}$, and ${ }^{136} \mathrm{Ba}$ samples are plotted in Fig.7 after projection of the twodimensional data in the sum energy range around the binding energy (see below) together with the background due to scattered neutrons. The spectra are from Run 3 with 100 $\mathrm{keV}$ maximum neutron energy. In this figure, three features are remarkable:

- In contrast to previous measurements with the $4 \pi \mathrm{BaF}_{2}$ detector [3][5][23], there is a significant background in the time interval used for the absolute normalization of the cross section (dashed area), resulting in a considerably reduced accuracy.

Table 7: SIGNAL/BACKGROUND RATIO FOR RUNS WITH DIFFERENT MAXIMUM NEUTRON ENERGY

\begin{tabular}{cccccc}
\hline Sample & $\begin{array}{c}\sigma_{t} / \sigma_{\gamma} \\
\text { at } 30 \mathrm{keV}\end{array}$ & $\begin{array}{c}\text { Maximum Neutron } \\
\text { Energy }(\mathrm{keV})\end{array}$ & \multicolumn{3}{c}{$\begin{array}{c}\text { Signal/Background ratio } \\
\text { neutron }\end{array}$} \\
& & & 30 & 20 & 10 \\
\hline${ }^{134} \mathrm{Ba}$ & 139 & 80 & 2.25 & 1.59 & 1.29 \\
${ }^{135} \mathrm{Ba}$ & 54 & & 3.66 & 1.95 & 1.34 \\
${ }^{136} \mathrm{Ba}$ & 366 & & 1.44 & 1.25 & 1.13 \\
${ }^{137} \mathrm{Ba}$ & 284 & & 1.39 & 1.14 & 1.07 \\
${ }^{197} \mathrm{Au}$ & 24 & & 15.5 & 6.4 & 3.4 \\
& & & & & \\
${ }^{134} \mathrm{Ba}$ & & 100 & 1.73 & 1.41 & 1.29 \\
${ }^{135} \mathrm{Ba}$ & & & 2.26 & 1.58 & 1.19 \\
${ }^{136} \mathrm{Ba}$ & & & 1.25 & 1.18 & 1.12 \\
${ }^{137} \mathrm{Ba}$ & & & 1.18 & 1.09 & 1.04 \\
${ }^{197} \mathrm{Au}$ & & & 8.0 & 4.3 & 2.88 \\
& & & & & \\
${ }^{134} \mathrm{Ba}$ & & & 1.58 & 1.33 & 1.24 \\
${ }^{135} \mathrm{Ba}$ & & & 2.13 & 1.57 & 1.26 \\
${ }^{136} \mathrm{Ba}$ & & & 1.22 & 1.15 & 1.09 \\
${ }^{137} \mathrm{Ba}$ & & & 1.17 & 1.07 & 1.04 \\
${ }^{197} \mathrm{Au}$ & & & 7.9 & 4.3 & 2.78 \\
\hline
\end{tabular}

${ }^{1}$ the ratios are defined as (effect+background)/(background) 


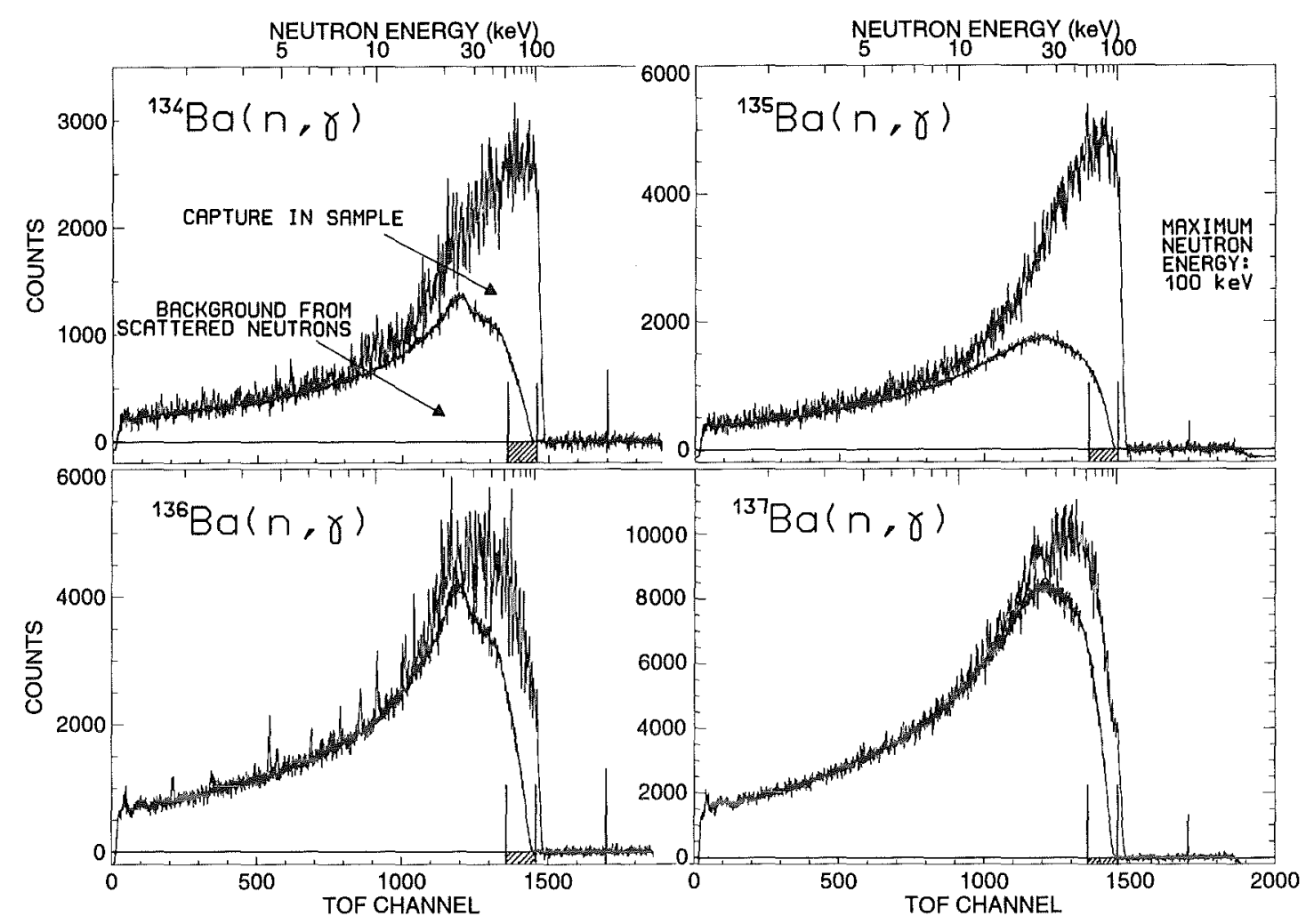

Figure 7: TOF spectra measured with the barium samples in run 3 with $100 \mathrm{keV}$ maximum neutron energy. The background due to sample scattered neutrons is shown separately. The region used for the absolute normalization of the cross section is shown by hatched boxes.

- The signal to background ratio deteriorates rapidly towards lower energies. Nevertheless, the data could be analyzed down to $3 \mathrm{keV}$, since the backgrounds are well known. However, the energy region below $5 \mathrm{keV}$ was not used for the final evaluation of the stellar cross sections.

- The isotope ${ }^{136} \mathrm{Ba}$ requires special consideration since the resonances are completely resolved up to $15 \mathrm{keV}$ neutron energy. Hence, the adopted procedure to evaluate average cross sections may not be adequate in this case, and fitting of the resonance parameters might be required. A corresponding study with the FANAC code[28][32] is in progress.

In view of the low signal to background ratio, the combination of runs with different neutron spectra was important. In this way, optimum conditions could be obtained in different energy regions, as illustrated in Fig. 8 at the example of the TOF spectra of the ${ }^{134} \mathrm{Ba}$ sample. At $30 \mathrm{keV}$, the best signal to background ratio is achieved in the run with $80 \mathrm{keV}$ maximum energy. Table 7 presents a more complete picture of the signal to background ratios in the critical energy range. For consistency with the previous publications [3] [5] [23], the quoted numbers are defined as the ratio (effect+background)/(background). For obtaining the true signal to background ratio, these numbers have, therefore, to be lowered 


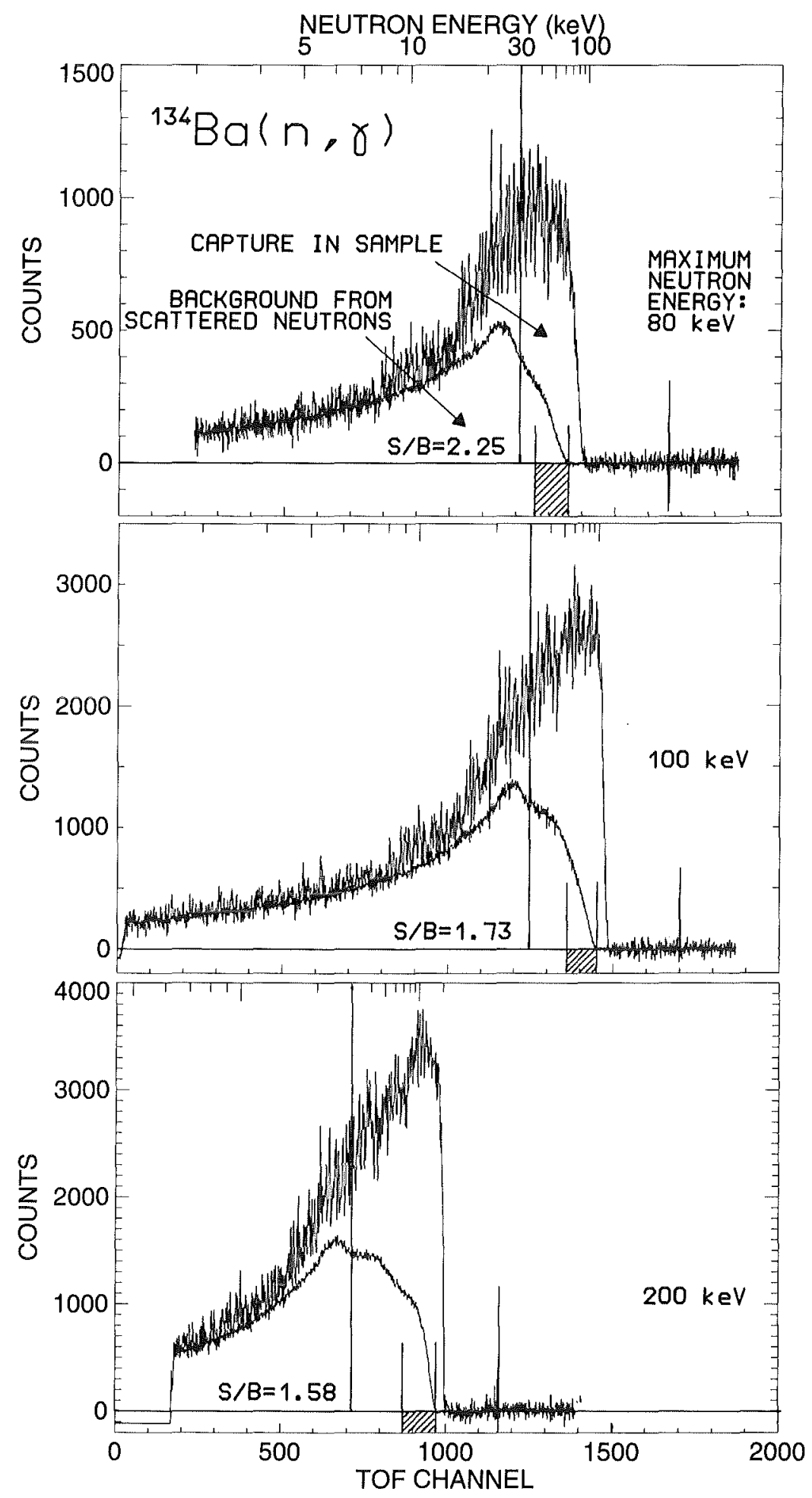

Figure 8: The signal to background ratio measured with the ${ }^{134} \mathrm{Ba}$ sample in runs with different maximum neutron energy. 


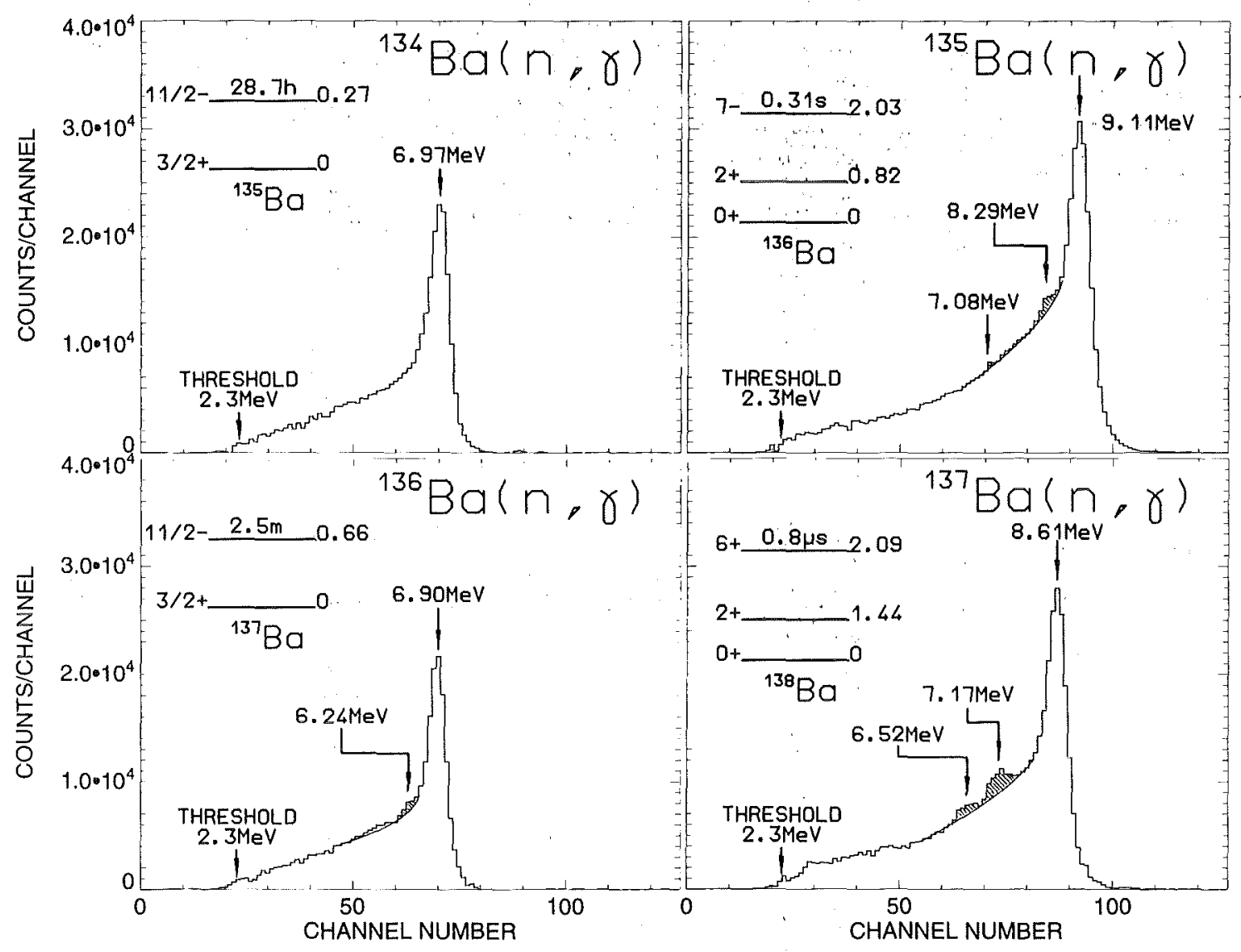

Figure 9: Sum energy spectra of all isotopes measured in run 1 containing all events with multiplicity $>2$. These spectra were obtained by projection of the two-dimensional spectra in the TOF region below the maximum neutron energy as indicated by hached boxes in Fig.7.

by one. While this difference was unimportant for the large ratios in the previous measurements, it now becomes significant. One finds that the signal to background ratios differ by a factor of two for different neutron spectra. The difficult background situation is characterized by the fact that the ratio of total and capture cross sections reaches values up to $\sim 400$, which is a factor of ten larger than for most isotopes measured up to now: That reliable $(n, \gamma)$ cross sections can be determined even in this extreme case confirms the reliability of the background subtraction and justifies again that the related systematic uncertainties could be neglected in the previous experiments. The uncertainties of the present data are discussed in $\S 5$.

After background subtraction, the TOF spectra in Fig.7 were used to determine the cross section shape. For normalization, the two-dimensional data were projected onto the sum energy axis using the TOF region of optimum signal to background ratio as indicated by in Fig. 7 by dashed boxes. The resulting pulse height spectra are shown in Fig.9 for the events with multiplicity $>2$. The spectra exhibit significant structures in the odd isotopes. The peaks in ${ }^{135} \mathrm{Ba}$ at $8.29 \mathrm{MeV}$ and in ${ }^{137} \mathrm{Ba}$ at $7.17 \mathrm{MeV}$ are due to the fact that nearly $80 \%$ of the capture cascades contain the $2^{+} \rightarrow 0^{+}$ground state transition in 
the respective compound nucleus (see inset of Fig.9). Since the solid angle for detecting the corresponding gamma-ray lines at $0.82 \mathrm{MeV}$ and $1.44 \mathrm{MeV}$ is only $94 \%$, the peak at the binding energy is shifted by this amount in the remaining $6 \%$ of all events.

The additional structures in the spectra of Fig.9 are, however, due to isomeric states in the respective compound nuclei, which are also indicated in the insets. The half-lives of these isomers are between $0.8 \mu \mathrm{s}$ and $29 \mathrm{~h}$, while the coincidence time for registration of a capture $\gamma$-ray cascades is $\sim 20 \mathrm{~ns}$. Thus, events feeding the isomer are registered with correspondingly lower sum energies. This is most clearly observed for ${ }^{137} \mathrm{Ba}$, where the respective energy is $6.52 \mathrm{MeV}$. In ${ }^{135} \mathrm{Ba}$, this effect is much weaker, yielding only an upper limit for the population of the isomer, while capture in ${ }^{134} \mathrm{Ba}$ feeds an isomer at $268 \mathrm{keV}$, which is too low to be resolved from the cascades to the ground state. But since ${ }^{134} \mathrm{Ba}$ and ${ }^{136} \mathrm{Ba}$ are very close in binding energy, the shape of the ${ }^{134} \mathrm{Ba}$ spectrum can be used to determine the population probability of the $662 \mathrm{keV}$ isomer in ${ }^{137} \mathrm{Ba}$. The structures in the spectra of Fig.9 are statistically significant since they are observed in all three runs. This means that the probability for the population of isomeric states has been measured for the first time in a neutron TOF experiment.

The corresponding isomeric ratios,

$$
I R=\frac{\text { partial cross section to isomer }}{\text { total }(n, \gamma) \text { cross section }}
$$

are determined to $\mathrm{IR}=<2 \%, 2.5 \pm 1 \%$, and $3 \pm 1 \%$ for ${ }^{135} \mathrm{Ba},{ }^{136} \mathrm{Ba}$, and ${ }^{137} \mathrm{Ba}$, respectively.

In Fig.10, the sum energy spectra of the barium isotopes are shown for different multiplicities. (These multiplicities are determined by the number of detector modules contributing to an event. The true multiplicities are slightly smaller, because of cross talking effects). In all cases, multiplicities $\geq 5$ are observed for $\sim 40 \%$ of the cascades, except for ${ }^{136} \mathrm{Ba}$ where the respective fraction is only $\sim 27 \%$. This latter isotope shows an average multiplicity of only 2.3 due to the comparatively low binding energy and the low level density in ${ }^{137} \mathrm{Ba}$ (see below); accordingly, one finds a rather large fraction of events with multiplicity 1. The arrows in Fig. 10 indicate the range of sum energy channels that were combined to the TOF spectra in Fig.7, from which the cross section shapes were determined.

The cross section ratio of isotope $\mathrm{X}$ relative to the gold standard is then

$$
\frac{\sigma_{i}(X)}{\sigma_{i}(A u)}=\frac{Z_{i}(X)}{Z_{i}(A u)} \cdot \frac{\Sigma Z(A u)}{\Sigma Z(X)} \cdot \frac{\Sigma E(X)}{\Sigma E(A u)} \cdot \frac{m(A u)}{m(X)} \cdot F_{1} \cdot F_{2}
$$

In this expression, $Z_{i}$ is the count rate in channel $i$ of the TOF spectrum, $\Sigma Z$ is the TOF rate integrated over the interval used for normalization (Fig.7), $\Sigma \mathrm{E}$ is the total count rate in the sum energy spectrum for all multiplicities summed over the normalization interval (Fig.9), and $\mathrm{m}$ is the sample thickness in atoms/barn. The factor $\mathrm{F}_{1}=(100-\mathrm{f}(\mathrm{Au})) /(100$ $f(X))$ corrects for the fraction of capture events $f$ below the experimental threshold in sum energy, where $X$ refers to the respective barium sample (Table 8), and $F_{2}$ is the respective ratio of the multiple scattering and self-shielding corrections . 


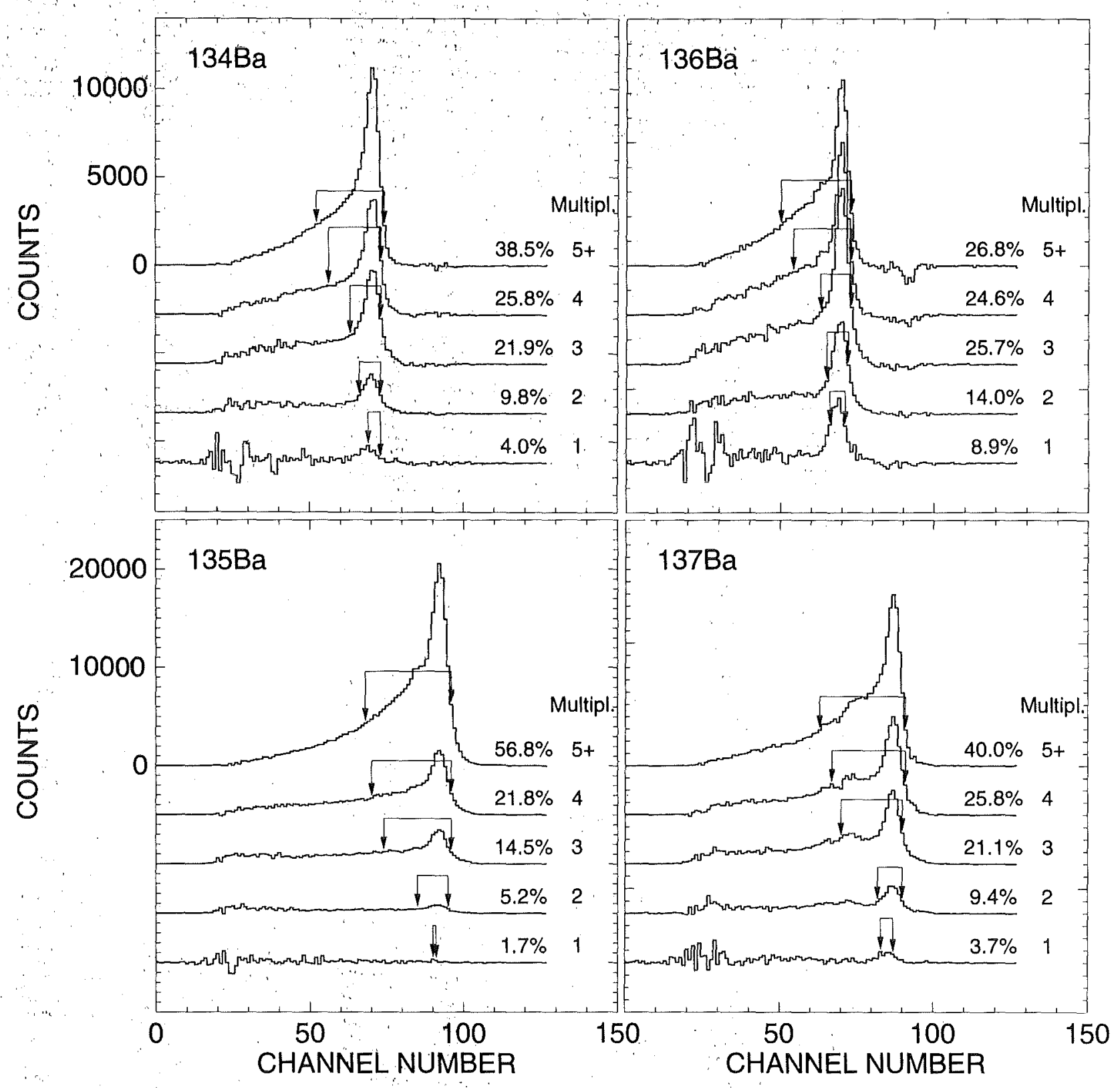

Figure 10: Sum energy spectra of all barium isotopes in dependence of the detector multiplicity (the same data as shown in Fig. 9). The regions used to determine the cross section shape are indicated by arrows. 
Table 8: FRACTION OF UNDETECTED CAPTURE EVENTS, f (\%), AND THE RELATED CORRECTION FACTORS ${ }^{1}$

\begin{tabular}{|c|c|c|c|c|c|}
\hline & \multicolumn{4}{|c|}{ Threshold in Sum Energy (MeV) } & \multirow{2}{*}{$\begin{array}{c}\text { Assumption for } \\
\text { Gamma-Ray Efficiency }\end{array}$} \\
\hline & 2.0 & 2.2 & 2.3 & 2.5 & \\
\hline$f(A u)$ & 4.99 & & & 7.25 & $\mathrm{SW}_{M A X}$ \\
\hline $\mathrm{f}\left({ }^{134} \mathrm{Ba}\right)$ & 5.92 & & & 6.92 & \\
\hline$f\left({ }^{135} \mathrm{Ba}\right)$ & 1.87 & & & 3.35 & \\
\hline$f\left({ }^{136} \mathrm{Ba}\right)$ & 5.05 & & & 6.96 & \\
\hline $\mathrm{f}\left({ }^{137} \mathrm{Ba}\right)$ & 2.41 & & & 3.06 & \\
\hline$f(A u)$ & 5.78 & & & 8.35 & $\mathrm{SW}_{M I N}$ \\
\hline$f\left({ }^{134} \mathrm{Ba}\right)$ & 6.30 & & & 7.91 & \\
\hline $\mathrm{f}\left({ }^{135} \mathrm{Ba}\right)$ & 2.41 & & & 3.64 & \\
\hline$f\left({ }^{136} \mathrm{Ba}\right)$ & 5.73 & & & 7.61 & \\
\hline $\mathrm{f}\left({ }^{137} \mathrm{Ba}\right)$ & 2.74 & & & 4.10 & \\
\hline $\mathrm{f}(\mathrm{Au})$ & 5.28 & & & 7.61 & from experiment $[33]$ \\
\hline$f\left({ }^{134} \mathrm{Ba}\right)$ & 5.35 & & & 6.89 & \\
\hline $\mathrm{f}\left({ }^{135} \mathrm{Ba}\right)$ & 1.83 & & & 2.95 & \\
\hline$f\left({ }^{136} \mathrm{Ba}\right)$ & 5.41 & & & 6.76 & \\
\hline $\mathrm{f}\left({ }^{137} \mathrm{Ba}\right)$ & 2.24 & & & 3.53 & \\
\hline $\mathrm{F}_{1}\left({ }^{134} \mathrm{Ba} / \mathrm{Au}\right)$ & 1.008 & & & 0.996 & $\left(\mathrm{SW}_{M A X}+\mathrm{SW}_{M I N}\right) / 2$ \\
\hline $\mathrm{F}_{1}\left({ }^{135} \mathrm{Ba} / \mathrm{Au}\right)$ & 0.967 & & & 0.955 & \\
\hline$F_{1}\left({ }^{136} \mathrm{Ba} / \mathrm{Au}\right)$ & 1.000 & & & 0.995 & \\
\hline $\mathrm{F}_{1}\left({ }^{137} \mathrm{Ba} / \mathrm{Au}\right)$ & 0.971 & & & 0.956 & \\
\hline $\mathrm{F}_{1}\left({ }^{134} \mathrm{Ba} / \mathrm{Au}\right)$ & 1.001 & 0.997 & 0.996 & 0.992 & from experiment $[33]$ \\
\hline $\mathrm{F}_{1}\left({ }^{135} \mathrm{Ba} / \mathrm{Au}\right)$ & 0.965 & 0.960 & 0.957 & 0.952 & \\
\hline $\mathrm{F}_{1}\left({ }^{136} \mathrm{Ba} / \mathrm{Au}\right)$ & 1.001 & 0.997 & 0.995 & 0.991 & \\
\hline $\mathrm{F}_{1}\left({ }^{137} \mathrm{Ba} / \mathrm{Au}\right)$ & 0.969 & 0.964 & 0.962 & 0.958 & \\
\hline
\end{tabular}

${ }^{1}$ Solid angle $94 \%$, gamma-ray threshold $50 \mathrm{keV}$

The fraction of unobserved capture events, $f$, and the correction factor $F_{1}$ were calculated as described in detail in Ref.[23]. The required input for this calculation are the individual neutron capture cascades and their relative contributions to the total capture cross section as well as the detector efficiency for monoenergetic gamma-rays in the energy range up to $10 \mathrm{MeV}$.

Capture cascades and capture gamma-ray spectra of the involved isotopes were calculated according to the statistical and optical models[34]. In Table 9, the calculated 
cross sections are given as a function of cascade multiplicity together with the gammaray energies of the 20 most probable cascades. The respective data for gold can be found in Ref.[23]. The first 20 cascades account for $27 \%$ to $73 \%$ of the cross sections, but up to 900 cascades were used to cover at least $95 \%$ in the calculations. The average cascade multiplicities range from 2.3 to 3.7 , and are significantly lower than for the previously investigated $\mathrm{Te}$ and $\mathrm{Sm}$ isotopes[3][5]. This difference reflects the proximity of the barium isotopes to the magic neutron configuration at $N=82$. The related capture gamma-ray spectra are given in Fig.11.

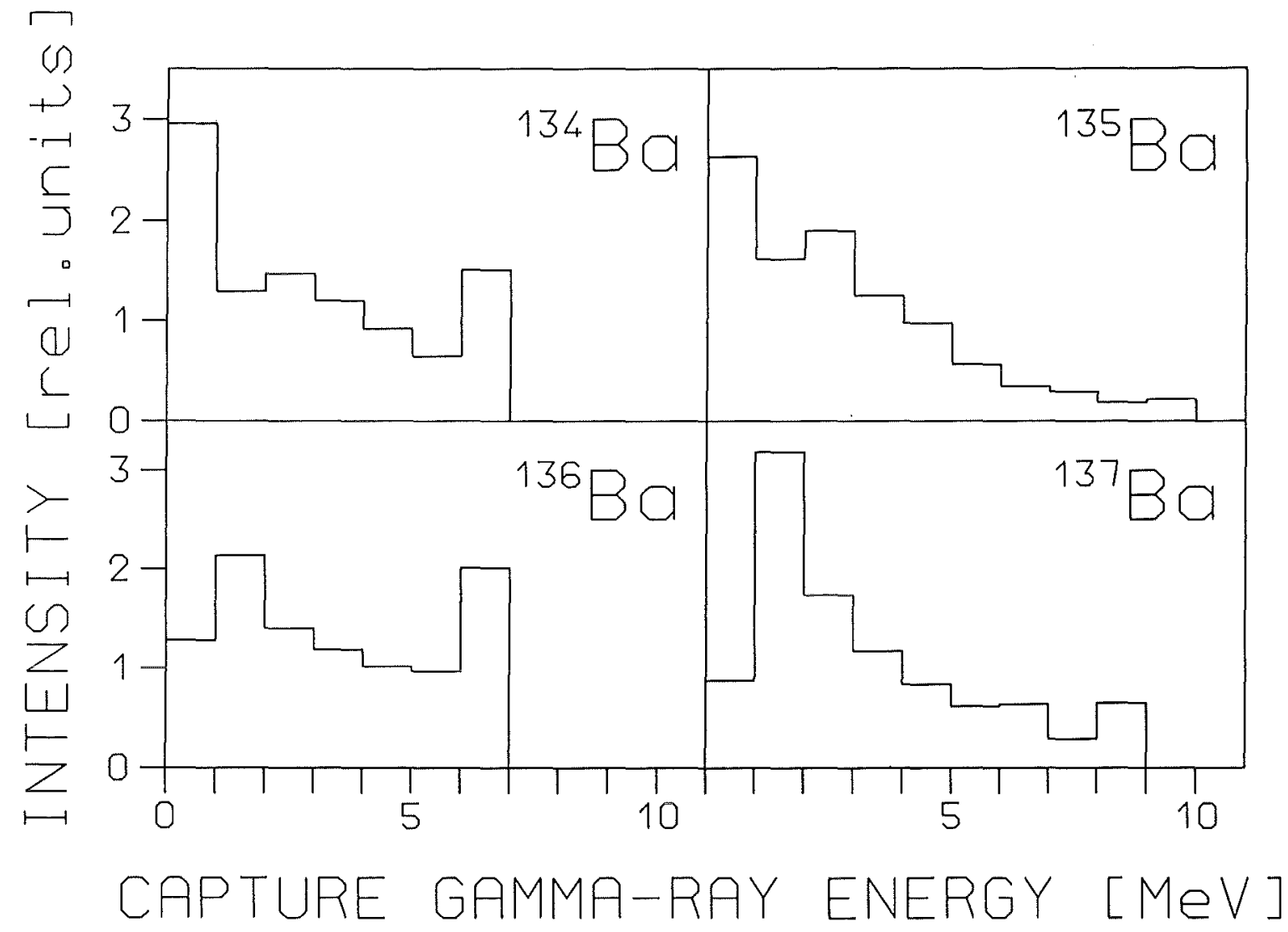

Figure 11: Calculated capture gamma-ray spectra for the barium isotopes. 
Table 9: CALCULATED CAPTURE GAMMA-RAY CASCADES INCLUDING MULTIPLICITIES, PARTIAL CROSS SECTIONS, $\sigma_{p}$, AND GAMMA-RAY ENERGIES OF THE 20 MOST SIGNIFICANT CASCADES

${ }^{134} \mathrm{Ba}$

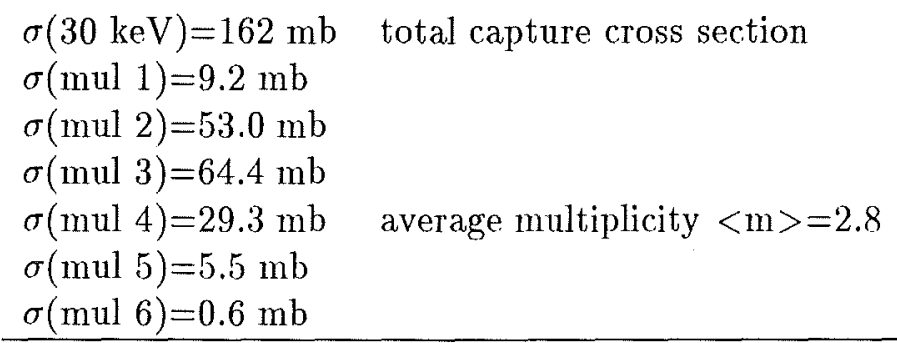

calculated number of cascades $=465$ (covering $95 \%$ of the cross section)

\begin{tabular}{lcccc}
$\begin{array}{l}\sigma_{p} \\
(\mathrm{mb})\end{array}$ & $\begin{array}{c}\sigma_{p} / \sigma \\
(\%)\end{array}$ & $\mathrm{E}_{\gamma 1}$ & $\mathrm{E}_{\gamma 2}$ & $\begin{array}{c}\mathrm{E}_{\gamma 3} \\
(\mathrm{MeV})\end{array}$ \\
9.21 & 5.68 & 7.003 & & \\
7.50 & 4.63 & 6.782 & 0.221 & \\
4.58 & 2.83 & 5.268 & 1.735 & \\
4.28 & 2.64 & 6.415 & 0.588 & \\
3.85 & 2.37 & 4.683 & 2.320 & \\
& & & & \\
3.54 & 2.18 & 4.097 & 2.906 & \\
3.47 & 2.14 & 6.523 & 0.480 & \\
3.41 & 2.10 & 6.071 & 0.932 & \\
3.34 & 2.06 & 3.512 & 3.491 & \\
3.04 & 1.88 & 6.093 & 0.910 & \\
& & & & \\
3.04 & 1.88 & 2.927 & 4.077 & \\
2.50 & 1.54 & 2.341 & 4.662 & \\
2.35 & 1.45 & 6.023 & 0.980 & \\
2.09 & 1.29 & 5.873 & 1.130 & \\
2.03 & 1.25 & 5.995 & 0.420 & 0.588 \\
& & & & \\
1.92 & 1.19 & 5.268 & 1.514 & 0.221 \\
1.83 & 1.13 & 6.148 & 0.634 & 0.221 \\
1.77 & 1.10 & 4.683 & 2.099 & 0.221 \\
1.74 & 1.07 & 4.097 & 2.685 & 0.221 \\
1.71 & 1.06 & 1.756 & 5.247 & \\
& $\Sigma=41.5 \%$ & & & \\
\hline
\end{tabular}


${ }^{135} \mathrm{Ba}$

$$
\begin{aligned}
& \sigma(30 \mathrm{keV})=465 \mathrm{mb} \text { total capture cross section } \\
& \sigma(\mathrm{mul} \mathrm{1})=10.3 \mathrm{mb} \\
& \sigma(\mathrm{mul} \mathrm{2})=54.3 \mathrm{mb} \\
& \sigma(\mathrm{mul} \mathrm{3})=131.1 \mathrm{mb} \\
& \sigma(\mathrm{mul} \mathrm{4})=156.4 \mathrm{mb} \text { average multiplicity }\langle\mathrm{m}\rangle=3.7 \\
& \sigma(\mathrm{mul} \mathrm{5})=82.7 \mathrm{mb} \\
& \sigma(\mathrm{mul} \mathrm{6})=24.9 \mathrm{mb} \\
& \sigma(\mathrm{mul} \mathrm{7})=5.3 \mathrm{mb}
\end{aligned}
$$

calculated number of cascades $=908$ (covering $95 \%$ of the cross section)

\begin{tabular}{lccccc}
$\begin{array}{l}\sigma_{p} \\
(\mathrm{mb})\end{array}$ & $\begin{array}{c}\sigma_{p} / \sigma \\
(\%)\end{array}$ & $\mathrm{E}_{\gamma 1}$ & $\mathrm{E}_{\gamma 2}$ & $\begin{array}{c}\mathrm{E}_{\gamma 3} \\
(\mathrm{MeV})\end{array}$ & $\mathrm{E}_{\gamma 4}$ \\
17.2 & 3.71 & 8.319 & 0.818 & & \\
10.3 & 2.22 & 9.137 & & & \\
8.60 & 1.85 & 4.114 & 4.204 & 0.818 & \\
8.47 & 1.82 & 4.800 & 3.519 & 0.818 & \\
8.31 & 1.79 & 3.429 & 4.890 & 0.818 & \\
& & & & & \\
8.28 & 1.78 & 5.486 & 2.833 & 0.818 & \\
8.02 & 1.72 & 6.172 & 2.147 & 0.818 & 0.818 \\
7.24 & 1.56 & 2.743 & 5.576 & 0.818 & \\
5.20 & 1.12 & 2.057 & 6.261 & 0.818 & \\
4.93 & 1.06 & 3.429 & 2.743 & 2.147 & \\
& & & & & \\
4.86 & 1.05 & 2.743 & 3.429 & 2.147 & \\
4.31 & 0.93 & 7.325 & 0.994 & 0.818 & \\
4.22 & 0.91 & 7.586 & 1.551 & & \\
4.19 & 0.90 & 4.114 & 5.023 & & \\
4.19 & 0.90 & 6.172 & 2.966 & & \\
& & & & & \\
4.15 & 0.89 & 4.800 & 4.337 & & \\
4.12 & 0.89 & 5.486 & 3.651 & & \\
4.11 & 0.88 & 3.429 & 5.708 & & \\
4.01 & 0.86 & 4.114 & 2.057 & 2.147 & \\
3.74 & 0.80 & 7.586 & 0.733 & 0.818 & \\
& $\Sigma=27.6 \%$ & & & & \\
\hline
\end{tabular}


${ }^{136} \mathrm{Ba}$

$\sigma(30 \mathrm{keV})=55 \mathrm{mb}$ total capture cross section

$\sigma(\mathrm{mul} \mathrm{1})=8.0 \mathrm{mb}$

$\sigma(\mathrm{mul} \mathrm{2})=25.7 \mathrm{mb}$

$\sigma(\mathrm{mul} \mathrm{3})=16.4 \mathrm{mb} \quad$ average multiplicity $<\mathrm{m}>=2.3$

$\sigma(\mathrm{mul} \mathrm{4})=4.2 \mathrm{mb}$

$\sigma(\mathrm{mul} 5)=0.7 \mathrm{mb}$

calculated number of cascades $=102$ (covering $95 \%$ of the cross section)

\begin{tabular}{lccccc}
$\sigma_{p}$ & $\begin{array}{c}\sigma_{p} / \sigma \\
(\mathrm{mb})\end{array}$ & $\mathrm{E}_{\gamma 1}$ & $\mathrm{E}_{\gamma 2}$ & $\mathrm{E}_{\gamma 3}$ & $\mathrm{E}_{\gamma 4}$ \\
7.97 & 14.5 & 6.928 & & & \\
6.08 & 11.1 & 6.649 & 0.279 & & \\
2.18 & 3.97 & 3.759 & 2.889 & 0.279 \\
2.18 & 3.97 & 3.759 & 2.507 & & \\
2.16 & 3.93 & 3.290 & 3.639 & & \\
& & & & & \\
2.05 & 3.72 & 4.229 & 1.236 & 1.463 & \\
1.84 & 3.35 & 2.820 & 4.108 & & \\
1.70 & 3.09 & 5.465 & 1.463 & & \\
1.67 & 3.04 & 5.634 & 1.294 & & \\
1.64 & 2.99 & 5.092 & 1.836 & & \\
& & & & & \\
1.61 & 2.93 & 5.071 & 1.857 & & \\
1.46 & 2.66 & 2.350 & 4.578 & & \\
1.40 & 2.55 & 4.887 & 2.041 & & \\
1.04 & 1.89 & 1.880 & 5.049 & & \\
0.99 & 1.80 & 5.029 & 1.899 & & \\
& & & & & \\
0.96 & 1.74 & 3.290 & 3.359 & 0.279 & \\
0.84 & 1.54 & 2.820 & 3.829 & 0.279 & \\
0.82 & 1.49 & 4.755 & 1.894 & 0.279 & \\
0.80 & 1.45 & 4.229 & 1.236 & 1.184 & \\
0.69 & 1.26 & 2.350 & 4.299 & 0.279 & \\
& $\Sigma=72.9 \%$ & & & & \\
\hline
\end{tabular}


${ }^{137} \mathrm{Ba}$

$\sigma(30 \mathrm{keV})=73 \mathrm{mb} \quad$ total capture cross section

$\sigma(\mathrm{mul} 1)=4.7 \mathrm{mb}$

$\sigma(\mathrm{mul} \mathrm{2})=14.1 \mathrm{mb}$

$\sigma(\mathrm{mul} \mathrm{3})=24.7 \mathrm{mb}$

$\sigma(\mathrm{mul} \mathrm{4})=20.3 \mathrm{mb}$ average multiplicity $\langle\mathrm{m}\rangle=3.3$

$\sigma(\mathrm{mul} 5)=7.0 \mathrm{mb}$

$\sigma(\mathrm{mul} \mathrm{6})=1.7 \mathrm{mb}$

$\sigma(\mathrm{mul} 7)=0.5 \mathrm{mb}$

calculated number of cascades $=586$ (covering $95 \%$ of the cross section)

\begin{tabular}{lcccc}
$\sigma_{p}$ & $\sigma_{p} / \sigma$ & $\mathrm{E}_{\gamma 1}$ & $\mathrm{E}_{\gamma 2}$ & $\mathrm{E}_{\gamma 3}$ \\
$(\mathrm{mb})$ & $(\%)$ & & & \\
4.72 & 6.47 & 8.641 & & \\
4.02 & 5.50 & 7.205 & 1.436 & \\
2.01 & 2.76 & 6.423 & 2.218 & \\
1.60 & 2.19 & 6.451 & 0.754 & 1.436 \\
1.25 & 1.71 & 6.002 & 2.639 & \\
& & & & \\
1.23 & 1.69 & 3.349 & 3.857 & 1.436 \\
1.23 & 1.68 & 5.023 & 2.182 & 1.436 \\
1.22 & 1.67 & 3.907 & 3.299 & 1.436 \\
1.22 & 1.67 & 4.465 & 2.740 & 1.436 \\
1.18 & 1.61 & 2.791 & 4.415 & 1.436 \\
& & & & \\
1.04 & 1.43 & 5.790 & 1.416 & 1.436 \\
1.01 & 1.38 & 5.710 & 1.496 & 1.436 \\
0.97 & 1.33 & 2.233 & 4.973 & 1.436 \\
0.92 & 1.26 & 5.023 & 3.618 & \\
0.90 & 1.23 & 6.743 & 0.463 & 1.436 \\
& & & & \\
0.88 & 1.20 & 4.465 & 4.176 & \\
0.87 & 1.19 & 3.349 & 5.292 & \\
0.87 & 1.19 & 3.907 & 4.734 & \\
0.86 & 1.18 & 6.196 & 1.010 & 1.436 \\
0.84 & 1.14 & 2.791 & 5.851 & \\
& $\Sigma=39.5 \%$ & & & \\
\hline & & & &
\end{tabular}



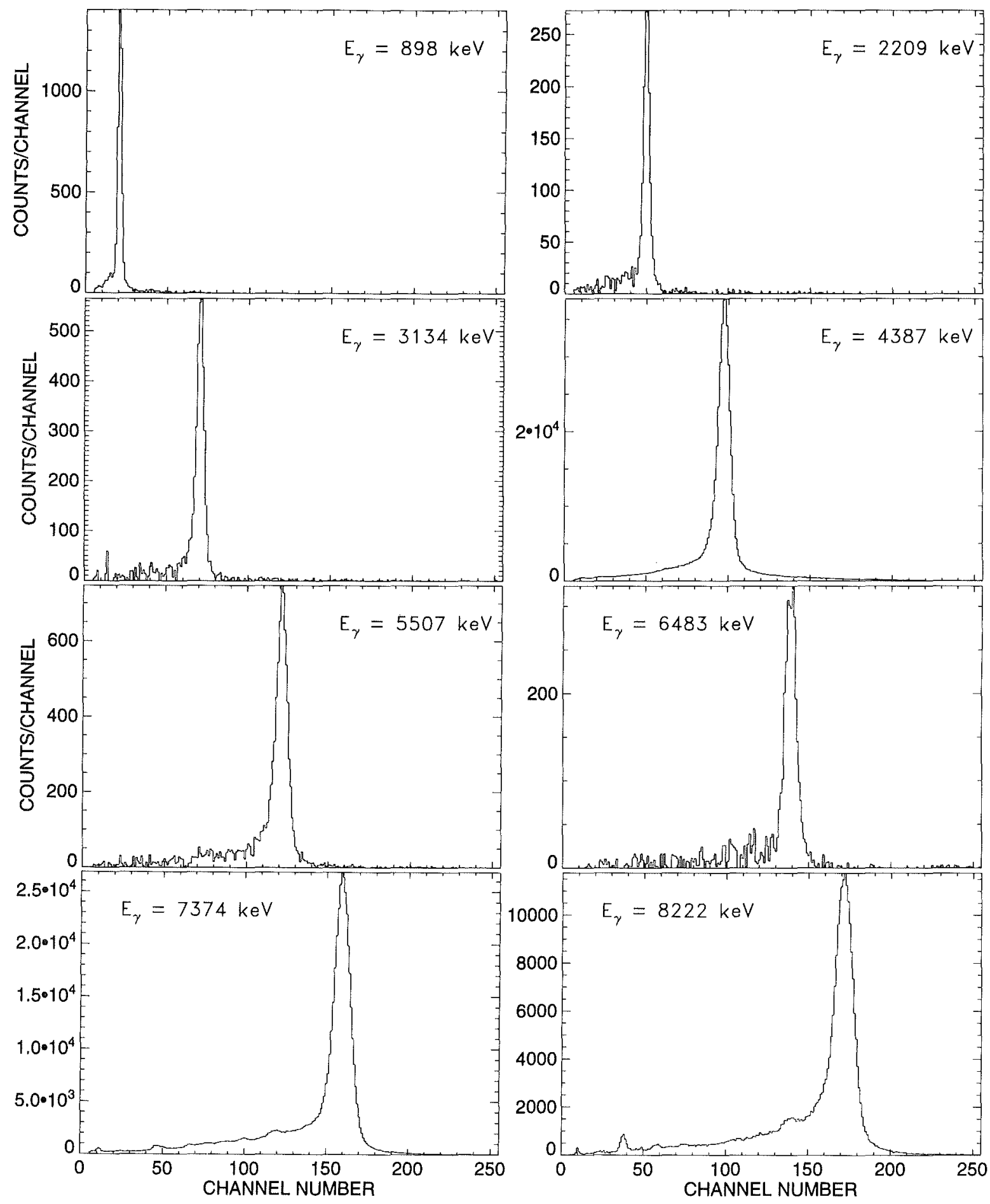

Figure 12: Measured line shape of the $4 \pi \mathrm{BaF}_{2}$ detector for monoenergetic gamma- rays in the energy range from 0.9 to $8.2 \mathrm{MeV}$ 
For multiplicity 1 , the calculated fraction of capture cascades can be checked with the measured intensities. According to Table 9, the calculated intensities for $m=1$ are $5.7 / 2.2 / 14.5 / 6.5 \%$ for ${ }^{134} \mathrm{Ba} /{ }^{135} \mathrm{Ba} /{ }^{136} \mathrm{Ba} /{ }^{137} \mathrm{Ba}$, respectively. For comparison with the measured values, corrections have to be applied for the $94 \%$ solid angle of the detector and for the probability of $\sim 30 \%$ that $6-8 \mathrm{MeV}$ gamma-rays may trigger two detector modules [35]. The corrected values 3.8/1.5/9.5/4.3\% are, indeed, in very good agreement with the measured intensities of 4.0/1.7/8.9/3.7\% (Fig.10), confirming the quality of the model calculations.

The efficiency of the $4 \pi \mathrm{BaF}_{2}$ detector for monoenergetic gamma-rays was calculated in Ref.[36] with different assumptions for multiple Compton events, resulting in an optimistic and a pessimistic estimate for the peak efficiency, SW(MAX) and SW(MIN). The corresponding data are listed in Ref.[23] and were since used to calculate the fraction $f$ of unobserved capture events. Recenty, the gamma-ray efficiency of the $4 \pi \mathrm{BaF}_{2}$ detector was determined experimentally[33] by measuring the line shapes for monoenergetic gamma-rays in the energy range from 0.8 to $8.4 \mathrm{MeV}$. These gamma-rays were produced by $(p, \gamma)$-reactions on thin ${ }^{26} \mathrm{Mg},{ }^{30} \mathrm{Si}$, and ${ }^{34} \mathrm{~S}$ targets. In these reactions, certain proton resonances decay predominantly by cascades with only two transitions. Replacing one of the $\mathrm{BaF}_{2}$ modules by a $\mathrm{Ge}$-detector, and looking for $\mathrm{BaF}_{2}-\mathrm{Ge}$-coincidences, two-dimensional spectra, $\mathrm{E}_{\gamma}(\mathrm{Ge})$ versus $\mathrm{E}_{\gamma}\left(\mathrm{BaF}_{2}\right)$ were recorded. The response of the $4 \pi$ $\mathrm{BaF}_{2}$ detector for monoenergetic gamma-rays was then obtained by selecting those events, where the full energy of the complementary gamma-ray is registered in the germanium detector.

Using seven $(p, \gamma)$-resonances and an ${ }^{88} \mathrm{Y}$ source, the line shapes of 20 gamma-transitions in the energy range from 0.843 to $8.392 \mathrm{MeV}$ could be determined. Some of these spectra are shown in Fig.12. With these data, the calculations of the spectrum fractions, $f$, and of the correction factors, $F_{1}$, were repeated (Table 8). The respective results for $F_{1}$ being in very good agreement confirms once more the reliability of the $4 \pi \mathrm{BaF}_{2}$ detector for precise cross section measurements.

The experimentally determined detector response is now used in further cross section analysis. The calculated sum-energy spectra in Fig.13 compare much better with the experimental spectra of Fig.9 than was found in the previous experiments using the SW(MIN)/SW(MAX)-approach[3][5]. The remaining difference is caused by the better energy resolution of the calculated spectra, and can be understood in terms of the different measuring times: the spectra with monoenergetic gamma-rays were taken in a few hours, whereas a run in the capture experiment lasted for 2 months.

It was found in these calculations that - in unfavorable cases - the result for the observed spectrum fraction may depend on the random numbers used to simulate the $94 \%$ solid angle of the detector. The barium isotopes are particularly sensitive to this effect, since single capture cascades contribute significantly to the cross section and the total number of cascades is low (Table 9). Therefore, all calculations were repeated with ten sets of random numbers in order to eliminate this ambiguity.

During the measurements, the threshold in sum energy was $2.2 \mathrm{MeV}$ in Run 1 and 2.3 $\mathrm{MeV}$ in Runs 2 and 3. The resulting efficiency of the detector was $97 \%$ for the odd and $93 \%$ for the even isotopes. Since the barium samples and the gold standard are measured with the same detector, the final correction factors, $F_{1}$, are very insensitive to the detector 


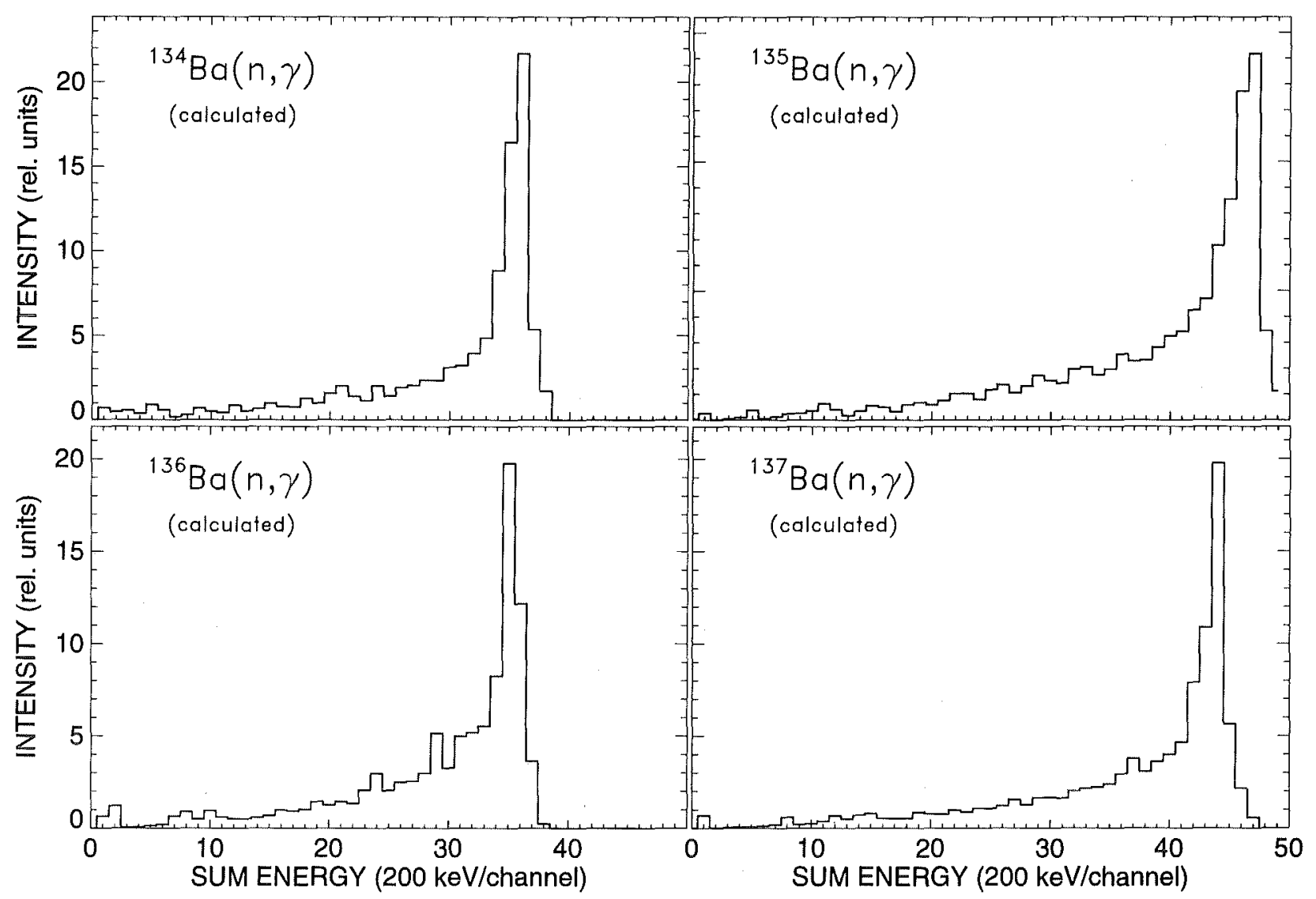

Figure 13: Calculated sum energy spectra of the $4 \pi \mathrm{BaF}_{2}$ detector as obtained using the measured lineshape given in Fig.12. These spectra were used to derive the correction $F_{1}$ for unobserved capture events.

efficiency (Table 8). For the even isotopes, which have binding energies similar to that of the gold standard, the efficiency correction is very small. For the odd isotopes, the efficiencies differ by $\leq 4 \%$.

The correction for multiple scattering and self-shielding in the sample was calculated with the SESH code[37]. In order to find consistent parameter sets that reproduce the capture cross section and the total cross section of each isotope, the parameters given by Mughabghab [38] were used to start the calculations. The pairing energies were taken from Ref.[39] and additional information came from Refs. [40][41]. These data sets were modified until the total cross sections of Table 5 could be reproduced within their uncertainties and the capture cross sections within $\sim 10 \%$. The adopted input parameters are listed in Table 10 together with the calculated total cross sections. In all calculations carbon and oxygen were considered according to the stoichiometry of $\mathrm{BaCO}_{3}$. The correction factors, $\operatorname{MS}(\mathrm{X})$ and $\mathrm{F}_{2}$, are compiled in Tables 11 and 12 . Due to the comparably small sample masses used in the present experiment, these corrections were only $\sim 2 \%$, except for the lowest neutron energies, considerably smaller than in the work of Musgrove et al [16].

In view of the revised total cross sections for the gold standard (\$3), which are significantly higher than the before adopted ENDF/B-5 evaluation[30], the input parameters for this isotope were changed accordingly. In fact, the second parameter set discussed in Ref.[23] was used, which is based on the data given by Mughabghab et al [38]. 
Table 10: PARAMETERS FOR THE CALCULATION OF NEUTRON SELFSHIELDING AND MULTIPLE SCATTERING CORRECTION FACTORS

\begin{tabular}{|c|c|c|c|c|c|c|c|c|}
\hline Parameter & & ${ }^{197} \mathrm{Au}$ & ${ }^{134} \mathrm{Ba}$ & ${ }^{135} \mathrm{Ba}$ & ${ }^{136} \mathrm{Ba}$ & ${ }^{137} \mathrm{Ba}$ & ${ }^{12} \mathrm{C}$ & ${ }^{16} \mathrm{O}$ \\
\hline Nucleon Number & & 197 & 134 & 135 & 136 & 137 & 12 & 16 \\
\hline Binding Energy $(\mathrm{MeV})$ & & 6.513 & 6.974 & 9.107 & 6.898 & 8.611 & 4.946 & 4.144 \\
\hline Pairing Energy (MeV) & & 0.0 & 1.58 & 2.28 & 1.58 & 2.43 & 2.50 & 2.50 \\
\hline Effective Temperature (K) & & 293 & 293 & 293 & 293 & 293 & 293 & 293 \\
\hline Nuclear Spin & & 1.5 & 0 & 1.5 & 0 & 1.5 & 0 & 0 \\
\hline Average Radiation & $\mathrm{s}$ & 0.128 & $\overline{0.08}$ & 0.20 & 0.06 & 0.095 & 0 & 0 \\
\hline Width $(\mathrm{eV})$ & $\begin{array}{l}\mathrm{p} \\
\mathrm{d}\end{array}$ & $\begin{array}{l}0.048 \\
0.048\end{array}$ & 0.08 & 0.08 & 0.04 & 0.12 & & \\
\hline Average Level & $\mathrm{s}$ & 16.5 & 150 & 27 & 430 & 250 & 0 & 0 \\
\hline Spacing $(\mathrm{eV})$ & $\begin{array}{l}\mathrm{p}^{1} \\
\mathrm{~d}^{1}\end{array}$ & $\begin{array}{l}8.25 \\
5.28\end{array}$ & 50 & 13.5 & 143 & 125 & & \\
\hline $\begin{array}{l}\text { Strength Function } \\
\left(10^{-4}\right)\end{array}$ & $\begin{array}{l}\mathrm{S}_{0} \\
\mathrm{~S}_{1} \\
\mathrm{~S}_{2}\end{array}$ & $\begin{array}{l}2.0 \\
0.4 \\
0.7\end{array}$ & $\begin{array}{l}1.2 \\
0.8\end{array}$ & $\begin{array}{c}1.7 \\
0.48\end{array}$ & $\begin{array}{l}0.6 \\
1.0\end{array}$ & $\begin{array}{l}0.41 \\
0.64\end{array}$ & 0 & 0 \\
\hline $\begin{array}{l}\text { Nuclear Radius } \\
\text { (fm) }\end{array}$ & $\begin{array}{l}\mathrm{s} \\
\mathrm{p}, \mathrm{d}\end{array}$ & $\begin{array}{l}9.5 \\
9.5\end{array}$ & $\begin{array}{l}6.0 \\
6.0\end{array}$ & $\begin{array}{l}6.0 \\
6.0\end{array}$ & $\begin{array}{l}5.45 \\
5.45\end{array}$ & $\begin{array}{l}5.45 \\
5.45\end{array}$ & 6.1 & 5.5 \\
\hline \multicolumn{9}{|c|}{ Calculated total cross sections } \\
\hline $5 \mathrm{keV}$ & & 22.6 & 11.6 & 14.4 & 7.4 & 6.2 & 4.67 & 3.80 \\
\hline $10 \mathrm{keV}$ & & 18.9 & 9.5 & 11.5 & 6.4 & 5.6 & 4.66 & 3.79 \\
\hline $20 \mathrm{keV}$ & & 16.1 & 8.1 & 9.3 & 5.8 & 5.1 & 4.63 & 3.77 \\
\hline $40 \mathrm{keV}$ & & 14.0 & 7.0 & 7.8 & 5.3 & 4.8 & 4.59 & 3.74 \\
\hline $80 \mathrm{keV}$ & & 12.1 & 6.3 & 6.6 & 5.1 & 4.6 & 4.49 & 3.68 \\
\hline $160 \mathrm{keV}$ & & 10.4 & 5.7 & 5.7 & 4.9 & 4.5 & 4.33 & 3.56 \\
\hline $320 \mathrm{keV}$ & & 7.6 & 5.2 & 4.9 & 4.8 & 4.5 & 3.96 & 3.31 \\
\hline
\end{tabular}

${ }^{1}$ Calculated with SESH [37]

Table 11: CORRECTION FACTORS FOR NEUTRON SELF-SHIELDING AND MULTIPLE SCATTERING, MS

\begin{tabular}{cccccc}
\hline $\begin{array}{c}\text { Energy Range } \\
(\mathrm{keV})\end{array}$ & ${ }^{197} \mathrm{Au}$ & ${ }^{134} \mathrm{Ba}$ & ${ }^{135} \mathrm{Ba}$ & ${ }^{136} \mathrm{Ba}$ & ${ }^{137} \mathrm{Ba}$ \\
\hline $3-5$ & 1.004 & 0.974 & 1.002 & 0.890 & 0.943 \\
$5-7.5$ & 1.014 & 1.001 & 1.010 & 0.934 & 0.975 \\
$7.5-10$ & 1.019 & 1.010 & 1.015 & 0.963 & 0.995 \\
$10-12.5$ & 1.023 & 1.015 & 1.016 & 0.977 & 1.006 \\
$12.5-15$ & 1.023 & 1.018 & 1.017 & 0.985 & 1.011 \\
\hline
\end{tabular}


Table 11 continued

\begin{tabular}{cccccc}
\hline $15-20$ & 1.022 & 1.021 & 1.018 & 0.995 & 1.017 \\
$20-25$ & 1.021 & 1.023 & 1.018 & 1.004 & 1.021 \\
$25-30$ & 1.020 & 1.025 & 1.018 & 1.011 & 1.024 \\
$30-40$ & 1.018 & 1.026 & 1.018 & 1.018 & 1.027 \\
$40-50$ & 1.017 & 1.027 & 1.018 & 1.025 & 1.030 \\
$50-60$ & 1.015 & 1.027 & 1.018 & 1.028 & 1.032 \\
$60-80$ & 1.013 & 1.028 & 1.018 & 1.031 & 1.034 \\
$80-100$ & 1.012 & 1.029 & 1.019 & 1.032 & 1.036 \\
$100-120$ & 1.011 & 1.029 & 1.019 & 1.031 & 1.037 \\
$120-150$ & 1.010 & 1.029 & 1.019 & 1.031 & 1.038 \\
$150-175$ & 1.009 & 1.029 & 1.019 & 1.030 & 1.038 \\
$175-200$ & 1.008 & 1.029 & 1.019 & 1.030 & 1.038 \\
$200-225$ & 1.007 & 1.028 & 1.019 & 1.030 & 1.038 \\
\hline Uncertainty (\%) & 0.2 & 0.3 & 0.2 & 0.3 & 0.4 \\
\hline
\end{tabular}

Table 12: CORRECTION FACTORS FOR THE CROSS SECTION RATIOS, $\mathrm{F}_{2}=$ $\operatorname{MS}(\mathrm{Au}) / \mathrm{MS}(\mathrm{X})$

\begin{tabular}{ccccc}
\hline $\begin{array}{c}\text { Energy Range } \\
(\mathrm{keV})\end{array}$ & ${ }^{134} \mathrm{Ba} / \mathrm{Au}$ & ${ }^{135} \mathrm{Ba} / \mathrm{Au}$ & ${ }^{136} \mathrm{Ba} / \mathrm{Au}$ & ${ }^{137} \mathrm{Ba} / \mathrm{Au}$ \\
\hline $3-5$ & 1.031 & 1.002 & 1.128 & 1.065 \\
$5-7.5$ & 1.013 & 1.004 & 1.086 & 1.040 \\
$7.5-10$ & 1.009 & 1.004 & 1.058 & 1.024 \\
$10-12.5$ & 1.008 & 1.007 & 1.047 & 1.017 \\
$12.5-15$ & 1.005 & 1.006 & 1.039 & 1.012 \\
$15-20$ & 1.001 & 1.004 & 1.027 & 1.005 \\
$20-25$ & 0.998 & 1.003 & 1.017 & 1.000 \\
$25-30$ & 0.995 & 1.002 & 1.009 & 0.996 \\
$30-40$ & 0.992 & 1.000 & 1.000 & 0.991 \\
$40-50$ & 0.990 & 0.999 & 0.992 & 0.987 \\
$50-60$ & 0.988 & 0.997 & 0.987 & 0.984 \\
$60-80$ & 0.985 & 0.995 & 0.983 & 0.980 \\
$80-100$ & 0.983 & 0.993 & 0.981 & 0.977 \\
$100-120$ & 0.983 & 0.992 & 0.981 & 0.975 \\
$120-150$ & 0.982 & 0.991 & 0.980 & 0.973 \\
$150-175$ & 0.981 & 0.990 & 0.980 & 0.972 \\
$175-200$ & 0.980 & 0.989 & 0.979 & 0.971 \\
$200-225$ & 0.980 & 0.988 & 0.978 & 0.970 \\
\hline Uncertainty (\%) & 0.4 & 0.3 & 0.4 & 0.4 \\
\hline
\end{tabular}




\section{RESULTS FOR THE NEUTRON CAPTURE CROSS SECTIONS}

The neutron capture cross section ratios of the barium isotopes relative to ${ }^{197} \mathrm{Au}$ are listed together with the respective statistical uncertainties in Tables 13 to 16. The data are given for the three runs and the two evaluations discussed in $\S 3$. The last column in each table contains the weighted average, the weight being determined by the square of the statistical uncertainties. Since the cross section ratios depend weakly on energy, the averages for the energy interval from 30 to $80 \mathrm{keV}$ are also included to allow for an easier comparison of the individual results. The statistical uncertainties quoted for these wider energy bins are lower limits, since they refer only to the uncertainties of the normalization factors from Eq.(1),

$$
N=\Sigma Z(A u) \Sigma E(X)) / \Sigma Z(X) \Sigma E(A u)),
$$

which dominate the total statistical uncertainties.

While the data obtained from the different analyses are in good agreement, there are significant differences in the results of individual runs. These discrepancies are due to the high scattering yield of the samples. As mentioned above, the subtraction of time-independent backgrounds were hampered due to the overlap from previous pulses, resulting in a significant background in the normalization interval (see Fig.7). This background is difficult to determine because the respective count rates from the samples and the carbon sample exhibit strong differences in this TOF range ( $\$ 5)$. The results from Run 2 (with $80 \mathrm{keV}$ maximum neutron energy) being lower than the results from the other runs may indicate a systematic trend. On average, the individual cross section ratios deviate by $3.2 \%$ from their respective mean.

These systematic uncertainties affect only the barium spectra, but not the gold standard. Therefore, their influence on the cross section ratio of two barium isotopes is less severe, since the related corrections are partly cancelling each other. Accordingly, the cross section ratios $\sigma_{\left({ }^{i} \mathrm{Ba}\right)} / \sigma_{\left({ }^{136} \mathrm{Ba}\right)}$ deviate from their means only by $1.7 \%$ on average. This behavior was considered in the evaluation of the uncertainties $(\$ 5)$.

As in the previous measurements with the $4 \pi \mathrm{BaF}_{2}$ detector[3][5], the final cross section ratios were adopted from evaluation 2 . The respective mean values are compiled for all runs in Table 17 together with the statistical, systematic, and total uncertainties. The chosen energy bins are sufficiently fine to avoid systematic uncertainties in the calculation of the Maxwellian averaged cross sections $(\S 6)$. The final uncertainties of the cross section ratios are $\sim 3 \%$, at least 5 times smaller than obtained previously[16][17]. However, the $1 \%$ accuracy reported for the first results with the $4 \pi \mathrm{BaF}_{2}$ detector[3][5] could not be met due to the background problems characteristic for the barium isotopes. 
Table 13: $\sigma\left({ }^{134} \mathrm{Ba}\right) / \sigma\left({ }^{197} \mathrm{Au}\right)$ AND STATISTICAL UNCERTAINTIES IN $(\%)$

\begin{tabular}{|c|c|c|c|c|c|c|c|c|}
\hline $\begin{array}{c}\text { Energy Range } \\
(\mathrm{keV})\end{array}$ & \multicolumn{2}{|c|}{ Run I } & \multicolumn{2}{|c|}{ Run II } & \multicolumn{2}{|c|}{ Run III } & \multicolumn{2}{|c|}{ Average } \\
\hline \multicolumn{9}{|l|}{ Evaluation 1} \\
\hline $3-5$ & - & - & 0.0813 & 223. & 0.2028 & 20.4 & 0.2018 & 20.4 \\
\hline $5-7.5$ & - & - & 0.1852 & 24.2 & 0.1818 & 13.2 & 0.1826 & 11.6 \\
\hline $7.5-10$ & 0.2984 & 9.7 & 0.3321 & 9.4 & 0.3146 & 7.1 & 0.3152 & 4.9 \\
\hline $10-12.5$ & 0.3097 & 7.1 & 0.2516 & 8.1 & 0.2891 & 5.8 & 0.2866 & 3.9 \\
\hline $12.5-15$ & 0.2478 & 7.9 & 0.1879 & 9.2 & 0.2473 & 6.1 & 0.2347 & 4.3 \\
\hline $15-20$ & 0.3291 & 3.5 & 0.3447 & 3.1 & 0.3541 & 2.8 & 0.3445 & 1.8 \\
\hline $20-25$ & 0.3332 & 2.8 & 0.3410 & 2.6 & 0.3570 & 2.4 & 0.3451 & 1.5 \\
\hline $25-30$ & 0.2609 & 2.7 & 0.2604 & 2.4 & 0.2709 & 2.3 & 0.2645 & 1.4 \\
\hline $30-40$ & 0.3238 & 1.5 & 0.3158 & 1.6 & 0.3425 & 1.4 & 0.3287 & 0.9 \\
\hline $40-50$ & 0.3020 & 1.6 & 0.2951 & 1.6 & 0.3260 & 1.4 & 0.3097 & 0.9 \\
\hline $50-60$ & 0.3237 & 1.5 & 0.3216 & 1.6 & 0.3485 & 1.2 & 0.3341 & 0.8 \\
\hline $60-80$ & 0.3097 & 1.2 & 0.3186 & 1.6 & 0.3394 & 1.0 & 0.3255 & 0.7 \\
\hline $80-100$ & 0.3379 & 1.2 & - & - & 0.3611 & 1.0 & 0.3511 & 0.8 \\
\hline $100-120$ & 0.3256 & 1.2 & - & - & 0.3546 & 1.2 & 0.3402 & 0.8 \\
\hline $120-150$ & 0.3247 & 1.1 & - & - & - & - & 0.3247 & 1.1 \\
\hline $150-175$ & 0.3338 & 1.1 & - & - & - & - & 0.3338 & 1.1 \\
\hline $175-200$ & 0.3257 & 1.3 & - & - & - & - & 0.3257 & 1.3 \\
\hline $200-225$ & 0.3179 & 2.1 & - & - & - & - & 0.3179 & 2.1 \\
\hline $30-80$ & 0.3148 & 0.9 & 0.3128 & 1.3 & 0.3391 & 0.9 & 0.3245 & 0.6 \\
\hline \multicolumn{9}{|l|}{ Evaluation 2} \\
\hline $3-5$ & - & - & 0.3458 & 37.2 & 0.2572 & 12.2 & 0.2658 & 11.7 \\
\hline $5-7.5$ & - & - & 0.2023 & 17.4 & 0.1986 & 9.2 & 0.1994 & 8.2 \\
\hline $7.5-10$ & 0.2990 & 7.8 & 0.3306 & 7.3 & 0.3330 & 5.0 & 0.3249 & 3.7 \\
\hline $10-12.5$ & 0.2732 & 6.3 & 0.2690 & 6.1 & 0.2902 & 4.3 & 0.2809 & 3.1 \\
\hline $12.5-15$ & 0.2258 & 6.9 & 0.1968 & 7.0 & 0.2314 & 5.0 & 0.2213 & 3.5 \\
\hline $15-20$ & 0.3203 & 2.8 & 0.3378 & 2.6 & 0.3482 & 2.2 & 0.3378 & 1.4 \\
\hline $20-25$ & 0.3293 & 2.3 & 0.3392 & 2.2 & 0.3596 & 1.8 & 0.3452 & 1.2 \\
\hline $25-30$ & 0.2650 & 2.1 & 0.2688 & 2.0 & 0.2912 & 1.7 & 0.2773 & 1.1 \\
\hline $30-40$ & 0.3240 & 1.2 & 0.3172 & 1.3 & 0.3466 & 1.0 & 0.3318 & 0.7 \\
\hline $40-50$ & 0.2992 & 1.3 & 0.2974 & 1.4 & 0.3250 & 1.1 & 0.3101 & 0.7 \\
\hline $50-60$ & 0.3262 & 1.2 & 0.3234 & 1.4 & 0.3503 & 1.0 & 0.3369 & 0.7 \\
\hline $60-80$ & 0.3116 & 0.9 & 0.3195 & 1.3 & 0.3390 & 0.8 & 0.3268 & 0.5 \\
\hline $80-100$ & 0.3373 & 0.9 & - & - & 0.3603 & 0.7 & 0.3510 & 0.6 \\
\hline $100-120$ & 0.3255 & 0.9 & - & - & 0.3535 & 0.9 & 0.3398 & 0.6 \\
\hline $120-150$ & 0.3252 & 0.8 & - & - & - & - & 0.3252 & 0.8 \\
\hline $150-175$ & 0.3326 & 0.9 & - & - & - & - & 0.3326 & 0.9 \\
\hline $175-200$ & 0.3295 & 1.0 & - & - & - & - & 0.3295 & 1.0 \\
\hline $200-225$ & 0.3152 & 1.7 & - & - & - & - & 0.3152 & 1.7 \\
\hline $30-80$ & 0.3152 & 0.6 & 0.3144 & 1.1 & 0.3402 & 0.6 & 0.3264 & 0.4 \\
\hline
\end{tabular}


Table 14: $\sigma\left({ }^{135} \mathrm{Ba}\right) / \sigma\left({ }^{197} \mathrm{Au}\right)$ AND STATISTICAL UNCERTAINTIES IN (\%)

\begin{tabular}{|c|c|c|c|c|c|c|c|c|}
\hline $\begin{array}{c}\text { Energy Range } \\
(\mathrm{keV})\end{array}$ & \multicolumn{2}{|c|}{ Run I } & \multicolumn{2}{|c|}{ Run II } & \multicolumn{2}{|c|}{ Run III } & \multicolumn{2}{|c|}{ Average } \\
\hline \multicolumn{9}{|l|}{ Evaluation 1} \\
\hline $3-5$ & - & - & 2.0400 & 22.3 & 0.4399 & 16.7 & 1.0148 & 16.7 \\
\hline $5-7.5$ & - & - & 0.3670 & 20.7 & 0.4595 & 9.4 & 0.4437 & 8.6 \\
\hline $7.5-10$ & 1.0023 & 5.4 & 0.5216 & 10.2 & 0.5421 & 7.4 & 0.7927 & 4.2 \\
\hline $10-12.5$ & 0.6061 & 6.2 & 0.5684 & 6.2 & 0.5225 & 5.7 & 0.5629 & 3.5 \\
\hline $12.5-15$ & 0.6235 & 5.4 & 0.6532 & 4.7 & 0.6816 & 4.0 & 0.6585 & 2.7 \\
\hline $15-20$ & 0.7221 & 2.7 & 0.7214 & 2.5 & 0.7889 & 2.2 & 0.7493 & 1.4 \\
\hline $20-25$ & 0.9139 & 1.9 & 0.8960 & 1.9 & 0.9651 & 1.7 & 0.9280 & 1.0 \\
\hline $25-30$ & 0.8539 & 1.5 & 0.8503 & 1.6 & 0.9183 & 1.3 & 0.8784 & 0.8 \\
\hline $30-40$ & 0.8446 & 1.0 & 0.8282 & 1.2 & 0.9158 & 1.0 & 0.8698 & 0.6 \\
\hline $40-50$ & 0.9000 & 1.0 & 0.8162 & 1.2 & 0.9544 & 0.9 & 0.9036 & 0.6 \\
\hline $50-60$ & 0.8664 & 1.0 & 0.7741 & 1.3 & 0.8725 & 0.9 & 0.8484 & 0.6 \\
\hline $60-80$ & 0.7952 & 0.8 & 0.7220 & 1.3 & 0.7852 & 0.7 & 0.7788 & 0.5 \\
\hline $80-100$ & 0.7770 & 0.9 & - & - & 0.7770 & 0.7 & 0.7770 & 0.6 \\
\hline $100-120$ & 0.7207 & 0.9 & - & - & 0.7506 & 0.9 & 0.7351 & 0.6 \\
\hline $120-150$ & 0.7005 & 0.8 & - & - & - & - & 0.7005 & 0.8 \\
\hline $150-175$ & 0.6891 & 0.9 & - & - & - & - & 0.6891 & 0.9 \\
\hline $175-200$ & 0.6753 & 1.0 & - & - & - & - & 0.6753 & 1.0 \\
\hline $200-225$ & 0.6642 & 1.7 & - & - & - & - & 0.6642 & 1.7 \\
\hline $30-80$ & 0.8516 & 0.6 & 0.7851 & 1.1 & 0.8820 & 0.6 & 0.8502 & 0.4 \\
\hline \multicolumn{9}{|l|}{ Evaluation 2} \\
\hline $3-5$ & - & - & 1.5693 & 17.8 & 0.5339 & 10.1 & 0.7861 & 10.1 \\
\hline $5-7.5$ & - & - & 0.7964 & 7.9 & 0.5371 & 6.1 & 0.6330 & 4.9 \\
\hline $7.5-10$ & 1.0987 & 4.0 & 0.8178 & 5.2 & 0.6106 & 4.8 & 0.8773 & 2.7 \\
\hline $10-12.5$ & 0.7639 & 4.0 & 0.7415 & 3.9 & 0.5539 & 3.9 & 0.6863 & 2.3 \\
\hline $12.5-15$ & 0.8083 & 3.4 & 0.8021 & 3.1 & 0.7213 & 2.9 & 0.7728 & 1.8 \\
\hline $15-20$ & 0.8277 & 1.9 & 0.8287 & 1.8 & 0.8073 & 1.7 & 0.8203 & 1.0 \\
\hline $20-25$ & 0.9818 & 1.4 & 0.9469 & 1.4 & 0.9302 & 1.3 & 0.9520 & 0.8 \\
\hline $25-30$ & 0.8858 & 1.2 & 0.8681 & 1.2 & 0.8758 & 1.1 & 0.8766 & 0.7 \\
\hline $30-40$ & 0.8607 & 0.8 & 0.8240 & 0.9 & 0.8780 & 0.8 & 0.8566 & 0.5 \\
\hline $40-50$ & 0.8974 & 0.8 & 0.8162 & 0.9 & 0.9105 & 0.7 & 0.8807 & 0.5 \\
\hline $50-60$ & 0.8616 & 0.8 & 0.7792 & 0.9 & 0.8568 & 0.7 & 0.8385 & 0.5 \\
\hline $60-80$ & 0.7954 & 0.7 & 0.7196 & 0.9 & 0.7894 & 0.6 & 0.7795 & 0.4 \\
\hline $80-100$ & 0.7697 & 0.7 & - & - & 0.7733 & 0.6 & 0.7718 & 0.4 \\
\hline $100-120$ & 0.7233 & 0.7 & - & - & 0.7437 & 0.7 & 0.7332 & 0.5 \\
\hline $120-150$ & 0.7033 & 0.6 & - & - & - & - & 0.7033 & 0.6 \\
\hline $150-175$ & 0.6863 & 0.7 & - & - & - & - & 0.6863 & 0.7 \\
\hline $175-200$ & 0.6754 & 0.8 & - & - & - & - & 0.6754 & 0.8 \\
\hline $200-225$ & 0.6648 & 1.4 & - & - & - & - & 0.6648 & 1.4 \\
\hline $30-80$ & 0.8538 & 0.4 & 0.7848 & 0.7 & 0.8587 & 0.4 & 0.8388 & 0.3 \\
\hline
\end{tabular}


Table 15: $\sigma\left({ }^{136} \mathrm{Ba}\right) / \sigma\left({ }^{197} \mathrm{Au}\right)$ AND STATISTICAL UNCERTAINTIES IN $(\%)$

\begin{tabular}{|c|c|c|c|c|c|c|c|c|}
\hline $\begin{array}{c}\text { Energy Range } \\
(\mathrm{keV})\end{array}$ & \multicolumn{2}{|c|}{ Run I } & \multicolumn{2}{|c|}{ Run II } & \multicolumn{2}{|c|}{ Run III } & \multicolumn{2}{|c|}{ Average } \\
\hline \multicolumn{9}{|l|}{ Evaluation 1} \\
\hline $3-5$ & - & - & 0.1341 & 55.1 & 0.1670 & 10.4 & 0.1658 & 10.2 \\
\hline $5-7.5$ & - & - & 0.0683 & 26.9 & 0.0906 & 10.8 & 0.0875 & 10.1 \\
\hline $7.5-10$ & 0.0938 & 12.3 & 0.0734 & 17.4 & 0.0944 & 9.6 & 0.0908 & 7.0 \\
\hline $10-12.5$ & 0.0893 & 10.0 & 0.0922 & 9.4 & 0.1026 & 6.7 & 0.0968 & 4.8 \\
\hline $12.5-15$ & 0.1412 & 5.9 & 0.1221 & 6.3 & 0.1394 & 4.7 & 0.1356 & 3.2 \\
\hline $15-20$ & 0.1453 & 3.3 & 0.1477 & 3.3 & 0.1535 & 2.8 & 0.1495 & 1.8 \\
\hline $20-25$ & 0.1186 & 3.4 & 0.1240 & 3.2 & 0.1223 & 3.0 & 0.1218 & 1.8 \\
\hline $25-30$ & 0.0904 & 3.3 & 0.0906 & 3.1 & 0.0856 & 3.1 & 0.0888 & 1.8 \\
\hline $30-40$ & 0.1223 & 1.7 & 0.1131 & 2.0 & 0.1211 & 1.6 & 0.1195 & 1.0 \\
\hline $40-50$ & 0.0989 & 1.9 & 0.0906 & 2.1 & 0.0975 & 1.7 & 0.0960 & 1.1 \\
\hline $50-60$ & 0.1194 & 1.6 & 0.1201 & 1.9 & 0.1213 & 1.4 & 0.1204 & 0.9 \\
\hline $60-80$ & 0.1077 & 1.3 & 0.1024 & 1.9 & 0.1125 & 1.1 & 0.1093 & 0.8 \\
\hline $80-100$ & 0.1116 & 1.3 & - & - & 0.1203 & 1.0 & 0.1168 & 0.8 \\
\hline $100-120$ & 0.1083 & 1.3 & - & - & 0.1197 & 1.2 & 0.1144 & 0.9 \\
\hline $120-150$ & 0.1092 & 1.1 & - & - & - & - & 0.1092 & 1.1 \\
\hline $150-175$ & 0.1022 & 1.2 & - & - & - & - & 0.1022 & 1.2 \\
\hline $175-200$ & 0.1085 & 1.3 & - & - & - & - & 0.108 .5 & 1.3 \\
\hline $200-225$ & 0.1083 & 2.1 & - & - & - & - & 0.1083 & 2.1 \\
\hline $30-80$ & 0.1121 & 0.9 & 0.1066 & 1.7 & 0.1131 & 0.9 & 0.1113 & 0.6 \\
\hline \multicolumn{9}{|l|}{ Evaluation 2} \\
\hline $3-5$ & - & - & 0.1384 & 40.6 & 0.1687 & 8.3 & 0.1675 & 8.2 \\
\hline $5-7.5$ & - & - & 0.0857 & 18.2 & 0.0979 & 8.3 & 0.0958 & 7.5 \\
\hline $7.5-10$ & 0.0792 & 12.4 & 0.0752 & 14.1 & 0.0895 & 8.0 & 0.0844 & 6.1 \\
\hline $10-12.5$ & 0.0800 & 9.2 & 0.0916 & 8.0 & 0.0835 & 6.5 & 0.0852 & 4.4 \\
\hline $12.5-15$ & 0.1319 & 5.3 & 0.1076 & 6.0 & 0.1236 & 4.3 & 0.1224 & 2.9 \\
\hline $15-20$ & 0.1322 & 3.0 & 0.1289 & 3.0 & 0.1395 & 2.5 & 0.1344 & 1.6 \\
\hline $20-25$ & 0.1171 & 2.9 & 0.1182 & 2.8 & 0.1226 & 2.5 & 0.1196 & 1.6 \\
\hline $25-30$ & 0.0915 & 2.7 & 0.0924 & 2.5 & 0.0935 & 2.4 & 0.0925 & 1.5 \\
\hline $30-40$ & 0.1195 & 1.4 & 0.1111 & 1.5 & 0.1190 & 1.3 & 0.1168 & 0.8 \\
\hline $40-50$ & 0.0995 & 1.7 & 0.0931 & 1.6 & 0.1012 & 1.4 & 0.0982 & 0.9 \\
\hline $50-60$ & 0.1195 & 1.4 & 0.1189 & 1.4 & 0.1228 & 1.1 & 0.1208 & 0.8 \\
\hline $60-80$ & 0.1063 & 1.1 & 0.1029 & 1.4 & 0.1111 & 0.9 & 0.1080 & 0.6 \\
\hline $80-100$ & 0.1113 & 1.1 & - & - & 0.1196 & 0.9 & 0.1164 & 0.7 \\
\hline $100-120$ & 0.1082 & 1.1 & - & - & 0.1184 & 1.0 & 0.1137 & 0.7 \\
\hline $120-150$ & 0.1080 & 1.0 & - & - & - & - & 0.1080 & 1.0 \\
\hline $150-175$ & 0.1028 & 1.1 & - & - & - & - & 0.1028 & 1.1 \\
\hline $175-200$ & 0.1092 & 1.1 & - & - & - & - & 0.1092 & 1.1 \\
\hline $200-225$ & 0.1077 & 1.8 & - & - & - & - & 0.1077 & 1.8 \\
\hline $30-80$ & 0.1112 & 0.7 & 0.1065 & 1.2 & 0.1135 & 0.7 & 0.1110 & 0.5 \\
\hline
\end{tabular}


Table 16: $\sigma\left({ }^{137} \mathrm{Ba}\right) / \sigma\left({ }^{197} \mathrm{Au}\right)$ AND STATISTICAL UNCERTAINTIES IN (\%)

\begin{tabular}{|c|c|c|c|c|c|c|c|c|}
\hline $\begin{array}{c}\text { Energy Range } \\
(\mathrm{keV})\end{array}$ & \multicolumn{2}{|c|}{ Run I } & \multicolumn{2}{|c|}{ Run II } & \multicolumn{2}{|c|}{ Run III } & \multicolumn{2}{|c|}{ Average } \\
\hline \multicolumn{9}{|l|}{ Evaluation 1} \\
\hline $3-5$ & - & - & 0.7731 & 19.8 & -.0411 & 47.2 & 0.6512 & 20.0 \\
\hline $5-7.5$ & - & - & 0.1365 & 15.8 & 0.0321 & 36.2 & 0.1198 & 15.2 \\
\hline $7.5-10$ & 0.0984 & 13.6 & 0.1042 & 14.6 & 0.0567 & 19.4 & 0.0918 & 9.0 \\
\hline $10-12.5$ & 0.0179 & 57.7 & 0.1010 & 10.2 & 0.0753 & 11.2 & 0.0881 & 7.6 \\
\hline $12.5-15$ & -.0139 & 68.5 & 0.0986 & 9.1 & 0.1095 & 7.2 & 0.1046 & 5.6 \\
\hline $15-20$ & 0.0588 & 9.1 & 0.1019 & 5.0 & 0.1053 & 4.6 & 0.0982 & 3.2 \\
\hline $20-25$ & 0.1532 & 3.1 & 0.1746 & 2.6 & 0.1675 & 2.7 & 0.1662 & 1.6 \\
\hline $25-30$ & 0.1143 & 3.1 & 0.1263 & 2.5 & 0.0956 & 3.4 & 0.1150 & 1.7 \\
\hline $30-40$ & 0.1567 & 1.6 & 0.1490 & 1.6 & 0.1535 & 1.5 & 0.1531 & 0.9 \\
\hline $40-50$ & 0.1459 & 1.7 & 0.1268 & 1.7 & 0.1495 & 1.4 & 0.1418 & 0.9 \\
\hline $50-60$ & 0.1366 & 1.7 & 0.1398 & 1.6 & 0.1492 & 1.3 & 0.1432 & 0.9 \\
\hline $60-80$ & 0.1260 & 1.3 & 0.1414 & 1.5 & 0.1488 & 0.9 & 0.1413 & 0.7 \\
\hline $80-100$ & 0.1255 & 1.3 & - & - & 0.1513 & 0.9 & 0.1430 & 0.7 \\
\hline $100-120$ & 0.1210 & 1.3 & - & - & 0.1523 & 1.0 & 0.1404 & 0.8 \\
\hline $120-150$ & 0.1208 & 1.1 & - & - & - & - & 0.1208 & 1.1 \\
\hline $150-175$ & 0.1310 & 1.1 & - & - & - & - & 0.1310 & 1.1 \\
\hline $175-200$ & 0.1231 & 1.2 & - & - & - & - & 0.1231 & 1.2 \\
\hline $200-225$ & 0.1237 & 2.0 & - & - & - & - & 0.1237 & 2.0 \\
\hline $30-80$ & 0.1413 & 0.8 & 0.1393 & 1.3 & 0.1503 & 0.8 & 0.1449 & 0.5 \\
\hline \multicolumn{9}{|l|}{ Evaluation 2} \\
\hline $3-5$ & - & - & 0.4877 & 16.6 & 0.0288 & 50.1 & 0.4423 & 16.5 \\
\hline $5-7.5$ & - & - & 0.1342 & 12.5 & 0.0585 & 15.3 & 0.1039 & 10.3 \\
\hline $7.5-10$ & 0.1412 & 7.7 & 0.1493 & 8.0 & 0.0971 & 8.6 & 0.1310 & 4.7 \\
\hline $10-12.5$ & 0.0857 & 9.5 & 0.1309 & 6.3 & 0.1109 & 5.8 & 0.1142 & 3.9 \\
\hline $12.5-15$ & 0.0740 & 10.3 & 0.1306 & 5.5 & 0.1342 & 4.6 & 0.1265 & 3.4 \\
\hline $15-20$ & 0.1018 & 4.3 & 0.1210 & 3.4 & 0.1291 & 3.0 & 0.1204 & 2.0 \\
\hline $20-25$ & 0.1712 & 2.2 & 0.1806 & 2.1 & 0.1740 & 2.0 & 0.1754 & 1.2 \\
\hline $25-30$ & 0.1230 & 2.3 & 0.1263 & 2.0 & 0.1089 & 2.3 & 0.1200 & 1.3 \\
\hline $30-40$ & 0.1564 & 1.2 & 0.1474 & 1.2 & 0.1549 & 1.1 & 0.1530 & 0.7 \\
\hline $40-50$ & 0.1479 & 1.3 & 0.1299 & 1.3 & 0.1537 & 1.1 & 0.1450 & 0.7 \\
\hline $50-60$ & 0.1413 & 1.3 & 0.1393 & 1.2 & 0.1526 & 1.0 & 0.1457 & 0.7 \\
\hline $60-80$ & 0.1307 & 1.0 & 0.1388 & 1.2 & 0.1481 & 0.7 & 0.1415 & 0.5 \\
\hline $80-100$ & 0.1241 & 1.0 & - & - & 0.1471 & 0.7 & 0.1400 & 0.6 \\
\hline $100-120$ & 0.1231 & 1.0 & - & - & 0.1491 & 0.8 & 0.1393 & 0.6 \\
\hline $120-150$ & 0.1194 & 0.9 & - & - & - & - & 0.1194 & 0.9 \\
\hline $150-175$ & 0.1280 & 0.9 & - & - & - & - & 0.1280 & 0.9 \\
\hline $175-200$ & 0.1201 & 1.0 & - & - & - & - & 0.1201 & 1.0 \\
\hline $200-225$ & 0.1223 & 1.6 & - & - & - & - & 0.1223 & 1.6 \\
\hline $30-80$ & 0.1441 & 0.6 & 0.1389 & 0.9 & 0.1523 & 0.5 & 0.1463 & 0.4 \\
\hline
\end{tabular}


Table 17: FINAL NEUTRON CAPTURE CROSS SECTION RATIOS OF ${ }^{134} \mathrm{Ba},{ }^{135} \mathrm{Ba}$, ${ }^{136} \mathrm{Ba}$, AND ${ }^{137} \mathrm{Ba}$ RELATIVE TO ${ }^{197} \mathrm{Au}$

\begin{tabular}{|c|c|c|c|c|c|c|c|c|}
\hline $\begin{array}{c}\text { Energy Interval } \\
(\mathrm{keV})\end{array}$ & $\frac{\sigma\left({ }^{134} \mathrm{Ba}\right)}{\sigma\left({ }^{197} \mathrm{Au}\right)}$ & \multicolumn{3}{|c|}{ Uncertainty (\%) } & $\frac{\sigma\left({ }^{135} \mathrm{Ba}\right)}{\sigma\left({ }^{197} \mathrm{Au}\right)}$ & \multicolumn{3}{|c|}{ Uncertainty (\%) } \\
\hline $3-5$ & 0.2658 & 11.7 & & & 0.7861 & 10.1 & & \\
\hline $5-7.5$ & 0.1994 & 8.2 & 3.1 & 8.8 & 0.6330 & 4.9 & & \\
\hline $7.5-10$ & 0.3249 & 3.7 & 3.1 & 4.8 & 0.8773 & 2.7 & & \\
\hline $10-12.5$ & 0.2809 & 3.1 & 3.1 & 4.4 & 0.6863 & 2.3 & 3.0 & 3.8 \\
\hline $12.5-15$ & 0.2213 & 3.5 & 3.1 & 4.7 & 0.7728 & 1.8 & 3.0 & 3.5 \\
\hline $15-20$ & 0.3378 & 1.4 & 3.1 & 3.4 & 0.8203 & 1.0 & 3.0 & 3.2 \\
\hline $20-25$ & 0.3452 & 1.2 & 3.1 & 3.3 & 0.9520 & 0.8 & 3.0 & 3.1 \\
\hline $25-30$ & 0.2773 & 1.1 & 3.1 & 3.3 & 0.8766 & 0.7 & 3.0 & 3.1 \\
\hline $30-40$ & 0.3318 & 0.7 & 3.1 & 3.2 & 0.8566 & 0.5 & 3.0 & 3.0 \\
\hline $40-50$ & 0.3101 & 0.7 & 3.1 & 3.2 & 0.8807 & 0.5 & 3.0 & 3.0 \\
\hline $50-60$ & 0.3369 & 0.7 & 3.1 & 3.2 & 0.8385 & 0.5 & 3.0 & 3.0 \\
\hline $60-80$ & 0.3268 & 0.5 & 3.1 & 3.1 & 0.7795 & 0.4 & 3.0 & 3.0 \\
\hline $80-100$ & 0.3510 & 0.6 & 3.1 & 3.2 & 0.7718 & 0.4 & 3.0 & 3.0 \\
\hline $100-120$ & 0.3398 & 0.6 & 3.1 & 3.2 & 0.7332 & 0.5 & 3.0 & 3.0 \\
\hline $120-150$ & 0.3252 & 0.8 & 3.1 & 3.2 & 0.7033 & 0.6 & 3.0 & 3.1 \\
\hline $150-175$ & 0.3326 & 0.9 & 3.1 & 3.2 & 0.6863 & 0.7 & 3.0 & 3.1 \\
\hline $175-200$ & 0.3295 & 1.0 & 3.1 & 3.3 & 0.6754 & 0.8 & 3.0 & 3.1 \\
\hline $200-225$ & 0.3152 & 1.7 & 3.1 & 3.5 & 0.6648 & 1.4 & 3.0 & 3.3 \\
\hline Energy Interval & $\frac{\sigma\left({ }^{136} \mathrm{Ba}\right)}{\sigma\left(^{197} \mathrm{Au}\right)}$ & \multicolumn{3}{|c|}{ Uncertainty $(\%)$} & $\frac{\sigma\left({ }^{137} \mathrm{Ba}\right)}{\sigma\left(^{197} \mathrm{Au}\right)}$ & \multicolumn{3}{|c|}{ Uncertainty (\%) } \\
\hline$(\mathrm{keV})$ & & stat & sys & tot & & stat & sys & tot \\
\hline $3-5$ & 0.1675 & 8.2 & & & 0.4423 & 16.5 & & \\
\hline $5-7.5$ & 0.0958 & 7.5 & 3.2 & 8.2 & 0.1039 & 10.3 & & \\
\hline $7.5-10$ & 0.0844 & 6.1 & 3.2 & 6.9 & 0.1310 & 4.7 & & \\
\hline $10-12.5$ & 0.0852 & 4.4 & 3.2 & 5.4 & 0.1142 & 3.9 & 3.2 & 5.0 \\
\hline $12.5-15$ & 0.1224 & 2.9 & 3.2 & 4.3 & 0.1265 & 3.4 & 3.2 & 4.7 \\
\hline $15-20$ & 0.1344 & 1.6 & 3.2 & 3.6 & 0.1204 & 2.0 & 3.2 & 3.8 \\
\hline $20-25$ & 0.1196 & 1.6 & 3.2 & 3.6 & 0.1754 & 1.2 & 3.2 & 3.4 \\
\hline $25-30$ & 0.0925 & 1.5 & 3.2 & 3.5 & 0.1200 & 1.3 & 3.2 & 3.5 \\
\hline $30-40$ & 0.1168 & 0.8 & 3.2 & 3.3 & 0.1530 & 0.7 & 3.2 & 3.3 \\
\hline $40-50$ & 0.0982 & 0.9 & 3.2 & 3.3 & 0.1450 & 0.7 & 3.2 & 3.3 \\
\hline $50-60$ & 0.1208 & 0.8 & 3.2 & 3.3 & 0.1457 & 0.7 & 3.2 & 3.3 \\
\hline $60-80$ & 0.1080 & 0.6 & 3.2 & 3.3 & 0.1415 & 0.5 & 3.2 & 3.2 \\
\hline $80-100$ & 0.1164 & 0.7 & 3.2 & 3.3 & 0.1400 & 0.6 & 3.2 & 3.3 \\
\hline $100-120$ & 0.1137 & 0.7 & 3.2 & 3.3 & 0.1393 & 0.6 & 3.2 & 3.3 \\
\hline $120-150$ & 0.1080 & 1.0 & 3.2 & 3.4 & 0.1194 & 0.9 & 3.2 & 3.3 \\
\hline $150-175$ & 0.1028 & 1.1 & 3.2 & 3.4 & 0.1280 & 0.9 & 3.2 & 3.3 \\
\hline $175-200$ & 0.1092 & 1.1 & 3.2 & 3.4 & 0.1201 & 1.0 & 3.2 & 3.4 \\
\hline $200-225$ & 0.1077 & 1.8 & 3.2 & 3.7 & 0.1223 & 1.6 & 3.2 & 3.6 \\
\hline
\end{tabular}


Table 18: NEUTRON CAPTURE CROSS SECTIONS OF ${ }^{134} \mathrm{Ba},{ }^{135} \mathrm{Ba},{ }^{136} \mathrm{Ba}$, AND ${ }^{137} \mathrm{Ba}$

\begin{tabular}{cccccc}
\hline $\begin{array}{c}\text { Energy Interval } \\
(\mathrm{keV})\end{array}$ & $\begin{array}{c}\sigma\left({ }^{197} \mathrm{Au}\right)^{2} \\
(\mathrm{mbarn})\end{array}$ & $\begin{array}{c}\sigma\left({ }^{134} \mathrm{Ba}\right) \\
(\mathrm{mbarn})\end{array}$ & $\begin{array}{c}\sigma\left({ }^{135} \mathrm{Ba}\right) \\
(\mathrm{mbarn})\end{array}$ & $\begin{array}{c}\sigma\left({ }^{136} \mathrm{Ba}\right) \\
(\mathrm{mbarn})\end{array}$ & $\begin{array}{c}\sigma\left({ }^{137} \mathrm{Ba}\right) \\
(\mathrm{mbarn})\end{array}$ \\
\hline $3-5$ & 2266.7 & & & & \\
$5-7.5$ & 1726.7 & 344.3 & & 165.4 & \\
$7.5-10$ & 1215.7 & 395.0 & & 102.6 & \\
$10-12.5$ & 1066.7 & 299.6 & 732.1 & 90.9 & 121.9 \\
$12.5-15$ & 878.0 & 194.3 & 678.5 & 107.4 & 111.1 \\
$15-20$ & 738.8 & 249.6 & 606.0 & 99.3 & 89.0 \\
$20-25$ & 600.0 & 207.1 & 571.2 & 71.8 & 105.3 \\
$25-30$ & 570.8 & 158.3 & 500.4 & 52.8 & 68.5 \\
$30-40$ & 500.4 & 166.1 & 428.6 & 58.5 & 76.6 \\
$40-50$ & 433.3 & 134.4 & 381.6 & 42.5 & 62.8 \\
$50-60$ & 389.6 & 131.3 & 326.7 & 47.1 & 56.8 \\
$60-80$ & 349.4 & 114.2 & 272.3 & 37.8 & 49.4 \\
$80-100$ & 298.3 & 104.7 & 230.2 & 34.7 & 41.8 \\
$100-120$ & 290.1 & 98.6 & 212.7 & 33.0 & 40.4 \\
$120-150$ & 274.1 & 89.1 & 192.8 & 29.6 & 32.7 \\
$150-175$ & 263.7 & 87.7 & 180.9 & 27.1 & 33.7 \\
$175-200$ & 252.6 & 83.2 & 170.6 & 27.6 & 30.3 \\
$200-225$ & 248.5 & 78.3 & 165.2 & 26.8 & 30.4 \\
\hline
\end{tabular}

${ }^{1}$ as used for calculating the Maxwellian averaged cross sections ${ }^{2}$ based on the ${ }^{197} \mathrm{Au}$ data from literature[42][43]

The experimental ratios were converted into cross sections by using the gold cross section of Macklin[42] after normalization by a factor of 0.989 to the absolute value of Ratynski and Käppeler[43] (Table 18). The uncertainties of these data can be obtained by adding the $1.5 \%$ uncertainty of the standard to the uncertainties of the respective cross section ratios.

The present results are compared to the data of Musgrove et al [18] in Figs.14 and 15. In the energy range of interest between 30 and $100 \mathrm{keV}$, these data exhibit uncertainties of $15,17,25$, and $17 \%$ for ${ }^{134} \mathrm{Ba},{ }^{135} \mathrm{Ba},{ }^{136} \mathrm{Ba}$, and ${ }^{137} \mathrm{Ba}$, and differ from the present results by factors $1.42,1.08,1.25$, and 0.83 , respectively. Except for ${ }^{134} \mathrm{Ba}$, these differences are consistent with the quoted uncertainties, but seem to confirm a trend that was already noted in case of the samarium isotopes[5]. Before 1988, the weighting functions in experiments with total energy detectors did not consider the influence of detector cannings and the surrounding setup. 

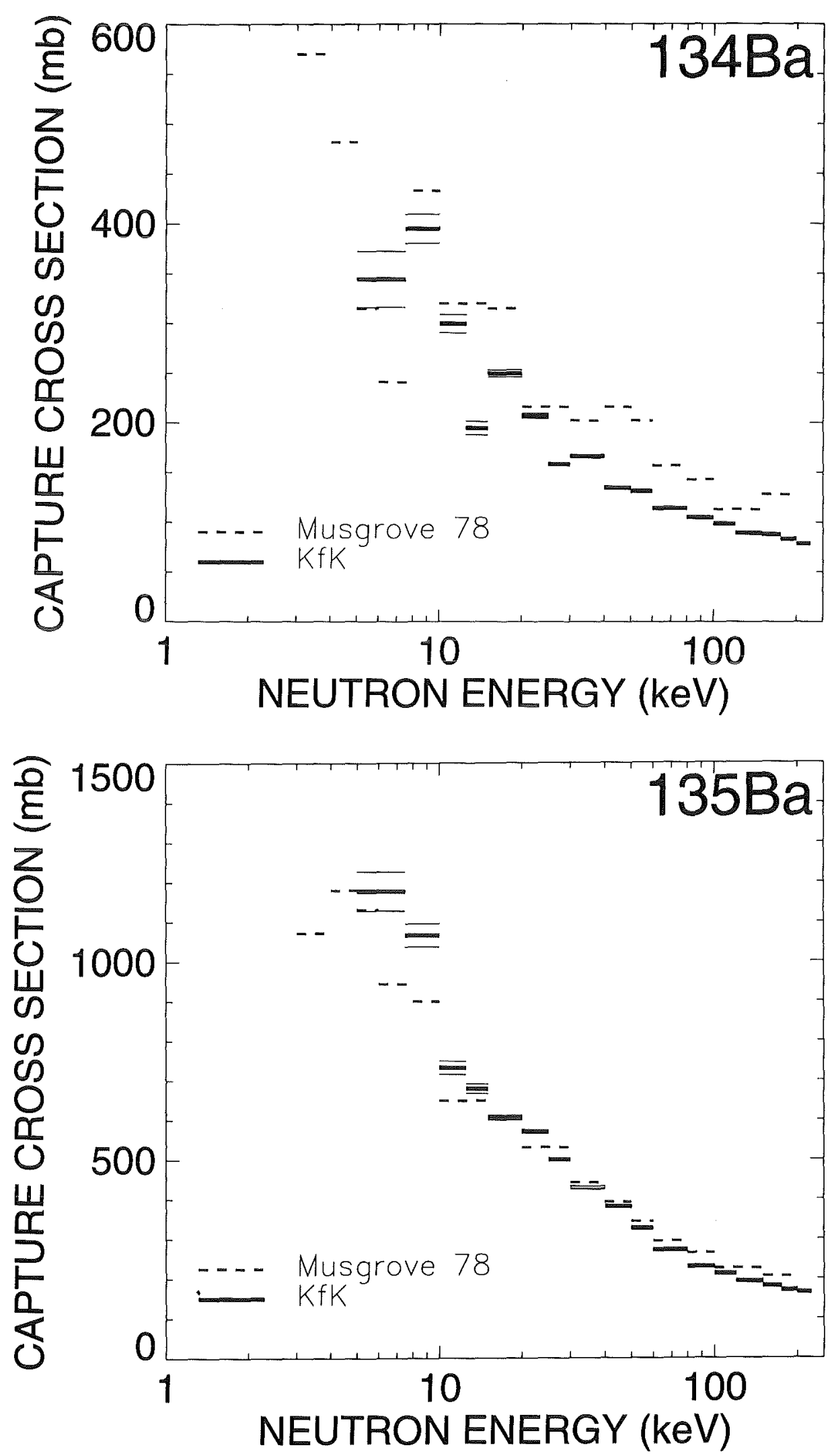

Figure 14: The neutron capture cross section of ${ }^{134} \mathrm{Ba}$ and ${ }^{135} \mathrm{Ba}$. 

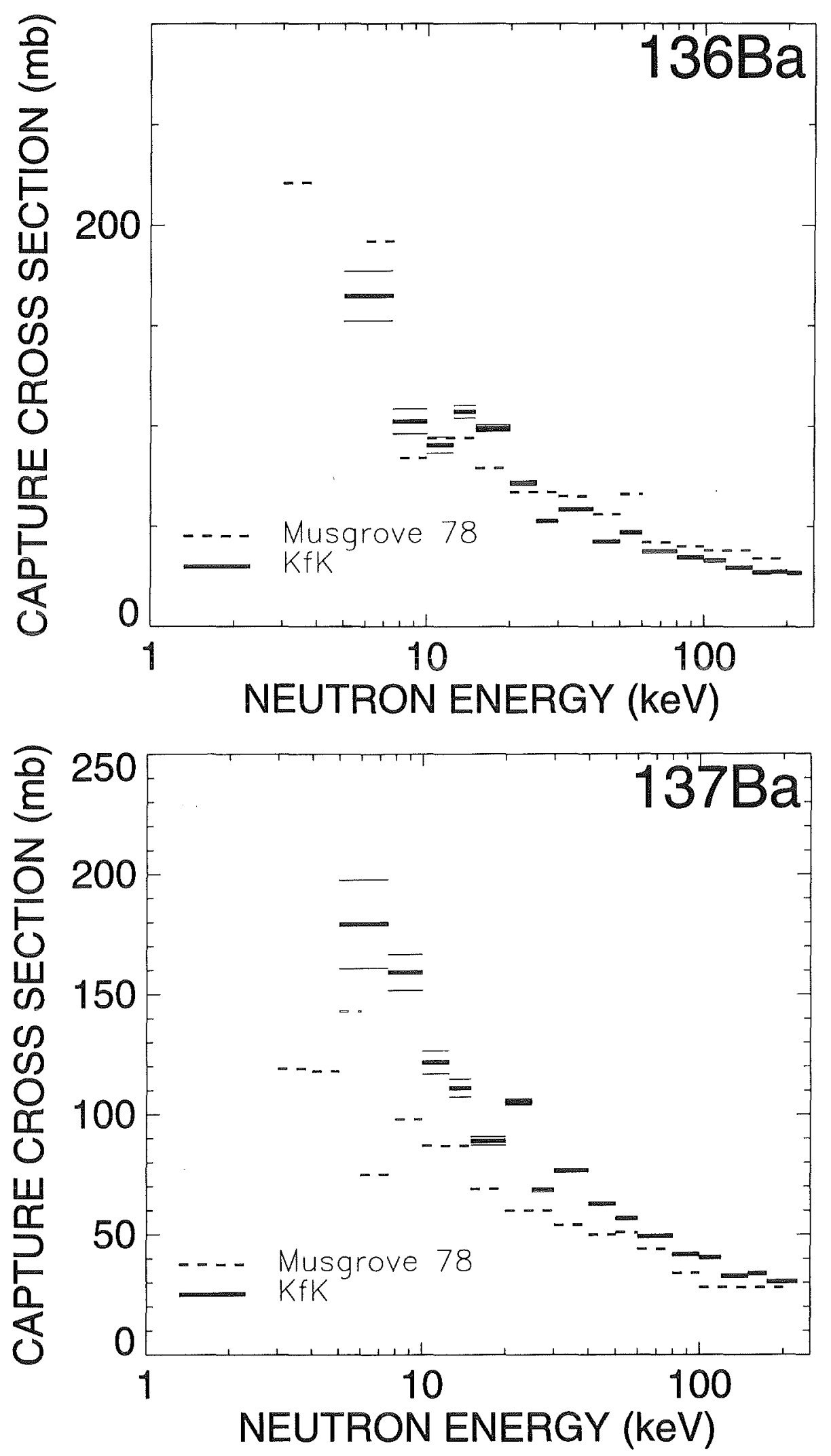

Figure 15: The neutron capture cross section of ${ }^{136} \mathrm{Ba}$ and ${ }^{137} \mathrm{Ba}$. 
In this way, the weight for high gamma-ray energies was consistently overestimated[44], leading to systematic uncertainties, whenever the capture gamma-ray spectra of the sample differed from that of the respective standard. The cross section ratio was overestimated, if the spectrum of the sample is harder than that of the standard, and underestimated, if it is softer. The spectra of both even barium isotopes being harder than that of gold[23], would explain the larger cross sections in the previous measurement. For the odd barium isotopes this effect is less pronounced since their spectra are rather similar to that of gold. This discussion holds also for the ${ }^{135} \mathrm{Ba}$ data of Mizumoto et al [21], which are in agreement with those of Musgrove et al [18].

For the even isotopes there are no significant differences in the cross section shapes down to $5 \mathrm{keV}$ neutron energy, though the cross sections of Musgrove et al [18] were determined from isolated resonances (in the energy range from 5 to $10 \mathrm{keV}$ for ${ }^{134} \mathrm{Ba}$ and from 5 to $35 \mathrm{keV}$ for ${ }^{136} \mathrm{Ba}$ ), whereas our data were calculated by averaging the observed capture yields directly. This agreement confirms the background correction applied to the present data. In particular, the low energy range of the ${ }^{136} \mathrm{Ba}$ cross section (see Fig.7), where only a few resonances are observed, would be extremely sensitive to a systematic uncertainty in the background subtraction. In spite of this good agreement, the resonance parameters for the isolated resonances in ${ }^{136} \mathrm{Ba}$ will also be deduced from the present data[32].

For the odd isotopes, deviations in the cross section shapes are observed below $10 \mathrm{keV}$. As discussed in Ref.[3], background subtraction at low energies is problematic, since the lines at $7 \mathrm{MeV}$ had to be integrated in the pulse height spectra (see Fig.6). Therefore, the data below $10 \mathrm{keV}$ were not used in the calculation of stellar cross sections. The very uncertain results in the energy range from 3 to $5 \mathrm{keV}$ were only included in Tables 13 to 16 to demonstrate that they show a reasonable trend despite of the extremely poor signal to background ratio in the TOF spectra.

\section{DISCUSSION OF UNCERTAINTIES}

The determination of statistical and systematic uncertainties in measurements with the $4 \pi \mathrm{BaF}_{2}$ detector has been described in Refs.[3][23]. The following discussion concentrates on the particular aspects of the present experiment on the barium isotopes. The various uncertainties are compiled in Table 19.

In contrast to previous experiments[3][5][23], the large scattering yields of the barium samples and the fact that discrimination of the corresponding backgrounds was hampered by the barium content of the scintillator resulted in significantly reduced signal to background ratios. Therefore, the related systematic uncertainties were no longer negligible. The $4 \mu$ s interval between the accelerator pulses was not completely sufficient to exclude TOF overlap from previous pulses. Hence, the count rate in the TOF region used for the determination of time-independent backgrounds (e.g. channels 1500 to 1690 in Fig.7) was still affected by a small time-dependent component. This gives rise to a systematic 
Table 19: SYSTEMATIC UNCERTAINTIES (\%)

\begin{tabular}{|c|c|}
\hline \multirow{2}{*}{\multicolumn{2}{|c|}{ Background subtraction in normalization }} \\
\hline & \\
\hline \multirow{2}{*}{$\begin{array}{l}\text { cross section ratio }{ }^{x} \mathrm{Ba} / \mathrm{Au} \\
\text { cross section ratio }{ }^{x} \mathrm{Ba} /{ }^{y} \mathrm{Ba}\end{array}$} & 3.0 \\
\hline & 1.5 \\
\hline Flight path & 0.1 \\
\hline Neutron flux normalization & 0.1 \\
\hline Sample mass & 0.1 \\
\hline Isotopic impurities $\left({ }^{134} \mathrm{Ba} /{ }^{135} \mathrm{Ba} /{ }^{136} \mathrm{Ba} /{ }^{137} \mathrm{Ba}\right.$ samples) & $0.2 / 0.1 / 0.3 / 1.0$ \\
\hline \multicolumn{2}{|l|}{$\begin{array}{l}\text { Multiple scattering and self-shielding } \\
\text { cross section ratio } \mathrm{Ba} / \mathrm{Au} \text { : }\end{array}$} \\
\hline $\begin{array}{l}{ }^{134} \mathrm{Ba} /{ }^{135} \mathrm{Ba} /{ }^{136} \mathrm{Ba} /{ }^{137} \mathrm{Ba} \text { samples } \\
\text { cross section ratio }{ }^{134} \mathrm{Ba} /{ }^{136} \mathrm{Ba}\end{array}$ & $\begin{array}{l}0.4 / 0.3 / 0.4 / 0.4 \\
0.4\end{array}$ \\
\hline \multicolumn{2}{|l|}{ Undetected events } \\
\hline $\begin{array}{c}\text { cross section ratio } \mathrm{Ba} / \mathrm{Au}: \\
{ }^{134} \mathrm{Ba} /{ }^{135} \mathrm{Ba} /{ }^{136} \mathrm{Ba} /{ }^{137} \mathrm{Ba} \text { samples } \\
\text { cross section ratio }{ }^{134} \mathrm{Ba} /{ }^{136} \mathrm{Ba}\end{array}$ & $\begin{array}{l}0.6 / 0.4 / 1.0 / 0.4 \\
1.0\end{array}$ \\
\hline \multicolumn{2}{|l|}{ total systematic uncertainties } \\
\hline$\sigma\left({ }^{134} \mathrm{Ba}\right) / \sigma(\mathrm{Au})$ & 3.1 \\
\hline$\sigma\left({ }^{135} \mathrm{Ba}\right) / \sigma(\mathrm{Au})$ & 3.0 \\
\hline$\sigma\left({ }^{136} \mathrm{Ba}\right) / \sigma(\mathrm{Au})$ & 3.2 \\
\hline$\sigma\left({ }^{137} \mathrm{Ba}\right) / \sigma(\mathrm{Au})$ & 3.2 \\
\hline$\sigma\left({ }^{134} \mathrm{Ba}\right) / \sigma\left({ }^{136} \mathrm{Ba}\right)$ & 1.9 \\
\hline
\end{tabular}

uncertainty in the normalization interval close to this region (see Fig.7).

In addition, the normalization of the scattering correction is strongly TOF-dependent in this critical interval as shown in Fig.16, leading to a systematic uncertainty in the normalization of the cross section. As discussed above, the ${ }^{136} \mathrm{Ba}$ cross section in the region of resolved resonances provides a sensitive test of this correction. Since the observed scatter in the data of individual runs at low energies (above $5 \mathrm{keV}$ for the even and above 10 $\mathrm{keV}$ for the odd isotopes) is fully compatible with the statistical uncertainties, a systematic uncertainty for the cross section shape could again be excluded. In the range from 30 to $80 \mathrm{keV}$, however, the data show statistically significant discrepancies in the absolute normalization. The corresponding systematic uncertainty affects mainly the cross section ratio relative to gold, since this problem occurs only for the barium isotopes. Actually, the average deviation from the respective mean suggested a systematic uncertainty of $3.0 \%$ for the cross section ratios relative to gold. For the ratio of two barium cross section, e.g. for the astrophsically important ratio $\sigma\left({ }^{134} \mathrm{Ba}\right) / \sigma\left({ }^{136} \mathrm{Ba}\right)$, this systematic uncertainty reduces to $1.5 \%$, since both isotopes are affected in a similar way.

This normalization problem dominates the total systematic uncertainty. All other uncertainties are comparably small, and are in most cases equivalent to the uncertainties discussed in Ref.[5]. The differences in the actual values listed in Table 19 refer to the following points: The uncertainty due to the correction for equal neutron flux could be reduced due to the larger number of measuring cycles. Also the sample masses were better 


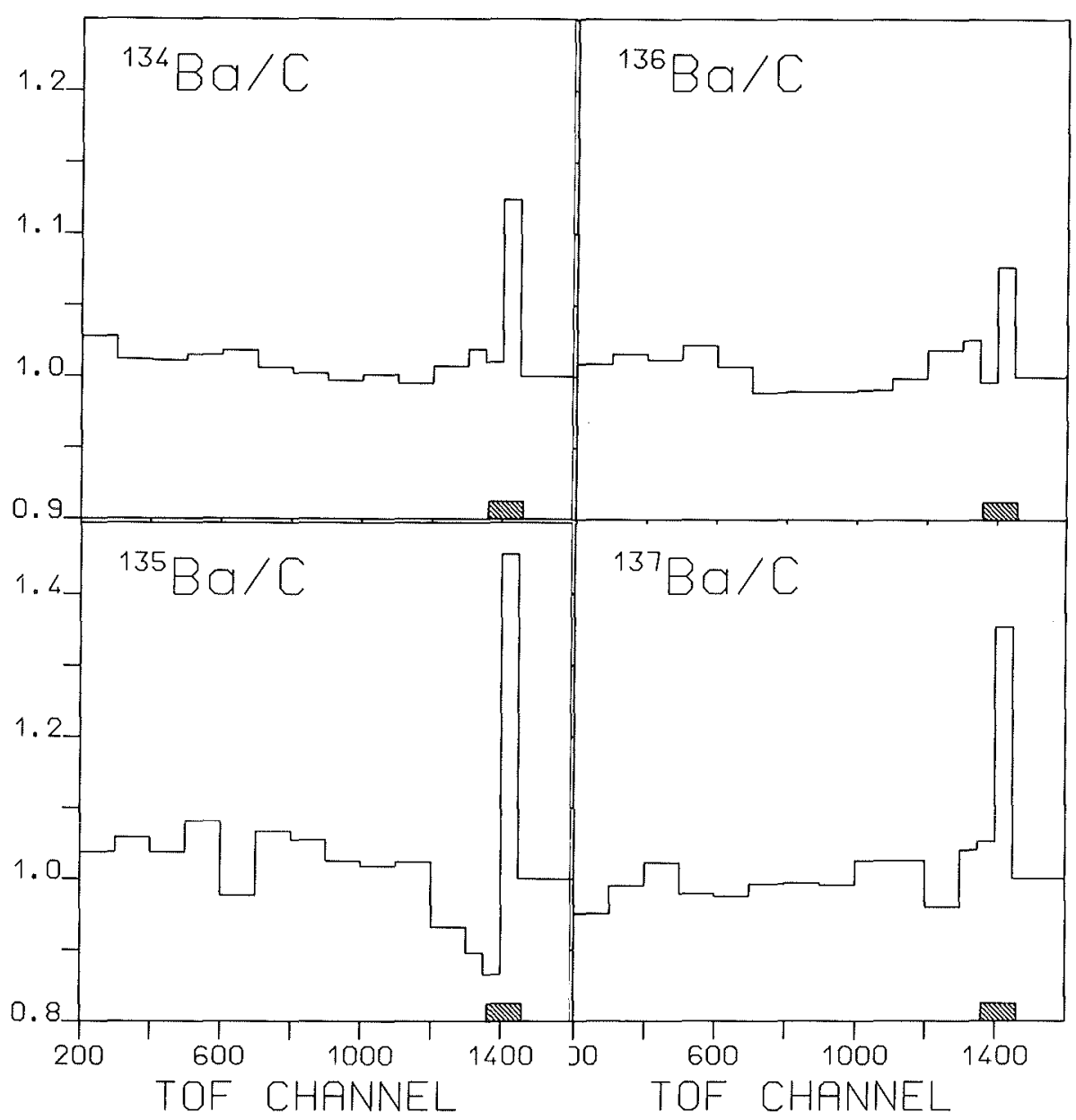

Figure 16: Ratio of capture events in the scintillator due to neutrons scattered in the different samples and in the graphite sample.

defined, since there were no problems with water absorption in the barium carbonate. The uncertainty of the isotopic correction is dominated by the fact that ${ }^{138} \mathrm{Ba}$ was neglected in our data analysis. With the new ${ }^{138} \mathrm{Ba}$ cross section[22] and the isotopic abundances of Table 2, a sizable uncertainty of $1 \%$ was found for ${ }^{137} \mathrm{Ba}$ only (Table 19). In fact, there are no indications for ${ }^{138} \mathrm{Ba}$ captures at $4.9 \mathrm{MeV}$ in the spectra of Fig.9. The uncertainties of the multiple scattering corrections are slightly larger than reported previously because of the larger samples used in the present experiment.

The correction for unobserved capture events needs special consideration. On one hand, the use of experimentally determined line shapes for monoenergetic gamma-rays certainly improved the reliability of the correction, but on the other hand, the low multiplicities of the barium capture cascades produced the problem that the calculations were slightly dependent on the random numbers in the Monte Carlo simulation of the effective solid angle. The correction factor $\mathrm{F}_{1}$ is plotted in Fig. 17 versus the differences in binding energy between the barium isotopes and gold; the linear relation observed previously[3][5] is confirmed by the present results. 


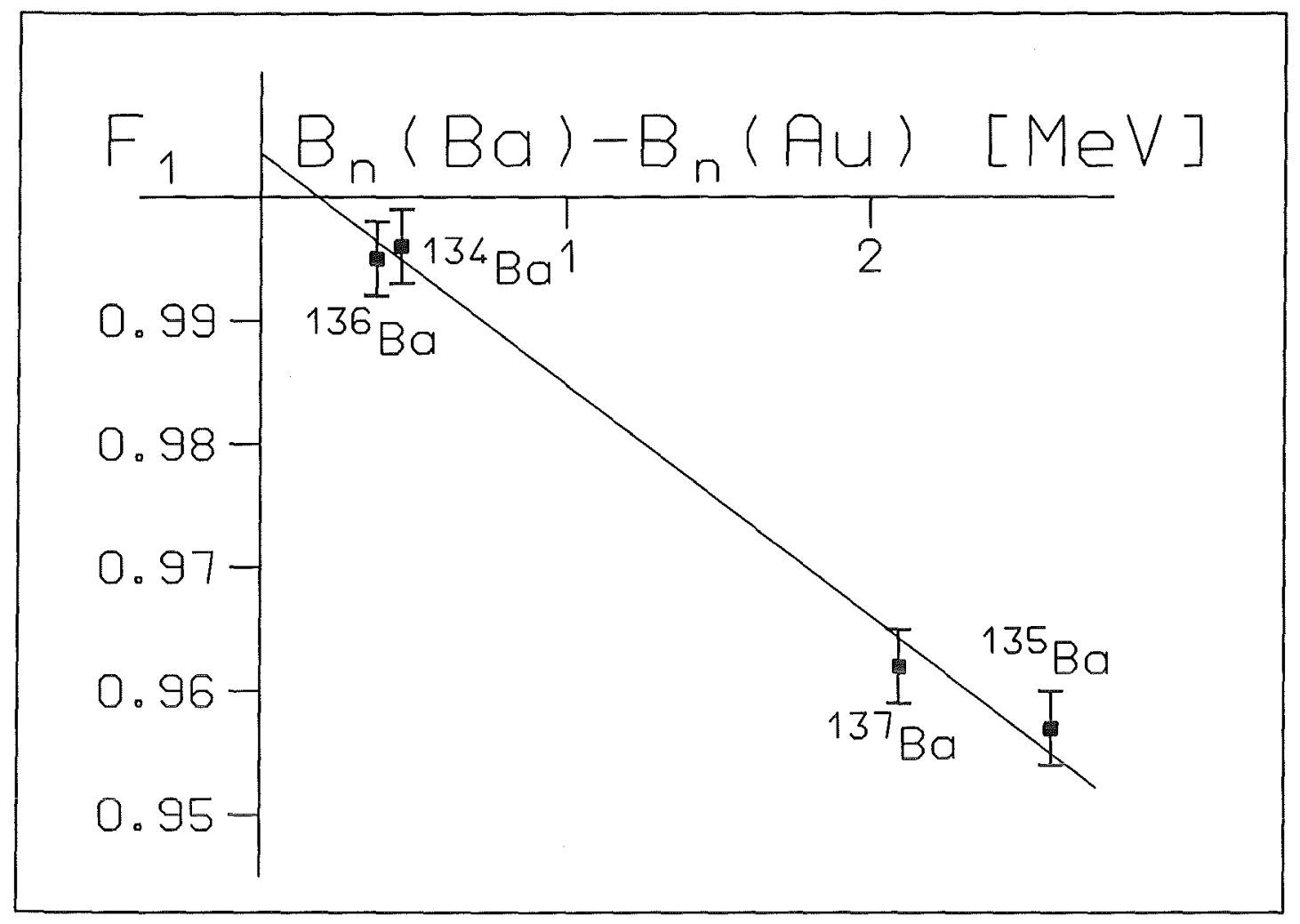

Figure 17: The correction $F_{1}$ for unobserved capture events, plotted versus the difference in binding energy between barium isotopes and gold standard.

\section{MAXWELLIAN AVERAGED CROSS SECTIONS}

Maxwellian averaged cross sections were calculated in the same way as described in Refs.[23][3]. The neutron energy range from 0 to $700 \mathrm{keV}$ was divided into three intervals according to the origin of the adopted cross sections. The respective contributions $I_{x}$ are given in Table 20 . The main contributions from the interval $I_{2}$ were obtained from the cross sections of the present experiment (Table 18). The energy bins of these data was chosen sufficiently fine to exclude systematic uncertainties that may result from a coarse energy grid. 
Table 20: MAXWELLIAN AVERAGED NEUTRON CAPTURE CROSS SECTIONS OF THE BARIUM ISOTOPES. THE CONTRIBUTIONS I ${ }_{x}$ FROM DIFFERENT ENERGY INTERVALS, $\triangle \mathrm{E}$, ARE QUOTED SEPARATELY WITH THEIR STATISTICAL UNCERTAINTIES

\begin{tabular}{|c|c|c|c|c|c|c|c|}
\hline \multicolumn{8}{|c|}{${ }^{134} \mathrm{Ba}$} \\
\hline $\begin{array}{c}\Delta \bar{E} \\
\text { Data: }\end{array}$ & $\begin{array}{l}0-5 \mathrm{keV} \\
\text { see text }\end{array}$ & $\begin{array}{l}5-225 \mathrm{keV} \\
\text { this work }\end{array}$ & $\begin{array}{l}225-700 \mathrm{keV} \\
\text { from Ref.[29] }\end{array}$ & \multicolumn{4}{|c|}{ Thermal Spectrum } \\
\hline$\overline{\mathrm{kT}}$ & $\mathrm{I}_{1}$ & $\overline{\mathrm{I}_{2}}$ & $I_{3}$ & \multicolumn{4}{|c|}{$<\sigma \mathrm{v}\rangle / \mathrm{v}_{T}(\mathrm{mbarn})$} \\
\hline$(\mathrm{keV})$ & (mbarn) & (mbarn) & (mbarn) & & stat & sys $^{2}$ & tot \\
\hline 10 & $68.7 \pm 6.9$ & $242.0 \pm 3.5$ & 0.0 & 310.7 & 7.7 & 9.6 & 12.3 \\
\hline 12 & $49.9 \pm 5.0$ & $231.5 \pm 2.8$ & 0.0 & 281.4 & 5.7 & 8.7 & 10.4 \\
\hline 20 & $19.7 \pm 2.0$ & $195.5 \pm 1.5$ & 0.0 & 215.2 & 2.5 & 6.7 & 7.1 \\
\hline 25 & $13.0 \pm 1.3$ & $179.4 \pm 1.2$ & 0.1 & 192.5 & 1.8 & 6.0 & 6.2 \\
\hline 30 & $9.2 \pm 0.9$ & $166.7 \pm 1.0$ & 0.4 & 176.3 & 1.3 & 5.5 & 5.6 \\
\hline 40 & $5.3 \pm 0.5$ & $147.2 \pm 0.7$ & $2.1 \pm 0.1$ & 154.6 & 0.9 & 4.8 & 4.9 \\
\hline 50 & $3.5 \pm 0.4$ & $131.7 \pm 0.6$ & $5.3 \pm 0.2$ & 140.5 & 0.7 & 4.4 & 4.4 \\
\hline 52 & $3.2 \pm 0.3$ & $128.9 \pm 0.6$ & $6.1 \pm 0.2$ & 138.2 & 0.7 & 4.3 & 4.3 \\
\hline 60 & $2.4 \pm 0.2$ & $118.5 \pm 0.5$ & $9.6 \pm 0.3$ & 130.5 & 0.6 & 4.0 & 4.1 \\
\hline 70 & $1.8 \pm 0.2$ & $106.8 \pm 0.5$ & $14.5 \pm 0.5$ & 123.1 & 0.7 & 3.8 & 3.9 \\
\hline 80 & $1.4 \pm 0.1$ & $96.5 \pm 0.4$ & $19.4 \pm 0.7$ & 117.3 & 0.8 & 3.6 & 3.7 \\
\hline 90 & $1.1 \pm 0.1$ & $87.4 \pm 0.4$ & $24.0 \pm 0.9$ & 112.5 & 1.0 & 3.5 & 3.6 \\
\hline 100 & $0.9 \pm 0.1$ & $79.3 \pm 0.4$ & $28.2 \pm 1.1$ & 108.4 & 1.2 & 3.4 & 3.6 \\
\hline \multicolumn{8}{|c|}{${ }^{135} \mathrm{Ba}$} \\
\hline $\begin{array}{c}\Delta \mathrm{E} \\
\text { Data: }\end{array}$ & $\begin{array}{c}0-10 \mathrm{keV} \\
\text { see text }\end{array}$ & $\begin{array}{c}10-225 \mathrm{keV} \\
\text { this work }\end{array}$ & $\begin{array}{l}225-700 \mathrm{keV} \\
\text { from Ref.[29] }\end{array}$ & \multicolumn{4}{|c|}{ Thermal Spectrum } \\
\hline $\mathrm{kT}$ & $\mathrm{I}_{1}$ & $\mathrm{I}_{2}$ & $\mathrm{I}_{3}$ & \multicolumn{4}{|c|}{$<\sigma \mathrm{v}>/ \mathrm{v}_{T}(\mathrm{mbarn})$} \\
\hline$(\mathrm{keV})$ & (mbarn) & (mbarn) & (mbarn) & & stat & sys $^{2}$ & tot \\
\hline 10 & $388.4 \pm 38.8$ & $457.5 \pm 2.8$ & 0.0 & 845.9 & 38.9 & 25.4 & 46.4 \\
\hline 12 & $293.6 \pm 29.4$ & $470.3 \pm 2.5$ & 0.0 & 763.9 & 29.5 & 22.9 & 37.4 \\
\hline 20 & $124.8 \pm 12.5$ & $447.8 \pm 1.8$ & 0.0 & 572.6 & 12.6 & 17.2 & 21.3 \\
\hline 25 & $84.2 \pm 8.4$ & $420.2 \pm 1.6$ & 0.2 & 504.6 & 8.6 & 15.1 & 17.4 \\
\hline 30 & $60.6 \pm 6.1$ & $393.6 \pm 1.4$ & 0.8 & 455.0 & 6.3 & 13.7 & 15.0 \\
\hline 40 & $35.7 \pm 3.6$ & $347.1 \pm 1.1$ & $3.9 \pm 0.1$ & 386.7 & 3.8 & 11.6 & 12.2 \\
\hline 50 & $23.5 \pm 2.4$ & $308.3 \pm 1.0$ & $9.9 \pm 0.3$ & 341.7 & 2.6 & 10.3 & 10.6 \\
\hline 52 & $21.8 \pm 2.2$ & $301.2 \pm 0.9$ & $11.4 \pm 0.3$ & 334.4 & 2.4 & 10.0 & 10.3 \\
\hline 60 & $16.6 \pm 1.7$ & $275.0 \pm 0.9$ & $17.9 \pm 0.6$ & 309.5 & 2.0 & 9.3 & 9.5 \\
\hline 70 & $12.4 \pm 1.2$ & $246.2 \pm 0.8$ & $26.7 \pm 0.9$ & 285.3 & 1.7 & 8.6 & 8.7 \\
\hline 80 & $9.6 \pm 1.0$ & $221.0 \pm 0.7$ & $35.3 \pm 1.2$ & 265.9 & 1.7 & 8.0 & 8.2 \\
\hline 90 & $7.6 \pm 0.8$ & $199.0 \pm 0.7$ & $43.4 \pm 1.6$ & 250.0 & 1.9 & 7.5 & 7.7 \\
\hline 100 & $6.2 \pm 0.6$ & $179.9 \pm 0.6$ & $50.6 \pm 1.9$ & 236.7 & 2.1 & 7.1 & 7.4 \\
\hline
\end{tabular}


Table 20 continued

\begin{tabular}{|c|c|c|c|c|c|c|c|}
\hline \multicolumn{8}{|c|}{${ }^{136} \mathrm{Ba}$} \\
\hline$\Delta \mathrm{E}$ & $0-5 \mathrm{keV}$ & $5-225 \mathrm{keV}$ & $225-700 \mathrm{keV}$ & \multicolumn{4}{|c|}{ Thermal Spectrum } \\
\hline & & & & \multirow{2}{*}{\multicolumn{4}{|c|}{$\langle\sigma \mathrm{v}\rangle / \mathrm{v}_{T}(\mathrm{mbarn})$}} \\
\hline $\mathrm{kT}$ & $\mathrm{I}_{1}$ & $\mathrm{I}_{2}$ & $\mathrm{I}_{3}$ & & & & \\
\hline$(\mathrm{keV})$ & (mbarn) & (mbarn) & (mbarn) & & stat & sys $^{2}$ & tot \\
\hline 10 & $25.70 \pm 5.14$ & $89.15 \pm 1.53$ & 0.00 & 114.9 & 5.4 & 3.7 & 6.5 \\
\hline 12 & $18.86 \pm 3.77$ & $84.68 \pm 1.24$ & 0.00 & 103.5 & 4.0 & 3.3 & 5.2 \\
\hline 20 & $7.59 \pm 1.52$ & $69.77 \pm 0.67$ & 0.00 & 77.4 & 1.7 & 2.5 & 3.0 \\
\hline 25 & $5.03 \pm 1.00$ & $63.31 \pm 0.51$ & 0.03 & 68.4 & 1.1 & 2.2 & 2.5 \\
\hline 30 & $3.58 \pm 0.72$ & $58.29 \pm 0.42$ & 0.13 & 62.0 & 0.8 & 2.0 & 2.1 \\
\hline 40 & $2.07 \pm 0.41$ & $50.79 \pm 0.31$ & $0.67 \pm 0.02$ & 53.5 & 0.5 & 1.7 & 1.8 \\
\hline 50 & $1.35 \pm 0.27$ & $45.06 \pm 0.25$ & $1.72 \pm 0.05$ & 48.1 & 0.4 & 1.5 & 1.6 \\
\hline 52 & $1.25 \pm 0.25$ & $44.04 \pm 0.25$ & $1.98 \pm 0.06$ & 47.3 & 0.4 & 1.5 & 1.6 \\
\hline 60 & $0.95 \pm 0.19$ & $40.29 \pm 0.22$ & $3.14 \pm 0.10$ & 44.4 & 0.3 & 1.4 & 1.5 \\
\hline 70 & $0.71 \pm 0.14$ & $36.18 \pm 0.20$ & $4.77 \pm 0.17$ & 41.7 & 0.3 & 1.3 & 1.4 \\
\hline 80 & $0.55 \pm 0.11$ & $32.58 \pm 0.18$ & $6.44 \pm 0.24$ & 39.6 & 0.3 & 1.3 & 1.3 \\
\hline 90 & $0.43 \pm 0.09$ & $29.42 \pm 0.16$ & $8.06 \pm 0.31$ & 37.9 & 0.4 & 1.2 & 1.3 \\
\hline 100 & $0.35 \pm 0.07$ & $26.65 \pm 0.15$ & $9.56 \pm 0.39$ & 36.6 & 0.4 & 1.2 & 1.2 \\
\hline \multicolumn{8}{|c|}{${ }^{137} \mathrm{Ba}$} \\
\hline $\begin{array}{c}\Delta \mathrm{E} \\
\text { Data: }\end{array}$ & $\begin{array}{c}0-10 \mathrm{keV} \\
\text { see text }\end{array}$ & $\begin{array}{c}10-225 \mathrm{keV} \\
\text { this work }\end{array}$ & $\begin{array}{l}225-700 \mathrm{keV} \\
\text { from Ref.[29] }\end{array}$ & \multicolumn{4}{|c|}{ Thermal Spectrum } \\
\hline $\mathrm{kT}$ & $\mathrm{I}_{1}$ & $\mathrm{I}_{2}$ & $\mathrm{I}_{3}$ & \multicolumn{4}{|c|}{$\left\langle\sigma_{\mathrm{V}}\right\rangle / \mathrm{v}_{T}(\mathrm{mbarn})$} \\
\hline$(\mathrm{keV})$ & (mbarn) & (mbarn) & (mbarn) & & stat & sys $^{2}$ & tot \\
\hline 10 & $63.13 \pm 9.47$ & $74.54 \pm 0.77$ & 0.00 & 137.7 & 9.5 & 4.4 & 10.5 \\
\hline 12 & $47.58 \pm 7.14$ & $76.99 \pm 0.70$ & 0.00 & 124.6 & 7.2 & 4.0 & 8.2 \\
\hline 20 & $20.30 \pm 3.05$ & $74.69 \pm 0.48$ & 0.00 & 95.0 & 3.1 & 3.0 & 4.3 \\
\hline 25 & $13.70 \pm 2.06$ & $70.80 \pm 0.40$ & 0.04 & 84.5 & 2.1 & 2.7 & 3.4 \\
\hline 30 & $9.86 \pm 1.48$ & $66.88 \pm 0.34$ & 0.14 & 76.9 & 1.5 & 2.5 & 2.9 \\
\hline 40 & $5.80 \pm 0.87$ & $59.72 \pm 0.27$ & $0.71 \pm 0.02$ & 66.2 & 0.9 & 2.1 & 2.3 \\
\hline 50 & $3.82 \pm 0.67$ & $53.50 \pm 0.23$ & $1.79 \pm 0.05$ & 59.1 & 0.7 & 1.9 & 2.0 \\
\hline 52 & $3.55 \pm 0.53$ & $52.34 \pm 0.23$ & $2.06 \pm 0.06$ & 58.0 & 0.6 & 1.8 & 1.9 \\
\hline 60 & $2.70 \pm 0.40$ & $48.01 \pm 0.21$ & $3.25 \pm 0.10$ & 54.0 & 0.5 & 1.7 & 1.8 \\
\hline 70 & $2.01 \pm 0.30$ & $43.15 \pm 0.19$ & $4.86 \pm 0.16$ & 50.0 & 0.4 & 1.6 & 1.6 \\
\hline 80 & $1.56 \pm 0.23$ & $38.86 \pm 0.17$ & $6.49 \pm 0.23$ & 46.9 & 0.4 & 1.5 & 1.5 \\
\hline 90 & $1.24 \pm 0.19$ & $35.08 \pm 0.15$ & $8.01 \pm 0.30$ & 44.3 & 0.4 & 1.4 & 1.5 \\
\hline 100 & $1.01 \pm 0.15$ & $31.76 \pm 0.14$ & $9.39 \pm 0.37$ & 42.2 & 0.4 & 1.3 & 1.4 \\
\hline
\end{tabular}

${ }^{1}$ normalized to present data

${ }^{2}$ The $1.5 \%$ uncertainty of the gold standard is not included here, since it cancels out in most applications of relevance for nuclear astrophysics 
Table 21: RATIO OF THE STELLAR ${ }^{134} \mathrm{Ba}$ AND ${ }^{136} \mathrm{Ba}$ CROSS SECTIONS AND CORRELATED UNCERTAINTIES

\begin{tabular}{cc}
\hline Thermal Energy (keV) & Cross Section Ratio \\
\hline 10 & $2.70 \pm 5.6 \%$ \\
12 & $2.72 \pm 4.7 \%$ \\
20 & $2.78 \pm 3.1 \%$ \\
25 & $2.82 \pm 2.7 \%$ \\
30 & $2.84 \pm 2.5 \%$ \\
40 & $2.89 \pm 2.2 \%$ \\
50 & $2.92 \pm 2.1 \%$ \\
52 & $2.92 \pm 2.1 \%$ \\
60 & $2.94 \pm 2.1 \%$ \\
70 & $2.96 \pm 2.1 \%$ \\
80 & $2.97 \pm 2.2 \%$ \\
90 & $2.97 \pm 2.3 \%$ \\
100 & $2.96 \pm 2.5 \%$ \\
\hline
\end{tabular}

The contributions $\mathrm{I}_{1}$ from the energy range from 0 to $5 \mathrm{keV}$ for the even and from 0 to $10 \mathrm{keV}$ for the odd isotopes was determined in two different ways. First, the cross section shapes from statistical model calculations were fitted at high energies to the present results and at low energies to the data that were calculated from resonance parameters [38]. In a second calculation, the cross sections of the Joint Evaluated File[29] were normalized to the present experiment in the region between 10 to $20 \mathrm{keV}$. Though the respective normalization factors were ranging from 1.20 to 1.42 , the cross section shapes were found in good agreement between both data sets. For the adopted contributions in Table 20 the results from both calculations were averaged, the quoted uncertainty of $10-20 \%$ corresponding to the respective differences includes the systematic uncertainty of this component.

The energy interval from 225 to $700 \mathrm{keV}$ contributes only very little to the Maxwellian average at typical s-process temperatures. There, the JEF data[29] were normalized to the present results between 100 to $200 \mathrm{keV}$. The quoted uncertainties were calculated under the assumption that the uncertainty of the normalized cross sections increases from $2 \%$ at $225 \mathrm{keV}$ to $10 \%$ at $700 \mathrm{keV}$.

The systematic uncertainties of the Maxwellian averaged cross sections in Table 20 correspond to the uncertainties of the cross section ratios (Table 17), and consider the contributions of the summed intensities, $\mathrm{I}_{2}+\mathrm{I}_{3}$. The $1.5 \%$ uncertainty of the gold standard was not included since it cancels out in most applications of relevance for s-process studies $(\$ 7)$. The total uncertainties are given in the last column; they are dominated by the systematic contributions.

In calculating ratios of two barium cross sections, one must consider that the uncertainties given in Table 20 are strongly correlated and should, therefore, not be added in quadrature. For example, the statistical uncertainties of the cross section ratios are partly determined by the respective gold count rates $\left(Z_{i}(A u), \Sigma Z(A u), \Sigma E(A u)\right.$ in Eq.1), which cancel out in the cross section ratio of two barium isotopes. As discussed in $\S 5$, the 
Table 22: MAXWELLIAN AVERAGED NEUTRON CAPTURE CROSS SECTIONS $\mathrm{AT} \mathrm{kT}=30 \mathrm{keV}$ COMPARED TO PREVIOUS EVALUATIONS

\begin{tabular}{cccc}
\hline Isotope & \multicolumn{3}{c}{$\left\langle\sigma v>/ v_{T}(\mathrm{mbarn})\right.$} \\
& This Work & Bao and Käppeler[20] & Beer, Voss, and Winters[11] \\
\hline${ }^{134} \mathrm{Ba}$ & $176.3 \pm 5.6$ & $221 \pm 35$ & $221 \pm 34$ \\
${ }^{135} \mathrm{Ba}$ & $455.0 \pm 15.0$ & $457 \pm 80$ & $295 \pm 59$ \\
${ }^{136} \mathrm{Ba}$ & $62.0 \pm 2.1$ & $69 \pm 10$ & $60 \pm 10$ \\
${ }^{137} \mathrm{Ba}$ & $76.9 \pm 2.9$ & $57 \pm 10$ & $52 \pm 10$ \\
\hline
\end{tabular}

systematic uncertainties of such cross section ratios are significantly smaller (Table 19). The proper uncertainty of the ratio of Maxwellian averaged cross sections of two barium isotopes was evaluated explicitly for the s-only isotopes ${ }^{134} \mathrm{Ba}$ and ${ }^{136} \mathrm{Ba}$, and is given in Table 21.

The present results at $\mathrm{kT}=30 \mathrm{keV}$ are eventually compared in Table 22 with the data given in the compilations of Bao and Käppeler[20] and of Beer, Voss and Winters[11]. Significant differences are found for the isotopes ${ }^{134} \mathrm{Ba}$ and ${ }^{137} \mathrm{Ba}$. The low value for ${ }^{135} \mathrm{Ba}$ given in Ref.[11], which is based on Refs.[15][17] is completely ruled out by the present data. On average, the uncertainties have been reduced by a factor of five.

\section{ASTROPHYSICAL IMPLICATIONS}

\subsection{Normalization of the $\mathrm{N}_{s}<\sigma>-$ Curve}

The s-process reaction flow from iron to bismuth is described by the product of the produced s-abundances and the respective cross sections of all involved isotopes. This quantity is characteristic for the s-process, since it reflects the correlation $\mathrm{N}_{s} \sim\langle\sigma\rangle^{-1}$ that follows from the fact that the neutron capture rates are practically independent of temperature in typical s-process environments. In the classical approach, the s-process abundances of neighboring isotopes are connected by a simple iterative expression[2],

$$
\left(\sigma N_{s}\right)_{A}=\zeta_{A} \times\left(\sigma N_{s}\right)_{A-1}
$$

with

$$
\zeta_{A}=\left(1+\frac{1}{\sigma_{A} \times \tau_{0}}\right)^{-1}
$$

If plotted versus mass number, the resulting $\mathrm{N}_{s}\langle\sigma\rangle-$ curve can be fitted to the empirical $\mathrm{N}_{s}<\sigma>$ products of those s-only isotopes, which are not affected by branchings, and hence experience the entire reaction flow. The corresponding fit parameters yield information on the neutron economy during the s-process (seed abundance and mean neutron exposure), while the $\mathrm{N}_{s}<\sigma>$-values correspond directly to the s-abundances[2]. 


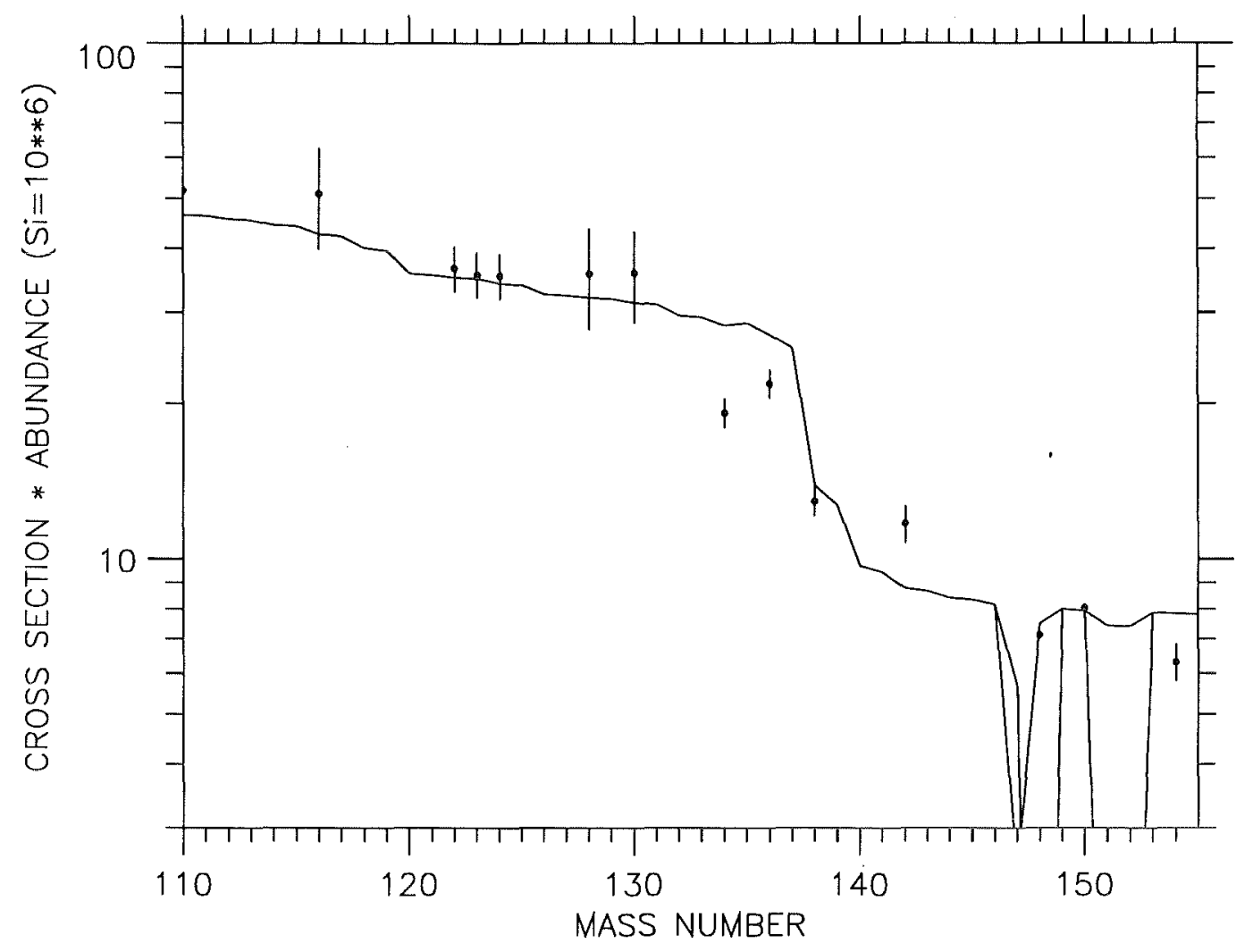

Figure 18: The $\mathrm{N}_{s}<\sigma>-$ curve calculated with the code SPEED.CLAS' in the mass region $120<\mathrm{A}<155$ in comparison to the empirical $\mathrm{N}_{s}<\sigma>$ values.

Among the normalization points of the $\mathrm{N}_{s}<\sigma>-$ curve, ${ }^{136} \mathrm{Ba}$ is important because it is situated close to the neutron magic nuclei with $\mathrm{N}=82$, thus defining the turn--off point where the $\mathrm{N}_{s}\langle\sigma\rangle$-curve exhibits a step-like decrease due to the small cross sections of the neutron magic nuclei. Together with the previously studied cases, ${ }^{124} \mathrm{Te}$ and ${ }^{150} \mathrm{Sm}$, ${ }^{136} \mathrm{Ba}$ is expected to represent a further test of the $\mathrm{s}$-process concept based on the classical approach. So far, this model has been surprisingly successful in spite of the extremely simple scenario, which assumes constant neutron density and temperature during the sprocess. In the following study, the currently best parameter set for the classical model was adopted from Ref.[6]: an exponential distribution $\rho(\tau) \sim \exp \left(-\tau / \tau_{0}\right)$ with a mean neutron exposure, $\tau_{0}=0.295 \mathrm{mbarn}^{-1}$ for $\mathrm{kT}=29 \mathrm{keV}$, and a thermal energy, $\mathrm{kT}=29$ $\mathrm{keV}$. The mean neutron density, $\mathrm{n}_{n}=(3.8 \pm 0.6) \times 10^{8} \mathrm{~cm}^{-3}$ is taken from Ref.[5].

Figure 18 shows the $\mathrm{N}_{s}\langle\sigma\rangle-$ curve calculated with the code SPEED.CLAS [45] in the mass region $120<A<155$. The empirical $N_{s}<\sigma>$ values of the respective s-only isotopes are given for comparison. While all normalization points are in reasonable agreement with the calculated curve, ${ }^{136} \mathrm{Ba}$ falls short by $20 \%$, which means that ${ }^{136} \mathrm{Ba}$ is overproduced in the model by this amount. Since the $\mathrm{N}_{s}\langle\sigma\rangle$-curve is a continuously decreasing function of mass number, there is no way to readjust the fit in order to satisfy the ${ }^{136} \mathrm{Ba}$ point without creating a systematic discrepancy for all the heavier s-isotopes.

An acceptable reason for an s-only isotope to fall below the calculated $\mathrm{N}_{s}\langle\sigma\rangle-$ curve could be that this isotope is partly bypassed in the s-process due to a branching as it holds 
for ${ }^{134} \mathrm{Ba}$ (Fig. 1). However, this possibility can be excluded for ${ }^{136} \mathrm{Ba}$ because of the short half-life of the only possible branch point ${ }^{136} \mathrm{Cs}$. The only other plausible explanation were then that the observed barium abundance, $\mathrm{N}_{\odot}=4.49 \pm 0.28\left[\mathrm{Si} \equiv 10^{6}\right]$, may be too small. However, this abundance is fairly well established (E. Anders, private communication to R. Gallino). Since the cross section determined in this work is also believed to be correct, this discrepancy seems to be the first point where the classical s-process model shows a true inconsistency! This is a most remarkable result, and the solution of this puzzle may, therefore, require a more sophisticated s-process scenario (see also §7.3).

The only alternative to the classical approach for quantitative s-process calculations in this mass region is the model for helium shell burning in low mass stars[46][47][48], which was also shown to reproduce the observed abundances rather well[6]. If this model is used with the latest input profiles for temperature and neutron density ( $R$. Gallino, private communication), the same $20 \%$ overproduction is obtained for ${ }^{136} \mathrm{Ba}$ as in the classical approach.

In the stellar model, however, neutron density and temperature are no longer constant. By far most of the neutron exposure occurs at significantly lower temperature $(\mathrm{kT}=12$ $\mathrm{keV}$ ), followed by a comparably short neutron burst at $\mathrm{kT}=26 \mathrm{keV}$. Normally, this second burst of neutrons does not affect the before produced abundances because most neutron capture rates do not depend on temperature. However, this can be different at or near magic neutron numbers, where the level spacings are large. Accordingly, the cross section at low neutron energies exhibit a pronounced resonance structure, which can result in significant departures from the usual $1 / \mathrm{v}$-behavior of the cross section shapes. A striking example for such a case was recently reported by Beer et al [22], who found a $50 \%$ enhancement in the $12 \mathrm{keV}$ cross section of ${ }^{138} \mathrm{Ba}$ compared to the extrapolated $1 / \mathrm{v}-$ shape.

Though the available information on resolved resonances was considered in evaluating the present Maxwellian average cross sections, it can not be excluded that this part (contribution $I_{1}$ in Table 20) has been underestimated due to missing resonances. In fact, one finds that the overproduction of ${ }^{136} \mathrm{Ba}$ can be removed, if the cross section is artificially enhanced by $30 \%$ during the main neutron burst at $\mathrm{kT}=12 \mathrm{keV}$.

This puzzling situation complementary cross section measurements at low energies are urgently needed for achieving a satisfactory interpretation of the observed barium abundance pattern.

\subsection{The s-Process Branching at ${ }^{134} \mathrm{Cs}$}

The neutron capture flow through the Xe-Cs-Ba isotopes (Fig.1) exhibits branchings at ${ }^{133} \mathrm{Xe},{ }^{134} \mathrm{Cs}$, and ${ }^{135} \mathrm{Cs}$. For all of these cases, the stellar $\beta$-decay rates differ from the respective laboratory rates[49], but only ${ }^{134} \mathrm{Cs}$ acts as a true branching point with significant competition between $\beta$-decay and neutron capture. For ${ }^{133} \mathrm{Xe}$, the neutron capture probability remains less than $0.5 \%$, and ${ }^{135} \mathrm{C}$ s affects the s-process flow only marginally, since its stellar half-life is still long compared to the time scale of the sprocess. The electron capture branch in the decay of ${ }^{134} \mathrm{Cs}$ is always less than $10^{-3}$ and can, therefore, be neglected.

The temperature-dependence of the ${ }^{134} \mathrm{Cs}$ decay makes this branching a potential s- 
process thermometer. With the present results for the $(\mathrm{n}, \gamma)$ cross sections of ${ }^{134} \mathrm{Ba}$ and ${ }^{136} \mathrm{Ba}$ this thermometer can be analyzed for the first time in a quantitative way. The following discussion is based on the classical s-process approach[2]. In addition to the barium cross sections described above, the stellar cross sections for the Cs and Xe isotopes in Fig.1, including the unstable branch point nuclei, are from Ref.[20].

With these data, the branching factor

$$
f_{n}=\frac{\lambda_{n}}{\lambda_{n}+\lambda_{\beta}}
$$

is defined in terms of the $\beta$-decay rate, $\lambda_{\beta}=\ln 2 / t_{1 / 2}$, and the neutron capture rate, $\lambda_{n}=$ $\mathrm{n}_{n} \sigma \mathrm{v}_{T}$ for the effective branch point ${ }^{134} \mathrm{Cs}$. ( $\sigma$ is the stellar $(\mathrm{n}, \gamma)$ cross section and $v_{T}$ the mean thermal neutron velocity). The temperature-dependence of the branching factor is shown in Fig.19. The shaded band is obtained for the standard input data quoted above. The difference between upper and lower bound reflects the uncertainty in the neutron density only. The dashed line is obtained if the ${ }^{134} \mathrm{Cs}$ cross section is increased by $50 \%$, corresponding to an optimistic estimate for the respective uncertainty. An even stronger effect is caused by the stellar $\beta$-decay rate of ${ }^{134} \mathrm{Cs}$, which could be uncertain by a factor 3 (dashed-dotted line).

The dashed bar in Fig.19 corresponds to the effective branching factor, which can be deduced via the s-only isotopes: Since ${ }^{134} \mathrm{Ba}$ is partially bypassed, while ${ }^{136} \mathrm{Ba}$ experiences the total flow, the branching factor can be calculated as

$$
f_{n}=1-\frac{\zeta_{135} \mathrm{Ba} \times \zeta_{136} \mathrm{Ba} \times\left(\sigma N_{s}\right)_{134} \mathrm{Ba}}{\left(\sigma N_{s}\right)_{136} \mathrm{Ba}}=0.176 \pm 0.025 .
$$

The quoted uncertainty originates from the uncertainty in the cross section ratio of ${ }^{134} \mathrm{Ba}$ and ${ }^{136} \mathrm{Ba}$. Note, that this discussion is based on the assumption that the relative sprocess yields of the barium isotopes are not affected by the problem presented above.

Comparison of the effective branching factor with the calculated dependences in Fig. 19 shows that the standard parameters suggest a mean s-process temperature $\mathrm{T}_{s} \sim 1.9 \times 10^{8}$ $\mathrm{K}$. This value is about $10 \%$ higher if the ${ }^{134} \mathrm{C}$ 's cross section is increased by $50 \%$. However, agreement with the temperature range $\mathrm{kT}_{s}=29 \pm 5 \mathrm{keV}$ obtained from the analysis of the branchings at ${ }^{151} \mathrm{Sm},{ }^{154} \mathrm{Eu}$, and ${ }^{175} \mathrm{Lu}[6]$ is only achieved when the decay rate of ${ }^{134}$ Cs is reduced by a factor 3 .

If this branching is treated in the frame of the stellar model for helium shell burning in low mass stars, one obtains a similar result. It turns out that the calculated branching factor is also too small, accounting only for $40 \%$ of the effective value derived via Eq. 6 .

In this situation, further studies have to concentrate on the improvement of the stellar $\beta$-decay rate of ${ }^{134} \mathrm{Cs}$. However, an experimental determination seems presently out of reach, since this decay is enhanced via allowed transitions from thermally populated states to excited states in ${ }^{134} \mathrm{Ba}$. Clearly, also the ${ }^{134} \mathrm{Cs}$ cross section needs to be improved. The statistical model calculations with global parameter systematics used so far may well exhibit much larger uncertainties than admitted above, particularly near closed neutron shells. In this respect, a measurement of the ${ }^{135} \mathrm{Cs}$ cross section [50] will be most helpful to build a local parameter systematics that is predominantly based on experimental data. 


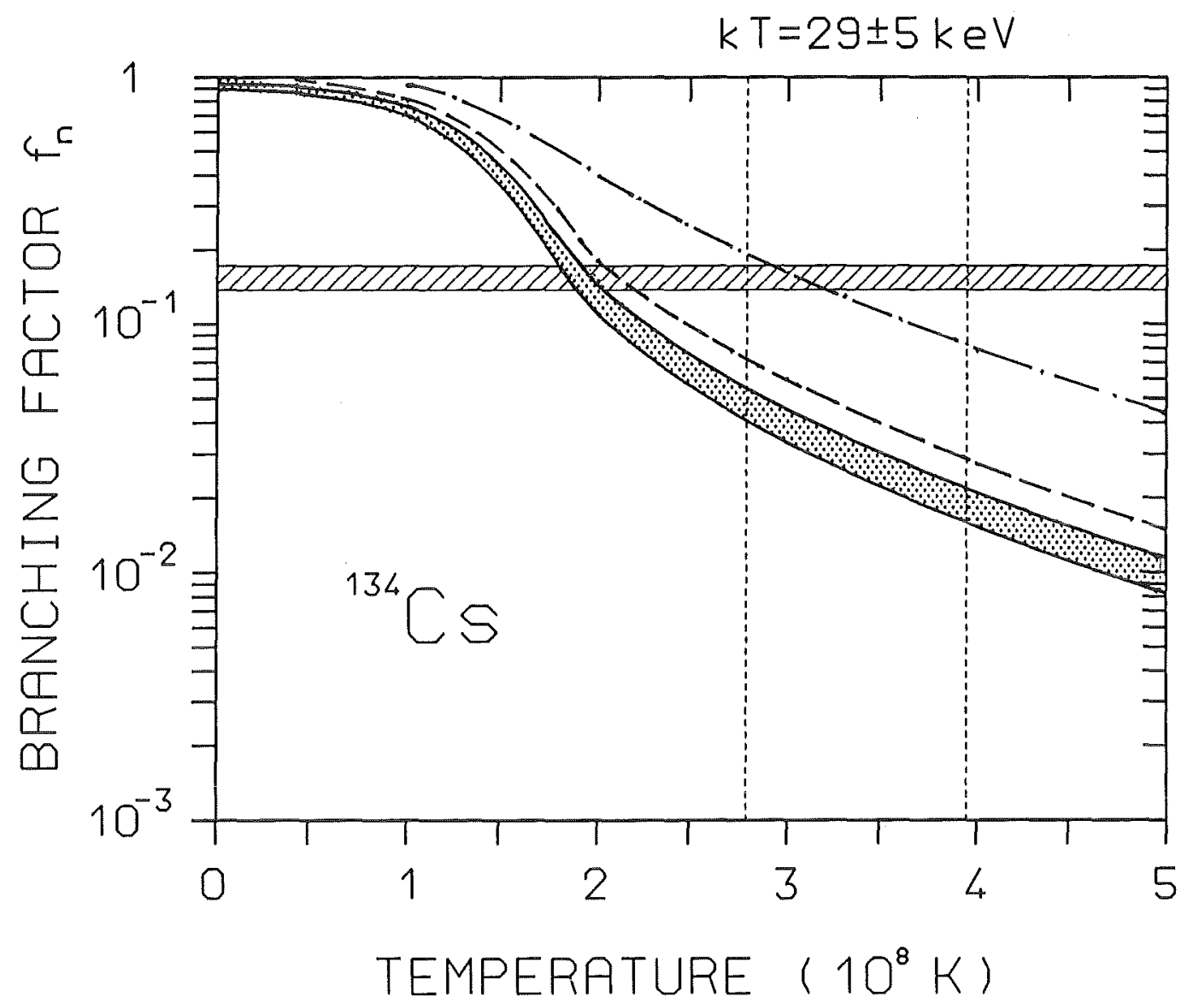

Figure 19: The branching factor $\mathrm{f}_{n}$ for the s-process flow at ${ }^{134} \mathrm{Cs}$. The dashed bar indicates the effective branching factor deduced from the $\left(\sigma \mathrm{N}_{s}\right)$-values of the s-only isotopes ${ }^{134} \mathrm{Ba}$ and ${ }^{136} \mathrm{Ba}$. The temperature-dependence was calculated assuming the standard parameters described in the text (shaded band) and with a modified cross section or $\beta$ decay rate for ${ }^{134} \mathrm{Cs}_{\mathrm{s}}$ (dashed and dashed-dotted lines, respectively). The temperature range obtained from other $s$-process thermometers ${ }^{2}$ is shown by the vertical lines.

\subsection{Decomposition into $\mathrm{s}-$ and $\mathrm{r}$-Process Contributions}

Because of the small isotopic $(n, \gamma)$ cross sections, the abundance of the element barium is dominated by the s-process. This makes it an important s-process indicator for astronomical observations related to studies of $A G B$ stars and of problems related to the chemical evolution of the galaxy. The improved cross sections presented here allow for a significantly better definition of the s-process yields and, hence, for a more reliable separation of $\mathrm{s}-$ and $\mathrm{r}$-process abundances.

The s-process yields that are obtained with the classical approach are given in column 3 of Table 23. Remarkably enough, all even isotopes are significantly overproduced! In order to avoid overproduction, these abundances were normalized at ${ }^{138} \mathrm{Ba}$ such that the sum of the resulting s-abundance of ${ }^{138} \mathrm{Ba}$ plus a plausible $\mathrm{r}$-contribution of $\mathrm{N}_{r}\left({ }^{138} \mathrm{Ba}\right)=0.1[2]$ fits the observed abundance (values in column 4). With this normalization by a factor 0.84 , the overproduction of ${ }^{136} \mathrm{Ba}$ is removed as well, while the remaining discrepancy with 
Table 23: DECOMPOSITION OF ISOTOPIC Ba ABUNDANCES

\begin{tabular}{|c|c|c|c|c|c|c|}
\hline \multirow[t]{2}{*}{ Isotope } & \multirow[t]{2}{*}{$\mathrm{N}_{\odot}$} & \multicolumn{3}{|c|}{ Classical Approach } & \multicolumn{2}{|c|}{ AGB stars 1} \\
\hline & & $\mathrm{N}_{s}^{2}$ & $\mathrm{~N}_{s, N O R M^{3}}$ & $\mathrm{~N}_{r}=\mathrm{N}_{\odot}-\mathrm{N}_{s}$ & $\mathrm{~N}_{s}^{2}$ & $\mathrm{~N}_{s, N O R M^{3}}$ \\
\hline${ }^{134} \mathrm{Ba}$ & 0.109 & 0.157 & 0.133 & - & 0.147 & 0.128 \\
\hline${ }^{135} \mathrm{Ba}$ & 0.296 & 0.064 & 0.054 & 0.24 & 0.055 & 0.048 \\
\hline${ }^{136} \mathrm{Ba}$ & 0.353 & 0.432 & 0.365 & - & 0.439 & 0.383 \\
\hline${ }^{137} \mathrm{Ba}$ & 0.504 & 0.334 & 0.282 & 0.22 & 0.372 & 0.325 \\
\hline${ }^{138} \mathrm{Ba}$ & 3.22 & 3.716 & 3.133 & 0.1 & 3.590 & 3.133 \\
\hline$B a_{t o t}$ & 4.48 & & 3.97 & & 4.02 & \\
\hline
\end{tabular}

${ }^{1}$ for details see text

${ }^{2}$ Normalized at ${ }^{124} \mathrm{Te}$

${ }^{3}$ Barium abundances renormalized to satisfy $\mathrm{N}_{\odot}\left({ }^{138} \mathrm{Ba}\right)=\mathrm{N}_{s}+0.1$

${ }^{134} \mathrm{Ba}$ may be due to the problem with the ${ }^{134} \mathrm{Cs}$ branching. The correspondingly tentative decomposition into s-and $\mathrm{r}$-abundances is given in column 5 of Table 23. Compared to the previous shape of the $\mathrm{r}$-distribution[2], the new ${ }^{137} \mathrm{Ba}$ cross sections lead to a considerably larger $\mathrm{r}$-abundance of this isotope, which fits much better to a smooth pattern at the lail of the $r-$ process peak around $A=130$.

If the same normalization procedure is repeated for the $s$-process yields obtained with the AGB model (column 6 and 7 in Table 23), the corresponding normalization factor of 0.90 is significantly closer to unity than in case of the classical approach, but here the overproduction of ${ }^{136} \mathrm{Ba}$ remains. However, since this difference is small compared to the total barium abundance, it can be neglected in determining the ratio $\mathrm{N}_{s}(\mathrm{Ba}) / \mathrm{N}_{\odot}(\mathrm{Ba})$. As a result, these ratios are in close agreement in both models, yielding an s-process contribution to the observed barium abundance of $89 \%$.

In order to achieve consistency with the overall s-process systematics, the above procedure implies an increase of the observed barium abundance by a renormalization of $16 \%$ in case of the classical model and by $10 \%$ in case of the stellar model. However, the solar $\mathrm{Ba}$ abundance is quoted with a $6.3 \%$ uncertainty by Anders and Grevesse[51], and any larger changes seem to be implausible. (E. Anders, private communication to R. Gallino). Whether this puzzle really requires a change of the solar barium abundance or whether an alternative solution within the stellar model can be found will be the subject of further studies, which will also deal with the interpretation of the isotopic anomalies mentioned in $\S 1$.

\section{ACKNOWLEDGMENTS}

We would like to thank the many colleagues of KfK who contributed to this work. In particular, we are indebted to Ch. Adelhelm, E. Nold and M. Mackert from the Institute 
of Material Research for analysing the water content of the samples and for converting the barium nitrate into carbonate, as well as for the spontaneous help of E. Gantner, H. Deutsch and H. Klewe-Nebenius from the Institute of Radiochemistry who determined the isotopic compositions. We have to thank F.H. Fröhner and B. Krieg from the Institute of Neutron Research and Reactor Technology for providing the JEF data, and H. Ottmar and $\mathrm{H}$. Eberle for analyzing the samples by $\mathrm{K} \mathrm{X}$-ray absorptiometry. Last not least, these measurements were possible only with the continuous support of the Van de Graaff crew, D. Roller, E.-P. Knaetsch and W. Seith who ran the accelerator in a most efficient way, and of G. Rupp, who was untiring in optimizing the experimental setup.

\section{References}

[1] K. Wisshak et al., Nucl. Instr. Meth. A 292, 595 (1990).

[2] F. Käppeler, H. Beer, and K. Wisshak, Rep. Prog. Phys. 52, 945 (1989).

[3] K. Wisshak, F. Voss, F. Käppeler, and G. Reffo, Phys. Rev. C 45, 2470 (1992).

[4] D. D. Clayton, W. A. Fowler, T. E. Hull, and B. A. Zimmerman, Ann. Phys. 12, 331 (1961).

[5] K. Wisshak et al., Phys. Rev. C 48, 1401 (1993).

[6] F. Käppeler et al., Ap. J. 354, 630 (1990).

[7] U. Ott and F. Begemann, Ap. J. 353, (1990).

[8] E. Zinner, S. Amari, and R. S. Lewis, Ap. J. 382, (1991).

[9] F. A. Prombo, S. Podosek, S. Amari, and R. S. Lewis, Ap. J. 410, 393 (1993).

[10] R. Gallino, C. M. Raiteri, and M. Busso, Ap. J. 410, 400 (1993).

[11] H. Beer, F. Voß, and R. R. Winters, Ap. J. Suppl. 80, 403 (1992).

[12] B. E. J. Pagel, Rev. Mexicana Astron. Astrof. 18, 161 (1989).

[13] D. L. Lambert, in Cosmic Abundances of Matter, edited by C. J. Waddington (American Institute of Physics, New York, 1989), p. 168.

[14] B. S. Meyer et al., Ap. J. 399, 656 (1992).

[15] A. R. de L. Musgrove, B. J. Allen, and R. L. Macklin, Technical report, Australian Atomic Energy Commission (unpublished).

[16] A. R. de L. Musgrove, B. J. Allen, J. W. Boldeman, and R. L. Macklin, Nucl. Phys. A 256, 173 (1976).

[17] A. R. de L. Musgrove, B. J. Allen, J. W. Boldeman, and R. L. Macklin, Aust. J. Phys. 29, 157 (1976). 
[18] A. R. de L. Musgrove, B. J. Allen, J. W. Boldeman, and R. L. Macklin, in Neutron Physics and Nuclear Data for Reactors and other Applied Purposes (OECD, Paris, 1978), p. 449.

[19] B. J. Allen, J. W. Boldeman, and R. L. Macklin, Nucl. Sci. Eng. 82, 230 (1982).

[20] Z. Y. Bao and F. Käppeler, Atomic Data Nucl. Data Tables 36, 411 (1987).

[21] M. Mizumoto et al., in Nuclear Data for Basic and Applied Science (Gordon and Breach, New York, 1985), Radiation Effects 92-96, 533 (1986).

[22] H. Beer, F. Corvi, A. Mauri, and K. Athanassopulos, in Nuclei in the Cosmos, edited by F. Käppeler and K. Wisshak (Institute of Physics, Bristol, 1993), p. 227.

[23] K. Wisshak, F. Voss, F. Käppeler, and G. Reffo, Phys. Rev. C 42, 1731 (1990).

[24] K. Guber, Ph.D. thesis, University of Karlsruhe, 1993.

[25] G. Winkler, Nucl. Instr. Meth. A 282, 317 (1989).

[26] H. Ottmar et al., in Proc. Int. Symp. Nuclear Material Safeguards (International Atomic Energy Agency, Vienna, 1987), p. 201.

[27] R. de Meester et al., in Proc. Int. Symp. Nuclear Material Safeguards (International Atomic Energy Agency, Vienna, 1987), p. 233.

[28] F. H. Fröhner, Technical report, Kernforschungszentrum Karlsruhe (unpublished).

[29] C. Nordborg, H. Gruppelaar, and M. Salvatores, in Nuclear Data for Science and Technology, edited by S. Qaim (Springer, Berlin, 1992), p. 782.

[30] V. McLane, C. L. Dunford, and P. F. Rose, in Neutron Cross Sections, Vol. 2 (Academic Press, New York, 1988).

[31] A. V. Murzin, private communication (unpublished).

[32] F. Voss, K. Wisshak, and F. Käppeler, in preparation (unpublished).

[33] N. Weber, Diploma Thesis 1993 (unpublished).

[34] G. Reffo, F. Fabbri, K. Wisshak, and F. Käppeler, Nucl. Sci. Eng. 80, 630 (1982).

[35] K. Guber, Diploma Thesis 1988 (unpublished).

[36] K. Wisshak, F. Käppeler, and G. Schatz, Nucl. Instr. Meth. 221, 385 (1984).

[37] F. H. Fröhner, Technical report, Gulf General Atomic (unpublished).

[38] J. F. Mughabghab, M. Divadeenam, and N. E. Holden, in Neutron Cross Sections, Vol. 1, Part $A$ (Academic Press, New York, 1981).

[39] A. Gilbert and A. G. W. Cameron, Can. J. Phys. 43, 1446 (1965). 
[40] B. Strohmaier, M. Uhl, and W. K. Matthes, Nucl. Sci. Eng. 65, 368 (1978).

[41] L. Koester, K. Knopf, and W. Waschkowski, Z. Phys. A 332, 105 (1985).

[42] R. L. Macklin, private communication (unpublished).

[43] W. Ratynski and F. Käppeler, Phys. Rev. C 37, 595 (1988).

[44] F. Corvi, A. Prevignano, H. Liskien, and P. B. Smith, Nucl. Instr. Meth. A 265, 475 (1988).

[45] H. Beer, Technical report, Kernforschungszentrum Karlsruhe (unpublished).

[46] D. E. Hollowell and I. Iben Jr., Ap. J. 333, (1988).

[47] D. E. Hollowell and I. Iben Jr., Ap. J. 340, 966 (1989).

[48] R. Gallino et al., Ap. J. 334, (1988).

[49] K. Takahashi and K. Yokoi, Atomic Data Nucl. Data Tables 36, 375 (1987).

[50] F. Käppeler, M. Wiescher, and P. E. Koehler, in Workshop on the Production and Use of Intense Radioactive Beams at the Isospin Laboratory, edited by J. D. Garrett (Joint Institute for Heavy Ion Research, Oak Ridge, 1992), p. 163.

[51] E. Anders and N. Grevesse, Geochim. Cosmochim. Acta 53, 197 (1989). 